\title{
The impact of aging on \\ lymphocytes and their function in \\ the human bone marrow
}

\section{DISSERTATION}

Submitted to Innsbruck Medical University

to obtain the academic degree

Doctor of Philosophy (PhD)

Submitted by

Mag. rer. nat. Theresa Pritz

\author{
Division of Immunology \\ Institute for Biomedical Aging Research \\ University of Innsbruck \\ Innsbruck, 2014
}




\section{TABLE OF CONTENTS}

SUMMARY

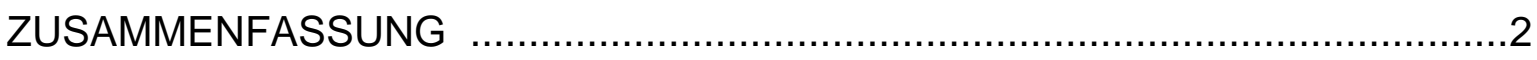

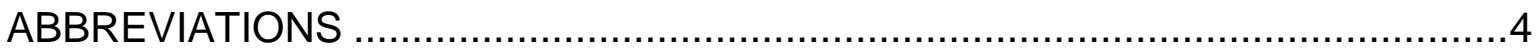

AIM AND STRUCTURE OF THE THESIS ……….......................................

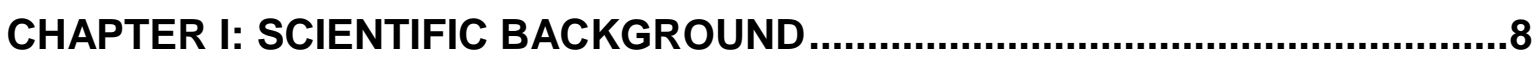

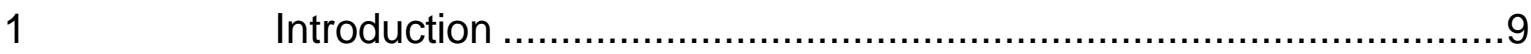

1.1 The adaptive immune system and age-related changes ..................

1.1.1 B cell development.............................................................

1.1.2 Age-related changes of the B cell compartment...........................14

1.1.3 T cell development ............................................................

1.1.4 Age-related changes of the T cell compartment............................18

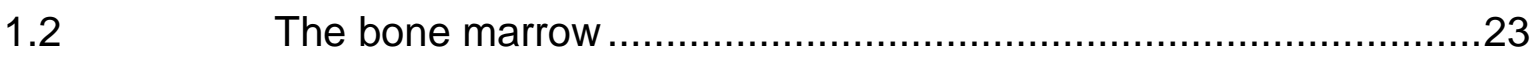

1.2.1 The role of the bone marrow as a secondary lymphoid organ and age-related changes of bone marrow adaptive immune cells ........23

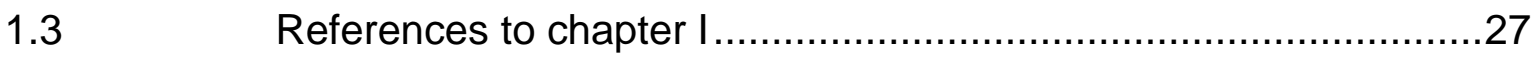

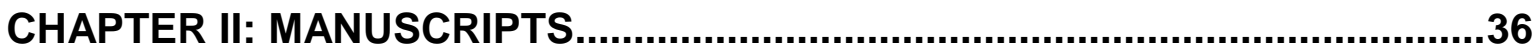

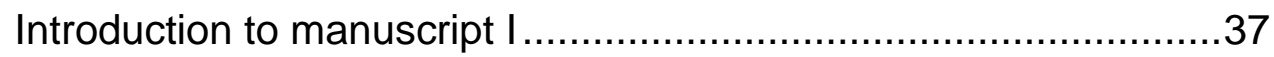

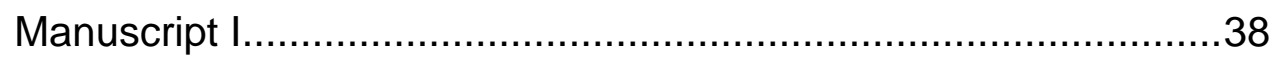

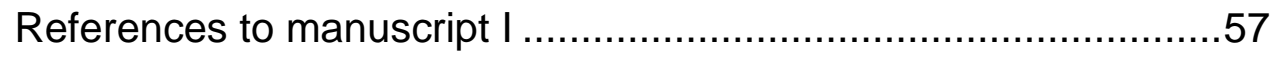

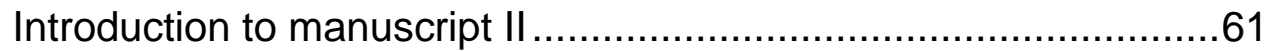

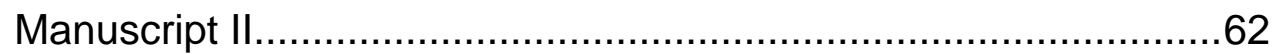

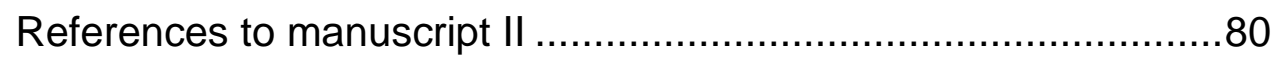


CHAPTER III: GENERAL DISCUSSION AND CONCLUSION .85

Discussion and conclusion .86

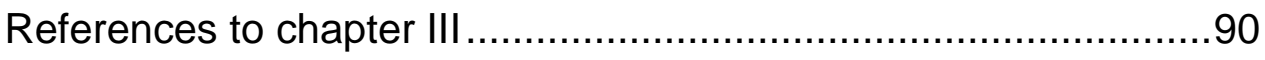

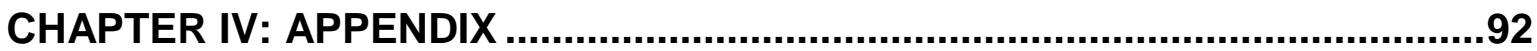

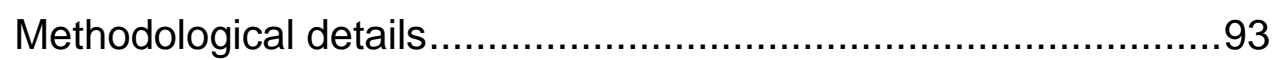

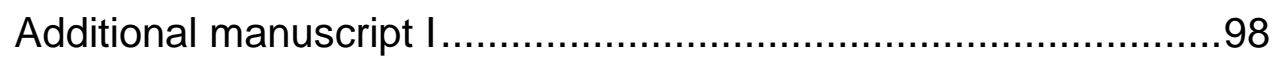

Additional manuscript II ........................................................105

CURRICULUM VITAE

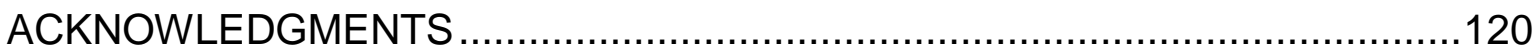




\section{SUMMARY}

Over the last decades the number of $60^{+}$people has increased. Aging causes a decrease in several physiological functions such as a lower immune response to infections and vaccination. Recently the role of the bone marrow (BM) as a homing and survival site for memory $T$ cells as well as plasma cells was described in mice. Still, little is known about lymphocytes in terms of their phenotype and function in the human BM in old age.

In the first part of the thesis we compared the phenotype and function of BM T cells from iliac crest- and femur shaft-derived bone biopsies. Our results demonstrated that there were no phenotypic differences between BM mononuclear cells (BMMC) from the two tissue sources. Compared to the peripheral blood (PB), both BM types contained fewer naïve and more antigen experienced polyfunctional $\mathrm{CD}^{+}$as well as $\mathrm{CD}^{+} \mathrm{T}$ cells, which, in contrast to peripheral cells, expressed CD69. Furthermore, we were able to demonstrate that BMMC from the femur shaft are a useful tool for further studies on different types of immune cells in the BM in old age.

With a bigger yield of BMMC from the femur shaft we were for instance able to analyze B cell subsets, the antigen-specificity of plasma cells and age-related changes of BM plasma cells. Our results demonstrated that higher numbers of immature $B$ and plasma cells are located in the $B M$, whereas naïve and memory $B$ cells mainly circulate in the PB. While the frequency of plasma and memory $B$ cells from the BM and PB declined, immature and naïve $B$ cells were unaffected by age. An age-related decrease of tetanus- and diphtheria-specific BM plasma cells was shown, whereas influenza-A and Cytomegalovirus (CMV)-specific BM plasma cells did not change with age. With the exception of CMV, peripheral antibody concentrations correlated with BM plasma cells of the same specificity but were independent of antigen-specific PB memory B cells. These results revealed that the human BM houses decreased numbers of plasma cells in old age. The number of cells of certain specificity may reflect the time and frequency of previous antigen encounters as well as intrinsic age-related changes of immune cells as well as of the BM niche. 


\section{ZUSAMMENFASSUNG}

In den letzten Jahrzehnten ist die Zahl der über 60-Jährigen drastisch gestiegen. Altern wird mit der Abnahme vieler physiologischer Funktionen, unter anderem mit charakteristischen Veränderungen des Immunsystems, assoziiert. Diese Veränderungen tragen zu einem schweren Verlauf von Infektionskrankheiten sowie einer schlechteren Impfantwort im Alter bei.

Kürzlich zeigten Mausstudien, dass das Knochenmark eine wichtige Rolle als sekundäres lymphoides Organ in der adaptiven Immunantwort spielt. Gedächtnis T-Zellen sowie Plasmazellen wandern in das Knochenmark und verweilen dort in einer sogenannten Überlebensniche. Momentan ist nur wenig über Lymphozyten im Knochenmark und deren altersabhängige Veränderungen beim Menschen bekannt. Daher beschäftigt sich diese Arbeit mit Zellen des adaptiven Immunsystems aus dem humanen Knochenmark und deren Veränderungen im Alter.

Der erste Teil dieser Dissertation beschreibt den phänotypischen und funktionellen Vergleich von T-Zellen aus dem Beckenkamm (Crista iliaca) und dem Oberschenkelhalsknochen (Femur). Unsere Ergebnisse zeigen, dass kein Unterschied zwischen den T- Zellpopulationen aus den beiden Knochentypen vorliegt. Beide Populationen enthielten eine gegenüber dem peripheren Blut erhöhte Anzahl an hoch differenzierten, polyfunktionalen $\mathrm{CD}^{+}$und $\mathrm{CD}^{+}$ Effektorzellen, sowie eine altersabhängige verminderte Zahl naiver und erhöhte Zahl Antigen-erfahrener T-Zellen. Diese Ergebnisse demonstrieren, dass sich TZellen aus dem Knochenmark des Femurs für Untersuchungen über die Bedeutung der Knochenmarksniche für T-Zellen im Alter gut eignen.

Der zweite Abschnitt dieser Arbeit behandelt B-Zellsubpopulationen im Knochenmark, im Speziellen die Antigenspezifizität von Plasmazellen sowie deren Veränderung im Alter. Aufgrund der relativ großen Zahl von mononukleären Zellen, die aus dem Oberschenkelhalsknochen isoliert werden können, war diese Analyse möglich. Die Ergebnisse zeigen, dass sich unreife B- sowie Plasmazellen vorwiegend im Knochenmark aufhalten, während naive und Gedächtnis B-Zellen hauptsächlich im Blut zirkulieren. Während keine altersabhängige Veränderung der unreifen und naiven B-Zellen nachweisbar war, nahm mit steigendem Alter die Gesamtzahl von Plasmazellen und Gedächtnis B-Zellen aus dem Knochenmark 
ab. Von dieser Abnahme waren allerdings nur Knochenmarksplasmazellen mit Reaktivität gegenüber Tetanus und Diphtherie, nicht aber gegenüber Influenza A und dem Cytomegalovirus, betroffen.

Periphere Antikörperkonzentrationen korrelieren stets mit der Zahl von Knochenmarksplasmazellen derselben Spezifität, aber nicht mit den entsprechenden peripheren Gedächtniszellen.

Die Arbeit lässt den Schluss zu, dass im humanen Knochenmark hoch differenzierte, polyfunktionale Effektor T-Zellen und Plasmazellen vorhanden sind, deren Phänotyp, Anzahl und Spezifität sich im Alter verändern. Dies lässt vermuten, dass das Knochenmark für die eingeschränkte Immunantwort im Alter mitverantwortlich sein könnte. 


\section{ABBREVIATIONS}

$A B$

AID

APC

APCs

APRIL

ASC

BAFF

BAX

$\mathrm{Bcl}-2$

BCR

BFA

BM

BMMC

BSA

CCR7

CD

CDR3

CFSE

CFU

CLP

CMP

CMJ

CMV

CXCL12

CXCR4

DC

DN

DP

ELISPOT

FACS

FCS

FITC
Antibody

Activation-Induced Deaminase

Allophycocyanin

Antigen-Presenting Cell

A Proliferation-Inducing Ligand

Antibody-Secreting Cell

B Cell Activation Factor

Bcl-2-Associated X Protein

B-Cell Lymphoma 2

B Cell Receptor

Brefaldin A

Bone Marrow

Bone Marrow Mononuclear Cells

Bovine Serum Albumin

CC-Chemokine Receptor 7

Cluster of Differentiation

Complementarity-Determining Region 3

Carboxyfluorescein Succinimidyl Ester

Colony-Forming Unit

Common Lymphoid Progenitor

Common Myeloid Progenitor

Cortico-Medullary Junction

Cytomegalovirus

C-X-C Ligand 12

C-X-C Chemokine Receptor 4

Dendritic Cell

Double Negative

Double Positive

Enzyme-Linked Immuno Spot Assay

Fluorescence-Activated Cell Sorter

Fetal Calf Serum

Fluorescein Isothiocyanat 


\begin{tabular}{|c|c|}
\hline FOXO3a & Forkhead Box O3a \\
\hline FSC & Forward-Scattered Light \\
\hline GC & Germinal Center \\
\hline HEV & High Endothelial Venules \\
\hline HLA & Human Leukocyte Antigen \\
\hline HSC & Hematopoietic Stem Cells \\
\hline ICAM1 & Intercellular Adhesion Molecule 1 \\
\hline IFN & Interferon \\
\hline $\lg$ & Immunoglobulin \\
\hline $\lg G$ & Immunoglobulin G \\
\hline $\lg \mathrm{H}$ & Immunoglobulin Heavy Chain \\
\hline $\lg \mathrm{L}$ & Immunoglobulin Light Chain \\
\hline $\lg M$ & Immunoglobulin M \\
\hline IL & Interleukin \\
\hline LFA1 & Lymphocyte Function-associated Antigen 1 \\
\hline LN & Lymph Node \\
\hline $\mathrm{mAb}$ & Monoclonal Antibody \\
\hline MACS & Magnetic Cell Sorting \\
\hline $\mathrm{MHC}$ & Major Histocompatibility Complex \\
\hline MSC & Mesenchymal Stem Cells \\
\hline NK & Natural Killer \\
\hline OKT3 & Orthoclone OKT3 (anti-CD3) \\
\hline Pacblue & Pacific Blue \\
\hline PAMPs & Pathogen Associated Molecular Patterns \\
\hline PB & Peripheral Blood \\
\hline PBMC & Peripheral Blood Mononuclear Cells \\
\hline PBS & Phosphate Buffered Saline \\
\hline PCR & Polymerase Chain Reaction \\
\hline PDGFa & Platelet-Derived Growth Factor- $\alpha$ \\
\hline PDGFRa & Platelet-Derived Growth Factor Receptor- $\alpha$ \\
\hline PE & Phycoerythrin \\
\hline PerCP & Peridinin Chlorophyll Protein \\
\hline PI3K-Akt & Phosphatidylinositol 3'-Kinase-Akt \\
\hline PMA & Phorbol 12-Myristate 13-Acetate \\
\hline
\end{tabular}




$\begin{array}{ll}\text { PNAd } & \text { Peripheral Node Adressin } \\ \text { PWM } & \text { Pokeweed Mitogen } \\ \text { RFU } & \text { Relative Fluorescence Units } \\ \text { SAC } & \text { Staphylococcus Aureus Cowan } \\ \text { S1P } & \text { Sphingosine 1-Phosphate } \\ \text { SDF-1 } & \text { Stromal Cell-Derived Factor-1 } \\ \text { SEM } & \text { Standard Error of Mean } \\ \text { SFC } & \text { Spot Forming Cell } \\ \text { SLO } & \text { Secondary Lymphoid Organ } \\ \text { SSC } & \text { Sideward-Scattered Light } \\ \text { STAT5a } & \text { Signal Transducer and Activator of Transcription 5a } \\ \text { TCM cell } & \text { Central Memory T cell } \\ \text { TCR } & \text { T Cell Receptor } \\ \text { TEC } & \text { Thymic Epithelial Cells } \\ \text { TEM cell } & \text { Effector Memory T cell } \\ \text { TEMRA cell } & \text { Effector Memory CD45RA }+ \text { T cell } \\ \text { TN cell } & \text { Naïve T cell } \\ \text { TNF } & \text { Tumor Necrosis Factor } \\ \text { VCAM1 } & \text { Vascular Cell Adhesion Molecule 1 } \\ \text { VLA-4 } & \text { Very Late Activation Antigen-4 } \\ \text { VLA-2 } & \end{array}$




\section{AIM AND STRUCTURE OF THE THESIS}

\section{Aim of the thesis}

The role of the human BM in regulating adaptive immune responses is still not well understood and there is only little information how aging affects adaptive immune cells in the BM. The aim of this study was therefore to investigate BM T and B cells, their function and changes in old age.

In the first part of the study we compared different BM tissue sources and investigated if the BMMC population derived from the femur shaft provides a useful tool for a variety of experimental protocols on adaptive immune cells.

In the second part of the study we analyzed BM- and PB-derived B cell subpopulations and their function under steady state conditions in old age.

\section{Structure of the thesis}

Chapter 1 provides information on the scientific background of the thesis, including an overview of the adaptive immune system, the impact of age on this system and a short introduction on the role of the BM as secondary lymphoid organ in old age.

Chapter 2 contains two manuscripts. The first paper summarizes results on the comparison of $T$ cells from two different sources of human BM tissue sources (Pritz et al., Immun Ageing 2013, 10:17). The second paper deals with the impact of aging on plasma cells and memory B cells in human BM and PB. This study was submitted to the European Journal of Immunology, favorably reviewed and a revised version is presently under revision.

Chapter 3 summarizes and discusses all results and provides a general conclusion.

Chapter 4 describes additional methodological details used in this thesis. As a second part of this chapter two more published articles (Pritz et al., Immunol Lett 2014, pii: S0165-2478(14)00129-1; Arnold et al., Exp Gerontol 2014, 54:75-83), the Curriculum vitae of the student and Acknowledgments are attached. 
CHAPTER I SCIENTIFIC BACKGROUND 


\section{Introduction}

Worldwide, life expectancy and mean life span increase mostly due to improved medical care. This leads to a demographic shift and to a rapid aging of the world population. Each year the size of the $60^{+}$population steadily increases. In 2030, over $25 \%$ of the population will be more than 60 years old (Lutz et al., 2008). Aging enhances the susceptibility to a number of infectious diseases which represent a major cause of morbidity and mortality in elderly people (Gavazzi and Krause, 2002). Preventive strategies such as vaccines may not work well in elderly persons because of their characteristically impaired immune response (Boraschi et al., 2013).

Age-related changes of the immune system are frequently referred to as "immunosenescence". The changes affect components of the innate as well as the adaptive immune system (Geiger et al., 2013; Weiskopf et al., 2009). Maintenance of intact immunity as long as possible is an important goal to improve longevity and healthy aging.

\subsection{The adaptive immune system and age-related changes}

The BM is a major reservoir for hematopoietic stem cells (HSC) which reside in a specialized microenvironment, the hematopoietic stem cell niche. This niche regulates HSC functions, such as self-renewal and differentiation by cell-to-cell interactions as well as by providing soluble factors (Harrison et al., 1993; Kent et al., 2009). Pluripotent HSC give rise to common lymphoid progenitors (CLPs) and common myeloid progenitors (CMPs) for the lymphoid and myeloid lineage of blood cell development. CMPs differentiate to become erythrocytes, platelets, basophils, eosinophils, neutrophils, monocytes, macrophages, mast cells or dendritic cells (DC). CLPs give rise to $B$ lymphocytes, $T$ lymphocytes as well as natural killer (NK) cells (Figure 1; Weinberger et al., 2009). 


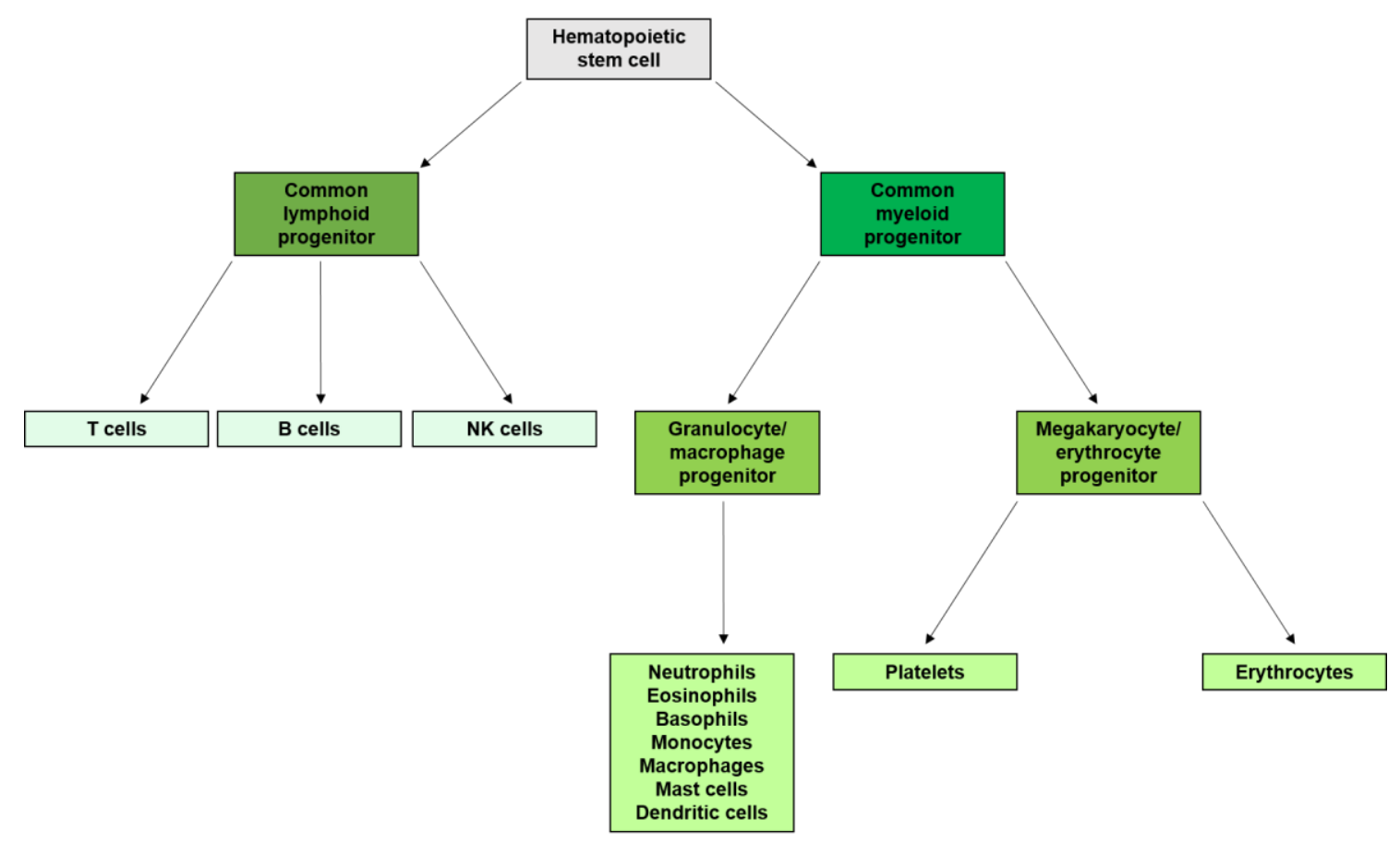

Figure 1: Schematic representation of hematopoiesis in the human BM. Hematopoietic stem cells differentiate into common lymphoid progenitors (CLPS) and common myeloid progenitors (CMPs) that give rise to different cell types (modified from Weinberger et al., Hazzard's Geriatric Medicine and Gerontology, $6^{\text {th }}$ edition, chapter 3 ).

During aging the overall amount of hematopoietic tissue in the BM declines. The age-related alterations of the hematopoietic microenvironment disturb self-renewal and lineage commitment of HSCs. However, aging has also an impact on HSCs themselves, like shortening of telomeres (Geiger et al., 2013). This process combined with disturbed self-renewal capacity leads to fewer and less functional HSCs in old age. With age HSCs are skewed towards myeloid commitment and in combination with an impaired BM environment, B cell development declines (Ademokun et al., 2010).

BM-derived T cell precursor cells seem to be less affected by aging. However, due to dramatic changes in the thymus, where $T$ cell maturation takes place, the $T$ cell compartment undergoes significant alterations with age (Weinberger et al., 2009). 


\subsubsection{B cell development}

B cells arise from BM-derived CLPs which are Immunoglobulin ( $\mathrm{lg}$ ) negative. B cell maturation follows across a range of distinguishable differentiation stages, termed pro-, pre-, immature and mature naïve B cells, which are characterized by the expression of distinct cell surface markers as well as Ig gene rearrangement (Murphy et al., 2008). The first differentiation step is called the pro-B cell. Pro-B cells do not produce $\mathrm{lg}$. This phase of $\mathrm{B}$ cell maturation is characterized by Ig gene rearrangement of the Ig heavy chain $(\mathrm{IgH})$ locus. Only pro-B cells which make productive gene rearrangements survive and further differentiate into pre-B cells. Pre-B cells rearrange their light chain ( $\mathrm{gL}$ ) loci which leads to the expression of $\operatorname{IgM}$ on the cell surface. $\lg M$ is also referred to as $B$ cell receptor (BCR) and characterizes the development of immature $B$ cells. At this maturation stage, the antigen-receptor of BM immature B cells is tested for tolerance to self-antigens, termed central tolerance. Cells that have no strong reactivity to self-antigens are allowed to mature. Immature B cells leave the BM as naïve mature B cells and migrate to peripheral lymphoid organs via the blood stream (Figure 2; Murphy et al., 2008; Abbas et al., 2007).

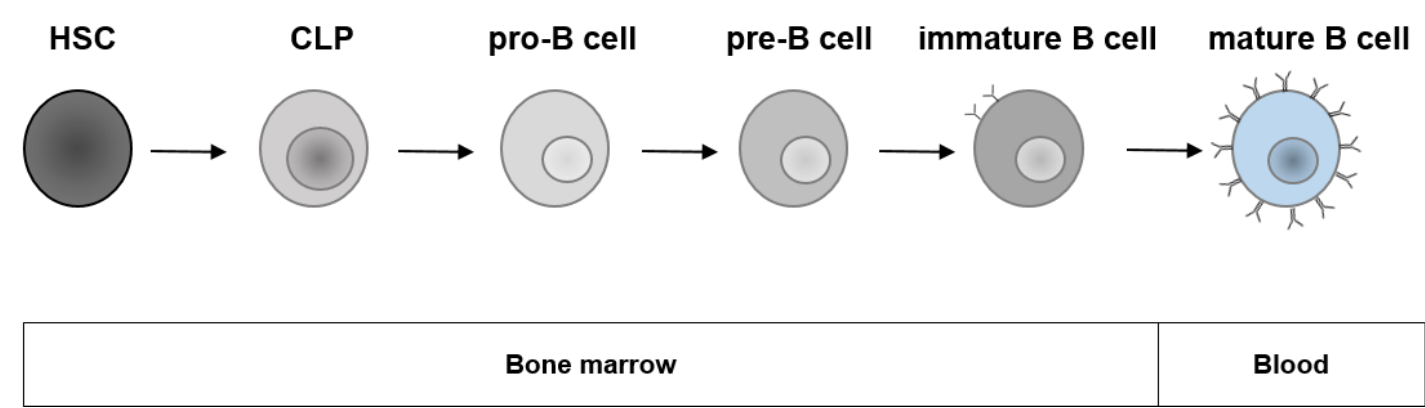

Figure 2: Schematic illustration of the B cell development. From hematopoietic stem cells (HSCs) common lymphoid progenitors (CLPs) arise and differentiate into pro-, pre-, immature and mature naïve $B$ cells. 
$\mathrm{B}$ cells can be divided into three subpopulations: follicular, marginal zone and B1 B cells. Follicular $B$ cells recirculate from one lymphoid organ to the next and reside in specialized niches, called B cell follicles in the lymph node (LN). Upon antigenic stimulation, germinal centers $(G C)$ develop in the $L N$. In GC, follicular B cells strongly proliferate and cells with a high affinity receptor for a specific antigen are selected to differentiate into memory $B$ or plasma cells. Follicular B cells are the main $B$ cell subset in the PB.

Marginal zone $B$ cells are a subset of $B$ cells exclusively found in the marginal sinus of the white pulp in the spleen. Marginal zone B cells rapidly respond and defend against blood borne microbial antigens and act as the first line of defense against pathogens.

$B 1 B$ cells differ from the majority of $B$ cell subsets. Only $5-10 \%$ of the total $B$ cell pool in secondary lymphoid organs and the periphery are B1 cells. They are characterized by a relatively restricted repertoire of Igs mainly recognizing common bacterial antigens.

Upon antigenic stimulation, naïve B cells secrete lgM. In response to cytokines and contact to $\mathrm{CD}^{+} \mathrm{T}$ helper cells, a proportion of activated $\mathrm{B}$ cells undergoes heavy chain isotype switching. This process leads to the secretion of antibodies with heavy chains of different classes, such as $\lg A$, $\lg E$ and $\lg G$. These antibody classes perform specific effector functions. IgA antibodies are mainly produced by $B$ cells in mucosal tissues. IgE antibodies mediate allergic reactions and are also generated in response to helminthes. IgG antibodies form an effective defense against most viral and bacterial pathogens and block the entry of pathogens and mediate phagocytosis by macrophages.

In a further maturation step, somatic recombination occurs in the variable regions of the Ig genes in order to generate antibodies with high affinity. The differentiation into antibody-secreting plasma and memory B cells ensures efficient recall responses in the body in the case of subsequent encounters of the same antigen (Figure 3; Weinberger et al., 2009; Murphy et al., 2008; Abbas et al., 2007). 


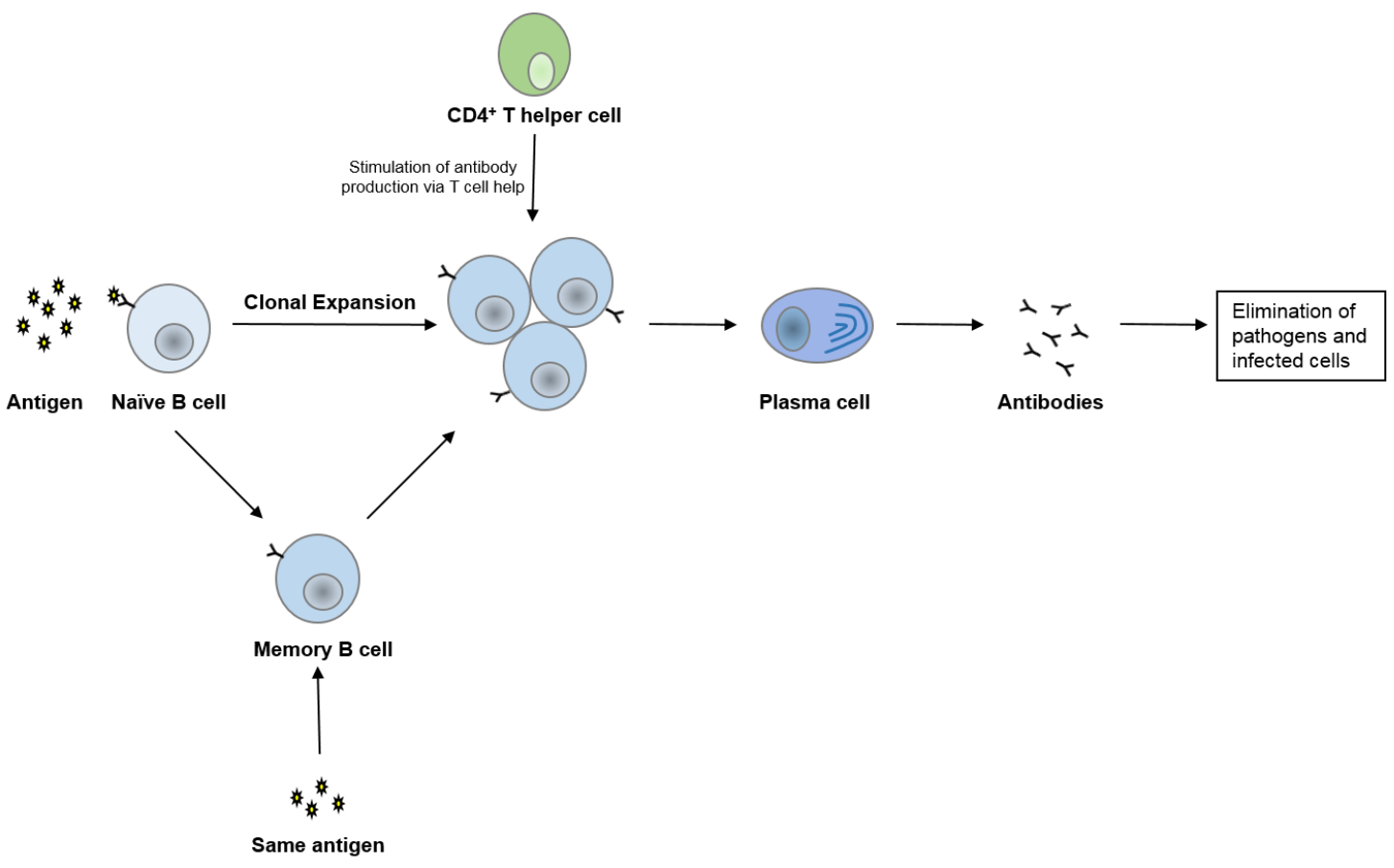

Figure 3: B cell activation. Antigen binds to the B cell receptor ( $\lg M)$ on naïve B cells which proliferate and differentiate into memory and plasma cells. Plasma cells secrete antibodies in order to eliminate pathogens (modified from Weinberger et al., Hazzard's Geriatric Medicine and Gerontology, $6^{\text {th }}$ edition, chapter 3$)$. 


\subsubsection{Age-related changes of the B cell compartment}

Primary antibody responses are often weaker in elderly individuals than in young adults and antibody levels drop faster during aging. These antibody responses have been studied in detail in the context of vaccination and it has been shown that the protective effect of vaccines against influenza, hepatitis B, Streptococcus pneumoniae and tetanus decreases with age (Weinberger et al., 2009).

Aging is also associated with an increased frequency of autoantibodies (Weinberger et al., 2009). Autoantibodies are in the majority of cases present at low concentrations and are directed against cellular components, like nuclei or mitochondria. They rarely contribute to autoimmune diseases (Naparstek and Plotz, 1993).

The impact of aging on peripheral B cells is complex and includes changes of single cells as well as of the repertoire. However, the literature about changes in peripheral B cell subpopulations is controversial. Some reports suggest an increase in memory B and plasma cells (Colonna-Romano et al., 2003; Veneri et al., 2009), while others show a decrease (Breitbart et al., 2002; Caraux et al., 2010; Chong et al., 2005; Frasca et al., 2008b). These controversial results may reflect differences in the study populations as well as in the techniques used for analysis (Ademokun et al., 2010). 


\subsubsection{T cell development}

Unlike B cells, which fully mature in the BM, T cell maturation and differentiation occurs in the thymus (Koch and Radtke, 2011). The thymus is a central lymphoid organ which is responsible for the development, selection and output of mature naïve T cells (Pearse, 2006).

The capacity of the thymus to produce functional $T$ cells is regulated by the structure and function of the thymic stroma, including the thymic epithelial cells (TEC) and other non-lymphoid cells that provide micro-environmental niches to promote T cell maturation and selection. TEC in the cortical region of the thymus are responsible for $\mathrm{T}$ cell lineage commitment, expansion, differentiation and positive selection, whereas medullary TEC are required for proper induction of central tolerance and the final stages of maturation prior to the thymic egress (Chinn et al., 2012).

$\mathrm{T}$ cell precursors enter the thymus at the cortico-medullary junctions (CMJ) and move through the medulla. The most immature thymocytes do not express the $T$ cell receptor (TCR), CD4 and CD8 and can be subdivided into four subsequential double negative (DN) phases. These stages are characterized by the temporary expression of cell surface proteins, including CD25 and CD44. As DN1 progenitor cells $\left(\mathrm{CD} 25{ }^{-} \mathrm{CD} 44^{+}\right)$differentiate into DN2 $\left(\mathrm{CD} 25^{+} \mathrm{CD} 44^{+}\right)$cells, they migrate to the subcapsular zone of the thymus and develop into DN3 (CD25+CD44) cells. Through DN2 to DN4 T cell differentiation phase, $\alpha \beta-T$ cell precursor cells express a pre-TCR which is composed of the non-rearranged pre-T $\alpha$ chain and a rearranged $\beta$ chain. TCR expression on the cell surface leads to proliferation during DN4 and the development of double positive (DP) $\mathrm{CD}^{+}{ }^{+} \mathrm{CD} 8^{+}$precursor cells. $\alpha \beta-T C R{ }^{+} C D 4^{+} C D 8^{+}$cells express fully assembled $\alpha \beta-T C R$ complexes and travel back to the cortex. DP cells whose receptors interact with self-peptide:selfMHC complexes expressed on thymic cortical epithelial cells are positively selected. Cells receiving signals through MHC class II-restricted TCR differentiate into $\mathrm{CD}^{+} \mathrm{T}$ cells, whereas cells with $\mathrm{MHC}$ class I-restricted TCR differentiate into $\mathrm{CD}^{+} \mathrm{T}$ cells. $\mathrm{T}$ cells whose TCRs recognize self-peptide:self-MHC complexes too strongly are deleted in the thymus. This process it termed negative selection. Thus, the outcome of positive and negative selection is the generation of mature $\mathrm{CD}^{+}$and $\mathrm{CD}^{+} \mathrm{T}$ cells. Within a few days these cells leave the thymus and 
circulate as mature naïve T cells (Figure 4; Chong et al., 2003; Germain, 2002; Starr et al., 2003; Yu et al., 2006).

$\mathrm{CD}^{+} \mathrm{T}$ cells ( $\mathrm{T}$ helper cells) are responsible for stimulation of $\mathrm{B}$ cells and activation of macrophages. $\mathrm{CD} 8^{+} \mathrm{T}$ cells (cytotoxic $\mathrm{T}$ cells) directly interact with virally infected tumor cells and kill these target cells (Murphy et al., 2008; Weinberger et al., 2009).

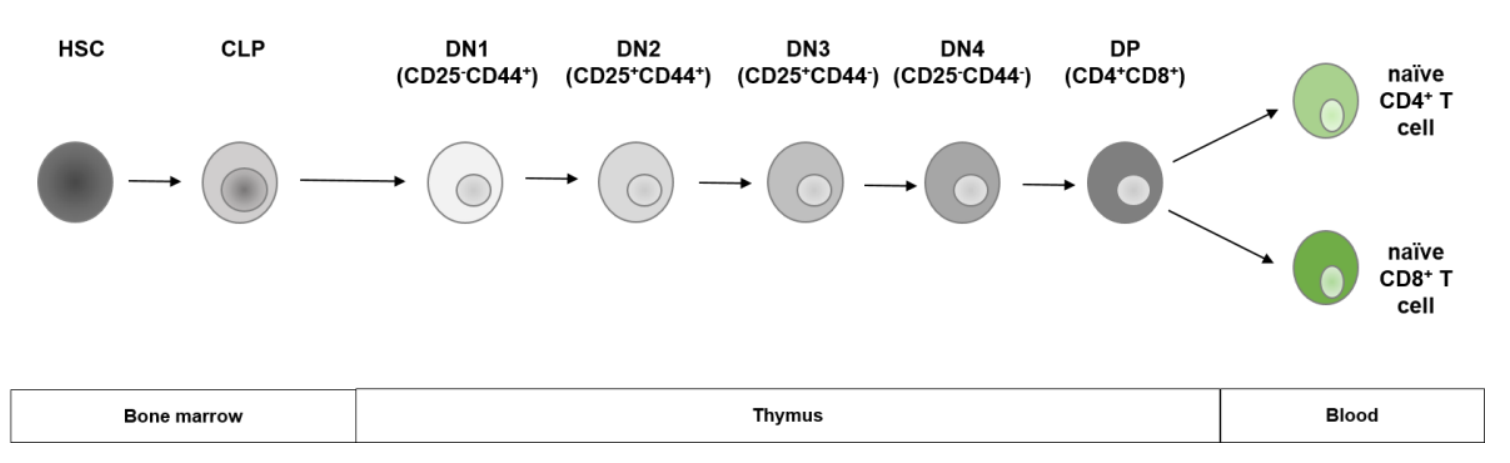

Figure 4: T cell development in the thymus. From a pluripotent hematopoietic stem cell (HSC) Common lymphoid progenitors (CLPs) arise in the bone marrow and migrate to the thymus. Double negative (DN) thymocytes are early committed $T$ cells which lack the expression of $T$ cell receptor (TCR), CD4 and CD8. DN thymocytes differentiate into four stages: DN1 (CD25-CD44+), DN2 $\left(\mathrm{CD} 25^{+} \mathrm{CD} 44^{+}\right)$, DN3 (CD25+CD44) and DN4 (CD25-CD44). During the DN4 stage, the pre-TCR expression leads to substantial proliferation and transition to double positive (DP) cells. The preTCR $\alpha$ chain is replaced by a rearranged TCR $\alpha$ chain, which yields a $\alpha \beta-T C R$. The DP thymocytes interact with MHC class I or II molecules on thymic epithelial cells. An appropriate TCR signaling initiates effective maturation, termed positive selection. Naïve $\mathrm{CD} 4^{+}$and $\mathrm{CD} 8^{+} \mathrm{T}$ cells are ready to export from the medulla of the thymus to peripheral lymphoid sites (modified from Germain et al., Nat Rev Immunol 2002; Starr et al., Annu Rev Immunol 2003).

Naïve T cells patrol the whole organism and search for antigens. They recirculate via the blood and lymph vasculature to secondary lymphoid organs (SLOs), like lymph nodes (LNs), where they scan antigen-presenting cells (APCs) for a cognate antigen before egressing via the efferent lymphatics.

To overcome shear forces in the blood and to ensure the entrance of naïve T cells into peripheral lymphoid tissues, L-selectin (CD62L) interacts with proteins such as peripheral node adressin (PNAd) on high endothelial venules (HEV). The 
interaction between CD62L and PNAd is responsible for the homing of naïve T cells to lymphoid organs (Gallatin et al., 1983; Masopust and Schenkel, 2013).

Furthermore, CC-chemokine ligand 21 (CCL21), which is immobilized on HEV is recognized by the CC-chemokine receptor 7 (CCR7). Thereby, T cells are chemotactically attracted to enter the LNs. Additionally, lymphocyte diapedesis is induced via lymphocyte function-associated antigen 1 (LFA1) and intercellular adhesion molecule 1 (ICAM1) interaction. Thus, CD62L, CCR7/CCL21 and LFA1 together mediate the migration processes by which naïve $T$ cells enter the $L N s$ (Masopust and Schenkel, 2013).

If a naïve $T$ cell which did not have contact with its specific antigen before recognizes its specific antigen in combination with the MHC complex on the surface of an APC, it undergoes clonal expansion which is triggered by IL-2 (Geginat et al., 2001). For an optimal activation and proliferation of naïve T cells, co-stimulatory signals such as CD27-CD70, CD28-CD80/CD86 and CD134 (OXO 40)-CD52 (OX40L) are essential (Billadeau et al., 2007; Chen et al., 1999; Rogers et al., 2001; Taraban et al., 2004). Once a naïve $T$ cell has been activated and clonally expanded, it differentiates into an effector $T$ cell of identical antigen specificity. Effector T cells express sphingosine 1-phosphate (S1P) receptor which binds S1P. S1P has chemotactic activity and signaling properties similar to those of chemokines. Therefore, it creates such a concentration gradient between the lymphoid tissue and lymph or blood that effector T cells expressing a S1P receptor are drawn away from the lymphoid tissue. Following the S1P gradient, effector T cells migrate to non-lymphoid tissues to seek cognate antigen (Murphy et al., 2008).

After pathogen clearance, most activated effector $T$ cells die by apoptosis and only few effector $T$ cells are maintained in the absence of antigen as memory $T$ cells. Memory $T$ cells remain in the body and ensure that the response to a second contact with the same antigen is faster and more pronounced than in the primary response. The generation of memory $T$ cells is associated with several functional and phenotypic changes, such as the capacity to upregulate IL-2, IFN- $\gamma$, TNF- $\alpha$, CD11a, CD44 and CD45RO (Wherry and Ahmed, 2004). The heterogeneous populations of memory $\mathrm{CD}^{+}$and $\mathrm{CD}^{+} \mathrm{T}$ cells consist of two main subtypes: central memory $\left(\mathrm{T}_{\mathrm{CM}}\right)$ and effector memory ( $\left.\mathrm{T}_{\mathrm{EM}}\right) \mathrm{T}$ cells. $\mathrm{T}_{\mathrm{CM}}$ mainly home to secondary lymphoid organs via their CCR7 expression. $T_{C M}$ are very sensitive to 
cross-linking of their TCR, but they take longer than TEM to differentiate into effector cells and do not secrete large amounts of cytokines early after restimulation. TEM which lack CD62L and CCR7 expression recirculate through non-lymphoid tissues. They express the chemokine receptor CCR5 which is associated with homing to inflammatory sites where TEM exhibit rapidly increased effector functions and secrete large amounts of IFN-y, IL-4 and IL-5 (Murphy et al., 2008; Masopust and Picker, 2012; Maospust and Schenkel, 2013).

\subsubsection{Age-related changes of the T cell compartment}

One hallmark of immunesenescence is the alteration of the $T$ cell pool, characterized by the decrease of naïve $T$ cells in the periphery and lymphoid organs (Arnold et al., 2011; Fagnoni et al., 2000; Herndler-Brandstetter et al., 2012; Lazuardi et al., 2005), while the counts of memory and terminally differentiated effector $T$ cells increase with age (Figure 5). The age-related changes are more pronounced in $\mathrm{CD}^{+}$than in $\mathrm{CD}^{+} \mathrm{T}$ cells. The number and diversity of naïve $\mathrm{CD}^{+} \mathrm{T}$ cells is maintained for decades, but at the age of approximately 70 years the naïve CD4+ $T$ cell compartment dramatically collapses in its diversity, leading to a more restricted repertoire (Goronzy et al., 2007). Naive $\mathrm{CD}^{+} \mathrm{T}$ cells are more and earlier affected by age-related changes than naïve CD4+ $T$ cells (Weinberger et al., 2009; Arnold et al., 2011). 


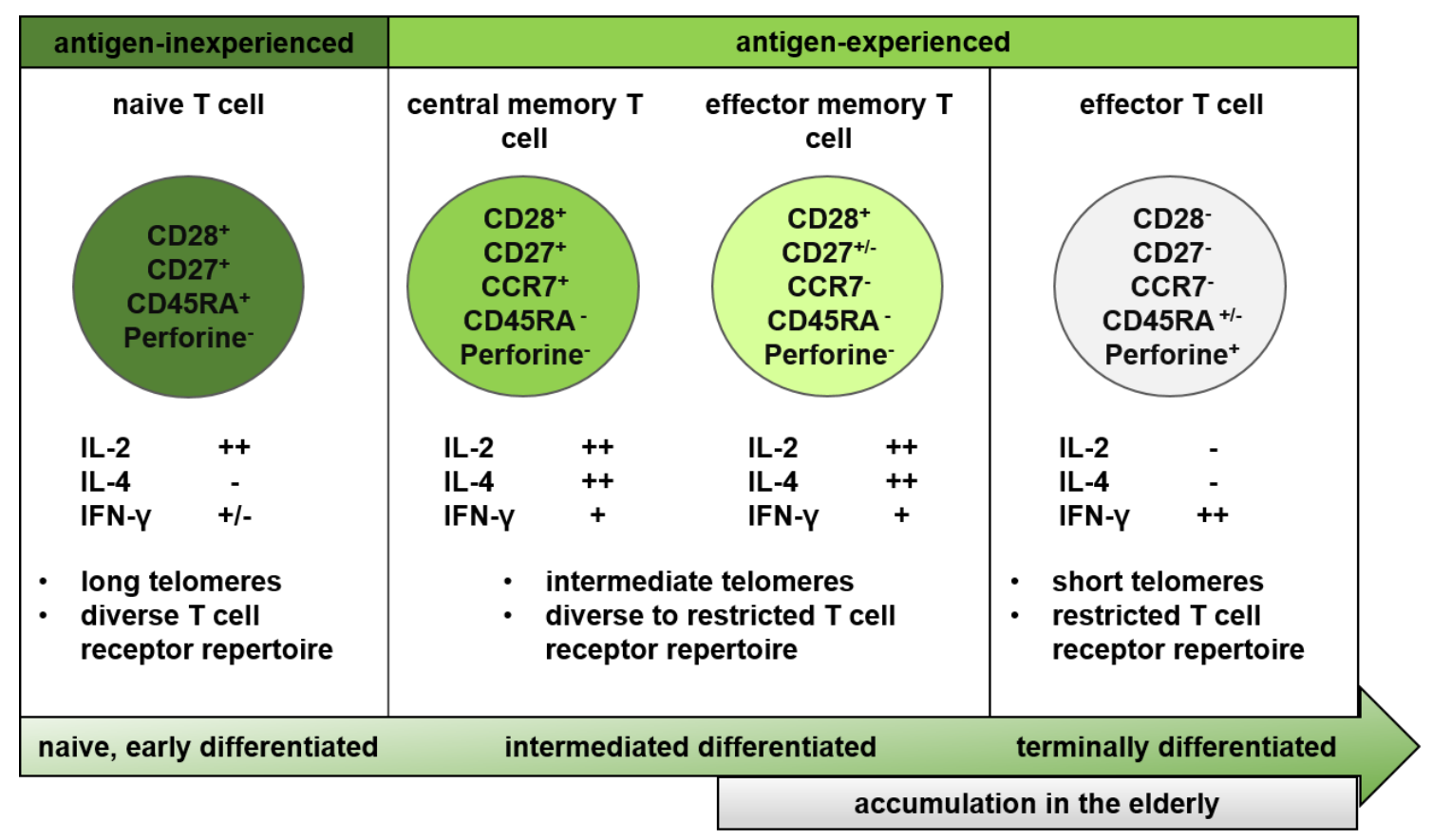

Figure 5: Age-related characteristics of different T cell subsets. Naïve, antigen-inexperienced and antigen-experienced (memory and effector) $T$ cells are summarized with respect to their surface molecule expression, cytokine production, telomere length and T cell receptor repertoire. Effector memory and terminally differentiated effector $\mathrm{T}$ cells accumulate in the elderly (modified from Weinberger et al., Hazzard's Geriatric Medicine and Gerontology, $6^{\text {th }}$ edition, chapter 3 ).

An initial trigger responsible for alterations of the $\mathrm{T}$ cell compartment are agerelated changes of the thymus, termed thymic involution. This process is characterized by a reduction in the overall size of the thymus and by the replacement of functional cortex and medulla tissue by fat. Thymic involution starts after birth and is complete at the age of about 40 to 50 years. This results in a shift in the composition of the $\mathrm{T}$ cell pool from naïve to antigen-experienced $\mathrm{T}$ cells (Figure 6; Aspinall and Andrew, 2000; George and Ritter, 1996; Steinmann, 1986). 


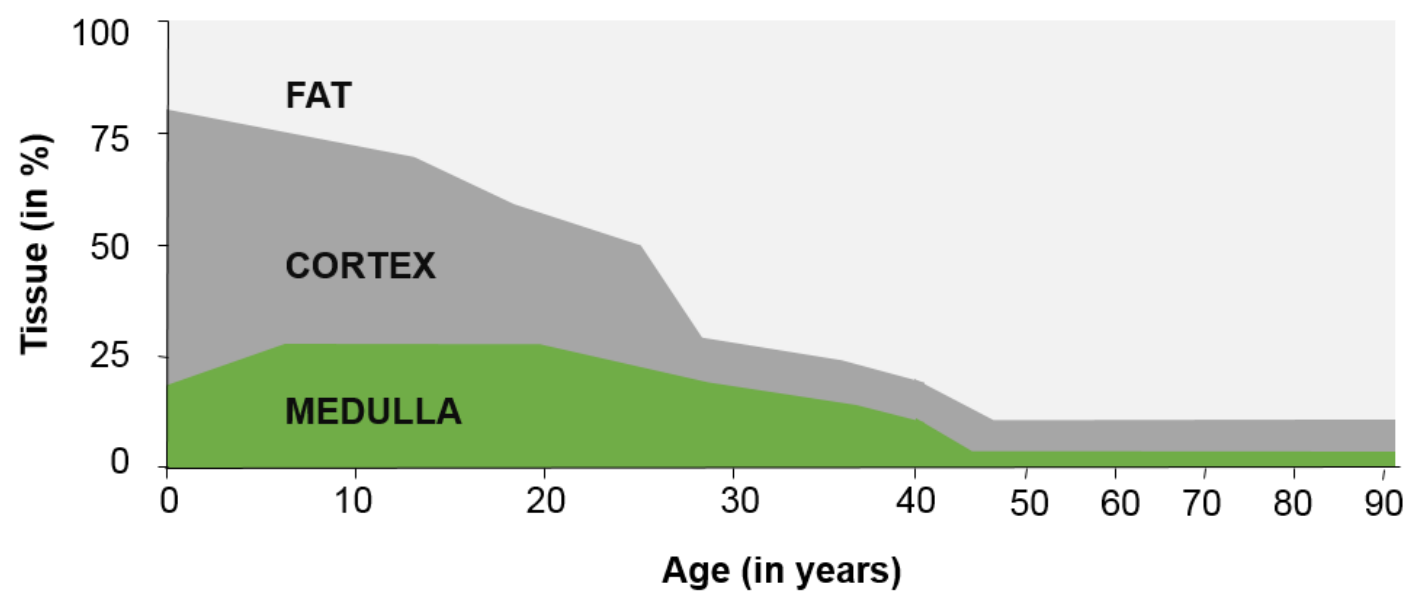

Figure 6: Thymic involution, a hallmark of human aging. During aging functional thymic tissue (medulla and cortex) is replaced by fat tissue. Histological pictures of human pediatric thymus and an 82-year old person are shown. Consequently, the output of naïve $T$ cells decreases after the age of 50 years (modified from George and Ritter, Immunol Today 1996).

The reduced thymic output of naïve $T$ cells is compensated by homeostatic proliferation mainly mediated by IL-7 (Schluns et al., 2000) and IL-15 (Lodolce et al., 1998), which increase $\mathrm{Bcl}-2$ expression, repress $\mathrm{Bcl}-2$-associated $\mathrm{X}$ protein (Bax) expression, phosphorylate signal transducer and activator of transcription $5 \mathrm{~A}$ (STAT5a) and forkhead box O3a (FOXO3a) as well as activate the phosphatidylinositol 3'-kinase (PI3K)-Akt pathway. This process keeps naïve T cells alive and extends their lifespan (Qin et al., 2001; Rathmell et al., 2001).

In old age the antigen-experienced $T$ cell population includes terminally differentiated $\mathrm{CD} 8^{+} \mathrm{CD} 28^{-}$effector $\mathrm{T}$ cells. These cells are characterized by the loss of the co-stimulatory molecules CD28 and CD40L, decreased proliferative capacity, a modified cytokine production profile, shortened telomeres, increased resistance to programmed cell death and a restricted TCR repertoire diversity (Effros et al., 2003; Effros et al., 2005; Grubeck-Loebenstein and Wick, 2002).

The co-stimulatory molecule CD28 is a member of the Tumor Necrosis Factor (TNF) family that interacts with CD80 and CD86 expressed on activated APCs. Along with TCR/MHC interaction, CD28 signaling is required to achieve full T cell activation (Bjorgo and Tasken, 2010). Signaling via the co-stimulatory molecule CD28 overcomes the $T$ cells auto-inhibitory pathway to sustain $T$ cell activation 
and proliferation by IL-2 production. The loss of CD28 signaling has also been associated with reduced telomerase activity (Plunkett et al., 2007) as well as altered cellular $\mathrm{T}$ cell function including decreased activation and proliferation. Furthermore, the loss of CD28 results in diminished ability to secrete IL-2. But a high expression of cytotoxic mediators (granzymes and perforine) and proinflammatory cytokines enables these cells to exhibit effector functions (Arnold et al., 2011; Kovaiou et al., 2005).

Terminally differentiated CD28-CD8 ${ }^{+} \mathrm{T}$ cells are - due to their pro-inflammatory functions - believed to contribute to a low-grade inflammatory background commonly observed in old age. This has been referred to as "inflamm-aging" (Franceschi et al., 2000).

Moreover, age-related changes of the $T$ cell pool can be accelerated by pathogens such as CMV (Brunner et al., 2011; Nikolich-Zugich, 2008). Latent CMV infection severely impairs the $T$ cell pool. Due to repeated rounds of $C M V$ reactivations, the frequency of highly differentiated $\mathrm{CD} 4^{+}$and $\mathrm{CD} 8^{+} \mathrm{T}$ cells increases (Figure 7; Arnold et al., 2011; Sylwester et al., 2005). 


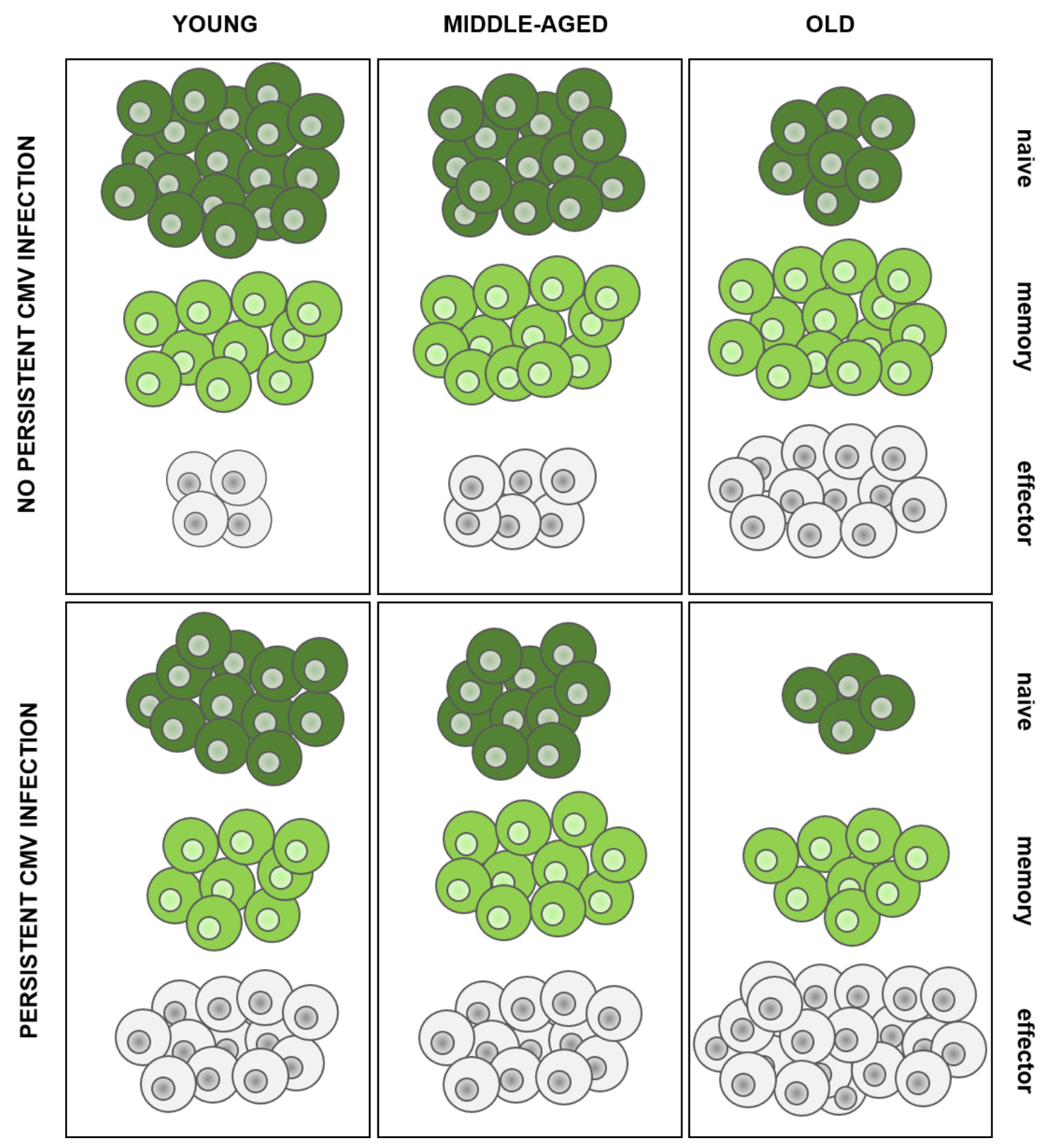

Figure 7: The composition of the $T$ cell pool is affected by aging and chronic Cytomegalovirus (CMV) infection. Due to thymic involution the naïve $\mathrm{T}$ cells (dark green) decrease with age while memory (light green) and highly differentiated effector T cells (light grey) increase in elderly persons. Latent CMV infection accelerates this process leading to a more pronounced accumulation of highly differentiated CD8 ${ }^{+} \mathrm{CD} 28-$ effector $\mathrm{T}$ cells. 


\subsection{The bone marrow}

Bones are highly structured organs which include the periosteum, endosteum, cartilage, red BM, blood vessels and nerves. The BM comprises the center and the epiphysis of bones and is the place where blood vessels are generated (Chinn et al., 2012).

BM can be divided into two compartments: the stromal compartment, which contains mesenchymal stem cells (MSCs) and stromal cells such as osteoblasts and adipocytes, and the hematopoietic stem cell (HSC) compartment, which contains HSCs and cells resulting from their differentiation. Age-related alterations in each of these compartments are known to contribute to changes in lymphocyte production during aging (Chinn et al., 2012).

It has long been thought that the BM is only a hematopoietic organ (Zhao et al., 2012), but is now well understood that it also plays an important role as secondary lymphoid organ, as described in the following.

\subsubsection{The role of the bone marrow as a secondary lymphoid organ and age-related changes of bone marrow adaptive immune cells}

The BM functions as a secondary lymphoid organ (Di Rosa and Santoni, 2002). It houses long-lived plasma cells (McHeyzer-Williams and Ahmed, 1999; Radbruch et al., 2006) and supports memory T cell survival in mice (Hanazawa et al., 2013b; Radbruch et al., 2006; Tokoyoda et al., 2009b) as well as in humans (HerndlerBrandstetter et al., 2011; Herndler-Brandstetter et al., 2012)

Upon antigenic stimulation, high affinity memory $B$ and plasma cells are generated in the GC of lymphoid organs (LNs, spleen). Within the GC, the variable gene region of the antibody undergoes hypermutation and cells with high affinity receptors are selected to differentiate into memory $B$ and plasma cells. While memory $B$ cells mainly relocate and remain in the spleen, plasmablasts leave the GC and migrate to the BM guided by a chemotactic response. The C-X-C chemokine receptor 4 (CXCR4) is an alpha-chemokine receptor which binds to stromal cell-derived factor-1 (SDF-1), also called CXCL12 (Tamamis and Floudas, 
2013). CXCR4 interaction with CXCL12 allows plasmablasts to home to the BM and mature into plasma cells (Chu and Berek, 2013; Hargreaves et al., 2001). Plasma cells also express the very late activation antigen (VLA)-4. VLA-4 is composed of an $\alpha 4$ and a $\beta 1$ chain and binds the vascular cell adhesion molecule1 (VCAM1), a cytokine-inducible endothelial cell surface protein. VLA-4 mediates cellular adhesion and activation through a variety of cell-cell and cellmatrix interactions that regulate leukocyte migration (Hemler et al., 1990). It is is therefore also important for the homing of plasma cells to the BM in mice (Figure 8; Belnoue et al., 2012).

$\mathrm{BM}$ eosinophils also trigger the differentiation of plasmablasts to plasma cells (Chu and Berek, 2013; Yu et al., 2002). Plasma cells then survive in distinct BM survival niches for a long period of time, probably years, without DNA synthesis and cell division, but highly activated in terms of protein synthesis (Tokoyoda et al., 2010). Little is still known about age-related changes of the BM as survival niche for plasma cells. Previous studies in mice suggest that the number of plasma cells of both, low and high affinity, is reduced in the BM in aged mice (Han et al., 2003). Therefore, two mechanisms may contribute to an impaired humoral immune response in old age: (1) Due to the diminished GC activity, lower numbers of high affinity ASCs are generated, and (2) the long-term survival of ASCs in the BM is impaired due to alterations of the BM environment (Han et al., 2003). Furthermore, TNF- $\alpha$ mediated inflammation suppresses CXCL12 expression and the resulting homing process of plasmablasts to the BM (Ueda et al., 2004). The decrease of CXCL12 expression in the BM could be associated with the low grade inflammatory background ("inflamm-aging"; Franceschi et al., 2000).

The BM also plays an important role in the long-term survival of memory $T$ cells. Memory $\mathrm{CD} 4{ }^{+} \mathrm{T}$ cells migrating to the BM utilize CD49b and CD69 and survive in the BM as resting but highly reactive T cells (Tokoyoda et al., 2009b). CD49b (alpha 2 integrin) together with $\beta 1$ integrin form VLA-2, which serves as a collagen receptor (Collagen I, II and XI; Hanazawa et al., 2013a; Hanazawa et al., 2013b; Heino, 2007; Hynes, 1992; Tuckwell et al., 1995). CD49b is required for memory $\mathrm{CD}^{+}{ }^{+} \mathrm{T}$ cell trafficking to the BM survival niche in mice (Hanazawa et al., 2013a; Hanazawa et al., 2013b). Moreover, the activation marker CD69 is a type II membrane protein of the C-type lectin family (Hanazawa et al., 2013b; Shinoda et al., 2012; Testi et al., 1994; Ziegler et al., 1994). In the murine system, CD69- 
deficient $\mathrm{CD} 4^{+} \mathrm{T}$ cells fail to facilitate the generation of $\mathrm{BM}$ long-lived plasma cells. Therefore, CD49b as well as CD69 are essential for the homing of memory CD4+ T cells to the BM in mice (Figure 8; Hanazawa et al., 2013a; Shinoda et al., 2012).

SPLEEN AND LYMPH NODES

BONE MARROW

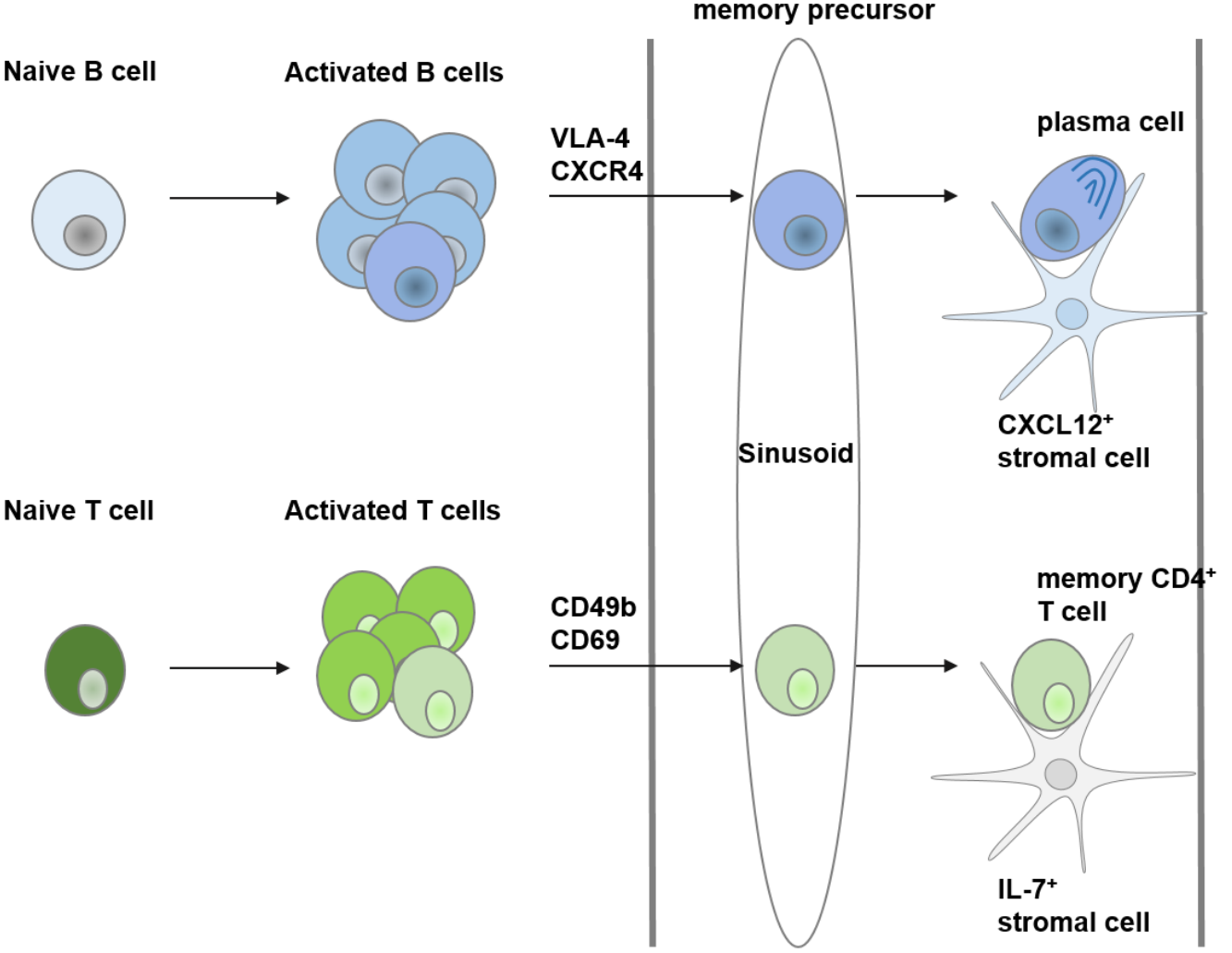

Figure 8: Relocation and maintenance of plasma and memory CD4 ${ }^{+} \mathrm{T}$ cells in the BM. During an immune response activated lymphocytes from LNs and spleen migrate to the BM and reside and rest there in distinct survival niches. While plasma cells use the C-X-C chemokine receptor 4 (CXCR4) and the very late activation antigen (VLA)-4 for their BM relocation, CD49b and CD69 are essential for memory $\mathrm{T}$ cell migration to the BM in mice (modified from Hanazawa et al., Front Immunol 2013). 
So far, most studies have been performed in mice. Little is still known about the relocation and maintenance of human memory $T$ cells to the BM and their survival. Early immunofluorescence staining studies date back to 1986 (Clark et al., 1986). Later, CD45RA ${ }^{+} \mathrm{CD} 27^{-} \mathrm{CD} 4^{+}$effector $\mathrm{T}$ cells were suggested to be generated in the human BM (Libri et al., 2011). Our group demonstrated that $\mathrm{CD}^{+}$and $\mathrm{CD}^{+}$ effector memory $\mathrm{T}$ cells accumulate in the human $\mathrm{BM}$ and that these cells are frequently polyfunctional (Herndler-Brandstetter et al., 2011).

Little information is still available about age-related changes of the $T$ cell pool in the human BM. Recently our group contributed to this topic by providing information about the effect of aging on BM T cells. While $\mathrm{CD} 4^{+}$and $\mathrm{CD} 8^{+} \mathrm{T}$ cells in the $\mathrm{BM}$ are not affected, the size of $\mathrm{CD}^{+}$and $\mathrm{CD}^{+} \mathrm{T}$ cell subpopulations in the BM changes with age (Herndler-Brandstetter et al., 2012). Similar to the PB (Arnold et al., 2011; Fagnoni et al., 2000), the numbers of naïve $\mathrm{CD}^{+}$and $\mathrm{CD}^{+} \mathrm{T}$ cells decrease in the $\mathrm{BM}$, while an age-dependent increase in the numbers of $\mathrm{CD}^{+}$and $\mathrm{CD} 8^{+} \mathrm{T}_{\mathrm{EM}}$ occurs. The numbers of $\mathrm{CD}^{+}$and $\mathrm{CD} 8^{+} \mathrm{TCM}_{\mathrm{CM}}$ as well as of TEMRA do not change in the BM during aging and a higher number of polyfunctional $\mathrm{CD}^{+}$and $\mathrm{CD}^{+}{ }^{+} \mathrm{T}$ cells which produce IFN- $\gamma$, Interleukin (IL)-2 and TNF- $\alpha$ still resides in the $\mathrm{BM}$ in old age.

$\mathrm{CD}^{+} \mathrm{T}$ cell aging in the periphery is associated with the loss of CD28, but the acquisition of CD57 (Brenchley et al., 2003; Effros et al., 2005; Focosi et al., 2010). CD57 is a late differentiation marker and its expression on human $T$ cells is described as a marker for replicative senescence (Brenchley et al., 2003). In the aged $\mathrm{BM}$ the percentage of $\mathrm{CD} 8^{+} \mathrm{CD} 28^{-} \mathrm{T}$ cells increases similar to the situation in the periphery. However, only a low number of highly differentiated $\mathrm{CD} 8{ }^{+} \mathrm{CD} 57^{+} \mathrm{T}$ cells accumulates in the BM of elderly persons (Herndler-Brandstetter et al., 2012). The reason for the absence of $C D 57^{+}$cells in the BM is not yet known. 


\subsection{References to chapter I}

Abbas, A. K. and Lichtman, A. H., 2007. Cellular and Molecular Immunology. $6^{\text {th }}$ Edition ed. Philadelphia: Elsevier.

Ademokun, A., Wu, Y.C., Dunn-Walters, D., 2010. The ageing B cell population: composition and function. Biogerontology 11:125-137.

Arnold, C.R., Wolf J., Brunner S., Herndler-Brandstetter D., Grubeck-Loebenstein B., 2011. Gain and loss of T cell subsets in old age--age-related reshaping of the T cell repertoire. Journal of clinical immunology 31:137-146.

Aspinall, R., Andrew, D., 2000. Thymic involution in aging. Journal of clinical immunology 20:250-256.

Belnoue, E., Tougne, C., Rochat, A.F., Lambert, P.H., Pinschewer, D.D., Siegrist, C.A., 2012. Homing and adhesion patterns determine the cellular composition of the bone marrow plasma cell niche. Journal of immunology 188:1283-1291.

Billadeau, D.D., Nolz, J.C, Gomez, T.S., 2007. Regulation of T-cell activation by the cytoskeleton. Nature reviews. Immunology 7:131-143.

Bjorgo, E., and Tasken K., 2010. Novel mechanism of signaling by CD28. Immunology letters 129:1-6.

Boraschi, D., Aguado, M.T., Dutel, C., Goronzy, J., Louis, J., GrubeckLoebenstein, B., Rappuoli, R., Del Giudice, G., 2013. The gracefully aging immune system. Science translational medicine 5:185ps188.

Breitbart, E., Wang, X., Leka, L.S., Dallal, G.E., Meydani, S.N., Stollar, B.D., 2002. Altered memory B-cell homeostasis in human aging. The journals of gerontology. Series A, Biological sciences and medical sciences 57:B304311.

Brenchley, J.M., Karandikar, N.J., Betts, M.R., Ambrozak, D.R., Hill, B.J., Crotty, L.E., Casazza, J.P., Kuruppu, J., Migueles, S.A., Connors, M., Roederer, M., Douek, D.C., Koup, R.A., 2003. Expression of CD57 defines replicative senescence and antigen-induced apoptotic death of CD8+ T cells. Blood 101:2711-2720. 
Brunner, S., Herndler-Brandstetter, D., Weinberger, B., Grubeck-Loebenstein, B., 2011. Persistent viral infections and immune aging. Ageing research reviews 10:362-369.

Caraux, A., Klein, B., Paiva, B., Bret, C., Schmitz, A., Fuhler, G.M., Bos, N.A., Johnsen, H.E., Orfao, A., Perez-Andres, M., Myeloma Stem Cell, N., 2010. Circulating human $B$ and plasma cells. Age-associated changes in counts and detailed characterization of circulating normal CD138- and CD138+ plasma cells. Haematologica 95:1016-1020.

Chen, A.I., McAdam, A.J., Buhlmann, J.E., Scott, S., Lupher, M.L., Greenfield, E.A., Baum, P.R., Fanslow, W.C., Calderhead, D.M., Freeman, G.J., Sharpe, A.H., 1999. Ox40-ligand has a critical costimulatory role in dendritic cell:T cell interactions. Immunity 11:689-698.

Chinn, I.K., Blackburn, C.C., Manley, N.R., Sempowski, G.D., 2012. Changes in primary lymphoid organs with aging. Seminars in immunology 24:309-320.

Chong, M.M., Cornish, A.L., Darwiche, R., Stanley, E.G., Purton, J.F., Godfrey, D.I., Hilton, D.J., Starr, R., Alexander, W.S., Kay, T.W., 2003. Suppressor of cytokine signaling-1 is a critical regulator of interleukin-7-dependent CD8+ T cell differentiation. Immunity 18:475-487.

Chong, Y., Ikematsu, H., Yamaji, K., Nishimura, M., Nabeshima, S., Kashiwagi, S., Hayashi, J., 2005. CD27(+) (memory) B cell decrease and apoptosisresistant CD27(-) (naive) B cell increase in aged humans: implications for age-related peripheral B cell developmental disturbances. International immunology 17:383-390.

Chu, V.T., Berek, C., 2013. The establishment of the plasma cell survival niche in the bone marrow. Immunological reviews 251:177-188.

Clark, P., Normansell, D.E., Innes, D.J., Hess, C.E., 1986. Lymphocyte subsets in normal bone marrow. Blood 67:1600-1606.

Colonna-Romano, G., Bulati, M., Aquino, A., Scialabba, G., Candore, G., Lio, D., Motta, M., Malaguarnera, M., Caruso, C., 2003. B cells in the aged: CD27, CD5, and CD40 expression. Mechanisms of ageing and development 124:389-393. 
Di Rosa, F., Santoni A., 2002. Bone marrow CD8 T cells are in a different activation state than those in lymphoid periphery. European journal of immunology 32:1873-1880.

Effros, R.B., Cai, Z., Linton, P.J., 2003. CD8 T cells and aging. Critical reviews in immunology 23:45-64.

Effros, R.B., Dagarag, M., Spaulding, C., Man, J., 2005. The role of CD8+ T-cell replicative senescence in human aging. Immunological reviews 205:147157.

Fagnoni, F.F., Vescovini, R., Passeri, G., Bologna, G., Pedrazzoni, M., Lavagetto, G., Casti, A., Franceschi, C., Passeri, M., Sansoni, P., 2000. Shortage of circulating naive CD8(+) T cells provides new insights on immunodeficiency in aging. Blood 95:2860-2868.

Focosi, D., Bestagno, M., Burrone, O., Petrini, M., 2010. CD57+ T lymphocytes and functional immune deficiency. Journal of leukocyte biology 87:107-116.

Franceschi, C., Bonafe, M., Valensin, S., Olivieri, F., De Luca, M., Ottaviani, E., De Benedictis, G., 2000. Inflamm-aging. An evolutionary perspective on immunosenescence. Annals of the New York Academy of Sciences 908:244-254.

Frasca, D., Landin, A.M., Riley, R.L., Blomberg, B.B., 2008. Mechanisms for decreased function of $B$ cells in aged mice and humans. Journal of immunology 180:2741-2746.

Gallatin, W.M., Weissman, I.L., Butcher, E.C., 1983. A cell-surface molecule involved in organ-specific homing of lymphocytes. Nature 304:30-34.

Gavazzi, G., Krause, K.H., 2002. Ageing and infection. The Lancet infectious diseases 2:659-666.

Geginat, J., Sallusto, F., Lanzavecchia, A., 2001. Cytokine-driven proliferation and differentiation of human naive, central memory, and effector memory CD4(+) T cells. The Journal of experimental medicine 194:1711-1719.

Geiger, H., de Haan, G., Florian, M.C., 2013. The ageing haematopoietic stem cell compartment. Nature reviews. Immunology 13:376-389. 
George, A.J., Ritter, M.A., 1996. Thymic involution with ageing: obsolescence or good housekeeping? Immunology today 17:267-272.

Germain, R.N., 2002. T-cell development and the CD4-CD8 lineage decision. Nature reviews. Immunology 2:309-322.

Goronzy, J.J., Lee, W.W., Weyand, C.M., 2007. Aging and T-cell diversity. Experimental gerontology 42:400-406.

Grubeck-Loebenstein, B., Wick, G., 2002. The aging of the immune system. Advances in immunology 80:243-284.

Han, S., Yang, K., Ozen, Z., Peng, W., Marinova, E., Kelsoe, G., Zheng, B., 2003. Enhanced differentiation of splenic plasma cells but diminished long-lived high-affinity bone marrow plasma cells in aged mice. Journal of immunology 170:1267-1273.

Hanazawa, A., Hayashizaki, K., Shinoda, K., Yagita, H., Okumura, K., Lohning, M., Hara, T., Tani-ichi, S., Ikuta, K., Eckes, B., Radbruch, A., Tokoyoda, K., Nakayama, T., 2013a. CD49b-dependent establishment of $T$ helper cell memory. Immunology and cell biology 91:524-531.

Hanazawa, A., Lohning, M., Radbruch, A., Tokoyoda, K., 2013b. CD49b/CD69Dependent Generation of Resting $\mathrm{T}$ Helper Cell Memory. Frontiers in immunology 4:183.

Hargreaves, D.C., Hyman, P.L., Lu, T.T., Ngo, V.N., Bidgol, A., Suzuki, G., Zou, Y.R., Littman, D.R., Cyster, J.G., 2001. A coordinated change in chemokine responsiveness guides plasma cell movements. The Journal of experimental medicine 194:45-56.

Harrison, D.E., Jordan, C.T., Zhong, R.K., Astle, C.M., 1993. Primitive hemopoietic stem cells: direct assay of most productive populations by competitive repopulation with simple binomial, correlation and covariance calculations. Experimental hematology 21:206-219.

Heino, J., 2007. The collagen family members as cell adhesion proteins. BioEssays : news and reviews in molecular, cellular and developmental biology 29:1001-1010. 
Hemler, M.E., Elices, M.J., Parker, C., Takada, Y., 1990. Structure of the integrin VLA-4 and its cell-cell and cell-matrix adhesion functions. Immunological reviews 114:45-65.

Herndler-Brandstetter, D., Landgraf, K., Jenewein, B., Tzankov, A., Brunauer, R., Brunner, S., Parson, W., Kloss, F., Gassner, R., Lepperdinger, G., Grubeck-Loebenstein, B., 2011. Human bone marrow hosts polyfunctional memory CD4+ and CD8+ T cells with close contact to IL-15-producing cells. Journal of immunology 186:6965-6971.

Herndler-Brandstetter, D., Landgraf, K., Tzankov, A., Jenewein, B., Brunauer, R., Laschober, G.T., Parson, W., Kloss, F., Gassner, R., Lepperdinger, G., Grubeck-Loebenstein, B., 2012. The impact of aging on memory $T$ cell phenotype and function in the human bone marrow. Journal of leukocyte biology 91:197-205.

Hynes, R.O., 1992. Integrins: versatility, modulation, and signaling in cell adhesion. Cell 69:11-25.

Kent, D.G., Copley, M.R., Benz, C., Wohrer, S., Dykstra, B.J., Ma, E., Cheyne, J., Zhao, Y., Bowie, M.B., Zhao, Y., Gasparetto, M., Delaney, A., Smith, C., Marra, M., Eaves, C.J., 2009. Prospective isolation and molecular characterization of hematopoietic stem cells with durable self-renewal potential. Blood 113:6342-6350.

Koch, U., Radtke, F., 2011. Mechanisms of $\mathrm{T}$ cell development and transformation. Annual review of cell and developmental biology 27:539562.

Kovaiou, R.D., Weiskirchner, I., Keller, M., Pfister, G., Cioca, D.P., GrubeckLoebenstein, B., 2005. Age-related differences in phenotype and function of CD4+ $\mathrm{T}$ cells are due to a phenotypic shift from naive to memory effector CD4+ T cells. International immunology 17:1359-1366.

Lazuardi, L., Jenewein, B., Wolf, A.M., Pfister, G., Tzankov, A., GrubeckLoebenstein, B., 2005. Age-related loss of naive $T$ cells and dysregulation of T-cell/B-cell interactions in human lymph nodes. Immunology 114:37-43. 
Libri, V., Azevedo, R.I., Jackson, S.E., Di Mitri, D., Lachmann, R., Fuhrmann, S., Vukmanovic-Stejic, M., Yong, K., Battistini, L., Kern, F., Soares, M.V., Akbar, A.N., 2011. Cytomegalovirus infection induces the accumulation of short-lived, multifunctional CD4+CD45RA+CD27+ T cells: the potential involvement of interleukin-7 in this process. Immunology 132:326-339.

Lodolce, J.P., Boone, D.L., Chai, S., Swain, R.E., Dassopoulos, T., Trettin, S., Ma, A., 1998. IL-15 receptor maintains lymphoid homeostasis by supporting lymphocyte homing and proliferation. Immunity 9:669-676.

Lutz, W., Sanderson, W., Scherbov, S., 2008. The coming acceleration of global population ageing. Nature 451:716-719.

Masopust, D., Picker, L.J., 2012. Hidden memories: frontline memory T cells and early pathogen interception. Journal of immunology 188:5811-5817.

Masopust, D., Schenkel, J.M., 2013. The integration of T cell migration, differentiation and function. Nature reviews. Immunology 13:309-320.

McHeyzer-Williams, M.G., Ahmed, R., 1999. B cell memory and the long-lived plasma cell. Current opinion in immunology 11:172-179.

Murphy, K., Travers, P., Walport, M., 2008 Janeway's Immuno Biology. Seventh Edition ed. New York: Garland Science.

Naparstek, Y., Plotz, P.H., 1993. The role of autoantibodies in autoimmune disease. Annual review of immunology 11:79-104.

Nikolich-Zugich, J., 2008. Ageing and life-long maintenance of T-cell subsets in the face of latent persistent infections. Nature reviews. Immunology 8:512522.

Pearse, G., 2006. Normal structure, function and histology of the thymus. Toxicologic pathology 34:504-514.

Plunkett, F.J., Franzese, O., Finney, H.M., Fletcher, J.M., Belaramani, L.L., Salmon, M., Dokal, I., Webster, D., Lawson, A.D., Akbar, A.N., 2007. The loss of telomerase activity in highly differentiated CD8+CD28-CD27- T cells is associated with decreased Akt (Ser473) phosphorylation. Journal of immunology 178:7710-7719. 
Qin, J.Z., Zhang, C.L., Kamarashev, J., Dummer, R., Burg, G., Dobbeling, U., 2001. Interleukin-7 and interleukin-15 regulate the expression of the bcl-2 and c-myb genes in cutaneous T-cell lymphoma cells. Blood 98:2778-2783.

Radbruch, A., Muehlinghaus, G., Luger, E.O., Inamine, A., Smith, K.G., Dorner, T., Hiepe, F., 2006. Competence and competition: the challenge of becoming a long-lived plasma cell. Nature reviews. Immunology 6:741-750.

Rathmell, J.C., Farkash, E.A., Gao, W., Thompson, C.B., 2001. IL-7 enhances the survival and maintains the size of naive $T$ cells. Journal of immunology 167:6869-6876.

Rogers, P.R., Song, J., Gramaglia, I., Killeen, N., Croft, M., 2001. OX40 promotes $\mathrm{Bcl}-\mathrm{xL}$ and $\mathrm{Bcl}-2$ expression and is essential for long-term survival of CD4 T cells. Immunity 15:445-455.

Schluns, K.S., Kieper, W.C., Jameson, S.C., Lefrancois, L., 2000. Interleukin-7 mediates the homeostasis of naive and memory CD8 T cells in vivo. Nature immunology 1:426-432.

Shinoda, K., Tokoyoda, K., Hanazawa, A., Hayashizaki, K., Zehentmeier, S., Hosokawa, H., Iwamura, C., Koseki, H., Tumes, D.J., Radbruch, A., Nakayama, T., 2012. Type II membrane protein CD69 regulates the formation of resting T-helper memory. Proceedings of the National Academy of Sciences of the United States of America 109:7409-7414.

Starr, T.K., Jameson, S.C., Hogquist, K.A., 2003. Positive and negative selection of T cells. Annual review of immunology 21:139-176.

Steinmann, G.G., 1986. Changes in the human thymus during aging. Current topics in pathology. Ergebnisse der Pathologie 75:43-88.

Sylwester, A.W., Mitchell, B.L., Edgar, J.B., Taormina, C., Pelte, C., Ruchti, F., Sleath, P.R., Grabstein, K.H., Hosken, N.A., Kern, F., Nelson, J.A., Picker, L.J., 2005. Broadly targeted human cytomegalovirus-specific CD4+ and CD8+ $T$ cells dominate the memory compartments of exposed subjects. The Journal of experimental medicine 202:673-685.

Tamamis, P., Floudas, C.A., 2013. Molecular recognition of CXCR4 by a dual tropic HIV-1 gp120 V3 loop. Biophysical journal 105:1502-1514. 
Taraban, V.Y., Rowley, T.F., Al-Shamkhani, A., 2004. Cutting edge: a critical role for CD70 in CD8 T cell priming by CD40-licensed APCs. Journal of immunology 173:6542-6546.

Testi, R., D'Ambrosio, D., De Maria, R., Santoni, A., 1994. The CD69 receptor: a multipurpose cell-surface trigger for hematopoietic cells. Immunology today 15:479-483.

Tokoyoda, K., Hauser, A.E., Nakayama, T., Radbruch, A., 2010. Organization of immunological memory by bone marrow stroma. Nature reviews. Immunology 10:193-200.

Tokoyoda, K., Zehentmeier, S., Hegazy, A.N., Albrecht, I., Grun, J.R., Lohning, M., Radbruch, A., 2009. Professional memory CD4+ T lymphocytes preferentially reside and rest in the bone marrow. Immunity 30:721-730.

Tuckwell, D., Calderwood, D.A., Green, L.J., Humphries, M.J., 1995. Integrin alpha $2 \mathrm{I}$-domain is a binding site for collagens. Journal of cell science $108 \mathrm{Pt}$ 4):1629-1637.

Ueda, Y., Yang, K., Foster, S.J., Kondo, M., Kelsoe, G., 2004. Inflammation controls B lymphopoiesis by regulating chemokine CXCL12 expression. The Journal of experimental medicine 199:47-58.

Veneri, D., Ortolani, R., Franchini, M., Tridente, G., Pizzolo, G., Vella, A., 2009. Expression of CD27 and CD23 on peripheral blood $B$ lymphocytes in humans of different ages. Blood transfusion = Trasfusione del sangue 7:2934.

Weinberger B, Weiskopf, D., Grubeck-Loebenstein, B., 2009. Immunology and Aging. In Hazzard's Geriatric Medicine and Gerontology, Vol $6^{\text {th }}$ edition.

Weiskopf, D., Weinberger, B., Grubeck-Loebenstein, B., 2009. The aging of the immune system. Transplant international : official journal of the European Society for Organ Transplantation 22:1041-1050.

Wherry, E.J., Ahmed, R., 2004. Memory CD8 T-cell differentiation during viral infection. Journal of virology 78:5535-5545.

Yu, C., Cantor, A.B., Yang, H., Browne, C., Wells, R.A., Fujiwara, Y., Orkin, S.H., 2002. Targeted deletion of a high-affinity GATA-binding site in the GATA-1 
promoter leads to selective loss of the eosinophil lineage in vivo. The Journal of experimental medicine 195:1387-1395.

Yu, Q., Park, J.H., Doan, L.L., Erman, B., Feigenbaum, L., Singer, A., 2006. Cytokine signal transduction is suppressed in preselection double-positive thymocytes and restored by positive selection. The Journal of experimental medicine 203:165-175.

Zhao, E., Xu, H., Wang, L., Kryczek, I., Wu, K., Hu, Y., Wang, G., Zou, W., 2012. Bone marrow and the control of immunity. Cellular \& molecular immunology 9:11-19.

Ziegler, S.F., Ramsdell, F., Alderson, M.R., 1994. The activation antigen CD69. Stem cells 12:456-465. 


\section{Introduction to manuscript I}

The BM is the primary organ of hematopoiesis and is responsible for the generation of precursors of innate and adaptive immune cells (Geiger et al., 2013). Over the last decades it has become clear that the BM also plays an important role as a secondary lymphoid organ (Di Rosa and Pabst, 2005).

Mice studies showed that a major proportion of antigen-experienced CD4 ${ }^{+}$and $\mathrm{CD}^{+} \mathrm{T}$ cells home to the $\mathrm{BM}$ and remain there for a prolonged period of time in distinct survival niches (Di Rosa and Pabst, 2005; Tokoyoda et al., 2009b).

Yet, little information is available on the role of the human BM in adaptive immune responses and potential changes during aging. Recently, our group contributed to this topic and studied $\mathrm{CD}^{+}$and $\mathrm{CD}^{+}$subpopulations from the human BM compared to the PB as well as their activation status, cytokine production and agerelated changes (Herndler-Brandstetter et al., 2012). For these studies iliac crest BM samples were used from young and elderly patients undergoing reconstructive surgery and bone remodeling of the jaw following accidents, tumor resection or for dental implants.

However, the iliac crest BM samples are generally very small with a low yield of BMMC. Therefore, in the present study we tested a different tissue source of BM samples, namely the femur shaft. These samples are available from patients undergoing hip replacement surgery and allow the isolation of a relatively high number of BMMC, which is necessary for many studies.

It was our first goal to compare the phenotype and function of BM T cells from the iliac crest and the femur shaft to exclude that inflammatory processes of the inflamed joint or anti-inflammatory drugs could influence the composition and activation state of adaptive immune cells. Our results demonstrated that the femur shaft provides a useful tool for a variety of experiments on human BM. 


\section{Manuscript I}

Bone marrow $\mathrm{T}$ cells from the femur are similar to iliac crest derived cells in old age and represent a useful tool for studying the aged immune system

Theresa Pritz ${ }^{1}$, Katja Landgraf-Rauf ${ }^{1}$, Dietmar Herndler-Brandstetter ${ }^{1 *}$, Rauend Rauf $^{2}$, Julian Lair ${ }^{2}$, Robert Gassner ${ }^{3}$, Birgit Weinberger ${ }^{1}$, Martin Krismer ${ }^{2}$, Beatrix Grubeck-Loebenstein ${ }^{1 \S}$

1 Institute for Biomedical Aging Research, University Innsbruck, Rennweg 10, Innsbruck, Austria

2 Department of Orthopedic Surgery, Innsbruck Medical University, Anichstrasse 35, Innsbruck, Austria

3 Department of Cranio-Maxillofacial and Oral Surgery, Innsbruck Medical University, Anichstrasse 35, Innsbruck, Austria

$\S$ Corresponding author

Immunity \& Aging 2013, 10(1):17. doi: 10.1186/1742-4933-10-17 This article is available from: http://www.immunityageing.com/content/10/1/17 


\section{Abstract}

Background: $\mathrm{CD} 4^{+}$and $\mathrm{CD} 8^{+} \mathrm{T}$ cells reside in the human bone marrow (BM) and show a heightened activation state. However, only small sample sizes are available from sources such as the iliac crest. Larger samples can be obtained from the femur in the course of hip replacement surgery. It was therefore the goal of the present study to compare the phenotype and function of BM T cells from different sources from elderly persons and to investigate how femur derived bone marrow $T$ cells can serve as a tool to gain a better understanding of the role of adaptive immune cells in the BM in old age.

Results: Bone marrow mononuclear cells (BMMC) were isolated from either the iliac crest or the femur shaft. As expected the yield of mononuclear cells was higher from femur than from iliac crest samples. There were no phenotypic differences between BMMC from the two sources. Compared to PBMC, both BM sample types contained fewer naïve and more antigen experienced $\mathrm{CD} 4^{+}$as well as $\mathrm{CD}^{+} \mathrm{T}$ cells, which, in contrast to peripheral cells, expressed CD69. Cytokine production was also similar in $\mathrm{T}$ cells from both BM types. Larger sample sizes allowed the generation of $\mathrm{T}$ cell lines from femur derived bone marrow using nonspecific as well as specific stimulation. The phenotype of $T$ cell lines generated by stimulation with OKT-3 and IL-2 for two weeks was very similar to the one of ex vivo BM derived T cells. Such lines can be used for studies on the interaction of different types of BM cells as shown by co-culture experiments with BM derived stromal cells. Using CMV NLV specific $T$ cell lines we additionally demonstrated that BM samples from the femur are suitable for the generation of antigen specific $T$ cell lines, which can be used in studies on the clonal composition of antigen specific BM T cells.

Conclusion: In conclusion, our results demonstrate that BMMC from the femur shaft are a useful tool for studies on the role of T cells in the BM in old age.

Keywords: bone marrow, iliac crest, femur, peripheral blood, mononuclear cells, T cells, cytokines, T cell lines, cytomegalovirus 


\section{Background}

Recent studies indicate that the bone marrow (BM) is a lymphoid organ which is important for adaptive immune responses (Di Rosa and Pabst, 2005). In mice it has been shown that a major proportion of memory $\mathrm{CD}^{+}$and $\mathrm{CD}^{+}{ }^{+} \mathrm{T}$ cells is located in the BM and remains there for a prolonged period of time in distinct survival niches (Tokoyoda et al., 2009a). The situation seems to be similar in humans (Herndler-Brandstetter et al., 2011).

Yet, little information is available on the role of the human BM in adaptive immune responses during aging. Our group has contributed to this topic using BM from iliac crest from young and elderly persons. Our results show that the number of $\mathrm{CD}^{+}$and $\mathrm{CD} 8^{+} \mathrm{T}$ cells in the $\mathrm{BM}$ is maintained during aging and that these cells are in a heightened activation state. However, the composition of the T cell pool in the aged BM is altered with a decline of naïve and an increase in effector memory T cells (Herndler-Brandstetter et al., 2012).

In previous studies we used iliac crest samples from patients undergoing reconstructive surgery and bone remodeling of the jaw following accidents or for dental implants. The major advantage of this source of bone marrow is that it is obtained from healthy donors of different age groups. However, the samples are generally very small with a low yield of BMMC. For many research questions higher cell numbers are needed. BM samples obtained from healthy donors by aspiration, e.g. for bone marrow transplantation frequently contain large numbers of peripheral mononuclear cells (Abrahamsen et al., 1995), which makes them unsuitable for studies in which e.g. T cell composition in the bone marrow is analyzed in direct comparison to peripheral blood. We therefore tested a different source of BM, namely the femur shaft. BM from the femur shaft is available from patients undergoing total hip replacement (Shen et al., 2012). Following collagenase digestions it is possible to isolate relatively high numbers of BMMC from these samples. A potential problem may be the close vicinity of the femur shaft to the inflamed joint in patients who undergo hip replacement, or the fact that these patients are frequently treated with anti-inflammatory drugs. In order to be suitable for studies on the physiology of the aging immune system the possibility that inflammatory processes and/or drugs could influence the composition and activation state of adaptive immune cells needs to be excluded. It was therefore 
the goal of our present study to compare the phenotype and function of BM T cells from the iliac crest and the femur shaft. We show that inflammatory processes in the joint do not affect the phenotype and function of T cells in the BM obtained from femur samples. We also suggest approaches how BMMC from the femur can be used for studies on the role of BM T cells in old age.

\section{Results}

Comparison of $\mathrm{CD} 4^{+}$and $\mathrm{CD} 8^{+} T$ cell phenotypes within $\mathrm{BM}$ from different sources

We first compared the composition of the $\mathrm{CD} 4^{+}$and $\mathrm{CD}^{+} \mathrm{T}$ cell pool in $\mathrm{BM}$ obtained from either the femur or iliac crest from elderly persons. Expectedly, the yield of BMMC was higher from femur than from iliac crest samples $\left(21.6 \times 10^{6} \pm 2.5\right.$; $n=13$ : femur versus $4.77 \times 10^{6} \pm 1.3 ; n=13$ : iliac crest; $p<0.001$ ). We analyzed the expression of the surface molecules CD45RA and CCR7 to define naïve $\left(C D 45 R A^{+} C C R 7^{+}\right)$, central memory (CD45RA-CCR7 ${ }^{+}$), effector memory (CD45RA CCR7 $)$ and TEMRA cells (CD45RA+CCR7 ${ }^{-}$). The relative numbers of $\mathrm{CD}^{+}$as well as $\mathrm{CD}^{+} \mathrm{T}$ cell subsets were similar in samples obtained from the femur and the iliac crest (Table 1). We were able to confirm characteristic differences between $B M M C$ and PBMC, which were previously described by our group (HerndlerBrandstetter et al., 2011; Herndler-Brandstetter et al., 2012). While the numbers of naïve $\mathrm{CD}^{+} \mathrm{T}$ as well as $\mathrm{CD}^{+} \mathrm{T}$ cells were decreased in both types of $\mathrm{BM}$ compared to $\mathrm{PB}$, there was an increase in the numbers of effector memory $T$ cells in the BM. In accordance with our previous results, a relatively large percentage of BM T cells expressed CD69. Again there were no differences in the number of $\mathrm{CD}^{2} 9^{+}$cells in BM samples from femur and iliac crest. In addition to the data in Table 1, we plotted the data on $T$ cell subsets versus age as a continuous variable for femur BM and PB, and linked BMMC and PBMC values in each donor (Fig. 1). Characteristic age related changes in the relative numbers of $T_{N}$ and $T_{E M}$ can be seen. The impact of CMV infection on the distribution of $\mathrm{T}$ cell subsets in the BM from iliac crest as well as from femur is similar to what is known from the periphery ((Herndler-Brandstetter et al., 2012) and data not shown). 


\begin{tabular}{|c|c|c|c|c|}
\hline & \multicolumn{3}{|c|}{ BM } & PB \\
\hline $\mathrm{CD4}^{+}$ & $\begin{array}{l}\text { Femur } \\
(\mathrm{n}=8)\end{array}$ & $\begin{array}{c}\text { Iliac crest } \\
(\mathrm{n}=8)\end{array}$ & $\mathrm{P}^{\#}$ & $(n=16)$ \\
\hline$\% \mathrm{CCR}^{+}{ }^{+} \mathrm{CD} 45 \mathrm{RA}^{+}\left(\mathrm{T}_{\mathrm{N}}\right)$ & $26.1 \pm 2.3$ & $19.8 \pm 1.9$ & 0.08 & $34.8 \pm 2.9^{* / \S}$ \\
\hline$\% \mathrm{CCR}^{+}{ }^{+} \mathrm{CD} 45 \mathrm{RA}^{-}\left(\mathrm{T}_{\mathrm{CM}}\right)$ & $21.9 \pm 5.9$ & $24.4 \pm 3.1$ & 0.89 & $28.8 \pm 3.7$ \\
\hline \% CCR7'CD45RA- $\left(\mathrm{T}_{\mathrm{EM}}\right)$ & $34.6 \pm 4.4$ & $44.3 \pm 3.6$ & 0.11 & $23.8 \pm 3.3^{* / \S}$ \\
\hline$\% \mathrm{CCR}^{-\mathrm{CD}} 45 \mathrm{RA}^{+}\left(\mathrm{T}_{\mathrm{EMRA}}\right)$ & $12.1 \pm 3.3$ & $13.4 \pm 3.0$ & 0.80 & $15.7 \pm 2.7$ \\
\hline CD69 & $16.9 \pm 3.1$ & $15.9 \pm 2.3$ & 0.69 & $0.7 \pm 0.1^{* / \S}$ \\
\hline $\mathrm{CD8}^{+}$ & $\begin{array}{l}\text { Femur } \\
(\mathrm{n}=8)\end{array}$ & $\begin{array}{c}\text { Iliac crest } \\
\quad(n=8)\end{array}$ & & $(n=16)$ \\
\hline$\% \mathrm{CCR}^{+}{ }^{+} \mathrm{CD} 45 \mathrm{RA}^{+}\left(\mathrm{T}_{\mathrm{N}}\right)$ & $17.8 \pm 3.5$ & $14.1 \pm 3.2$ & 0.47 & $29.3 \pm 3.4^{* / \S}$ \\
\hline$\% \mathrm{CCR}^{+}{ }^{+} \mathrm{CD} 45 \mathrm{RA}^{-}\left(\mathrm{T}_{\mathrm{CM}}\right)$ & $16.7 \pm 3.1$ & $10.9 \pm 4.1$ & 0.68 & $14.5 \pm 2.2$ \\
\hline \% CCR7-CD45RA- $\left(\mathrm{T}_{\mathrm{EM}}\right)$ & $29.1 \pm 4.2$ & $34.1 \pm 6.7$ & 0.64 & $21.9 \pm 2.6^{* / \S}$ \\
\hline$\%$ CCR7 $^{-C D 45 R A}{ }^{+}\left(\mathrm{T}_{\text {EMRA }}\right)$ & $33.0 \pm 0.5$ & $41.6 \pm 5.9$ & 0.59 & $39.5 \pm 3.7$ \\
\hline CD69 & $39.0 \pm 6.1$ & $46.3 \pm 4.1$ & 0.59 & $1.9 \pm 0.4^{* / \S}$ \\
\hline
\end{tabular}

Table 1. Comparison of mononuclear cells from different sources of $B M$ and from peripheral blood (PB). BM was obtained either from the femur shaft or from iliac crest, as described in Materials and Methods. All samples were from elderly persons (mean age $\pm S E M$ : femur $68.6 \pm 2.1$ years; iliac crest $66 \pm 3.1$ years). Data were calculated using $t$ test and are presented as mean \pm SEM. $" p<0.05$ : PBMC vs. femur derived BMMC; $\$ p<0.05$ : PBMC vs. iliac crest-derived BMMC. There were no significant differences between samples obtained from the two different sources of BM. ${ }^{\#}$ values: femur versus iliac crest 

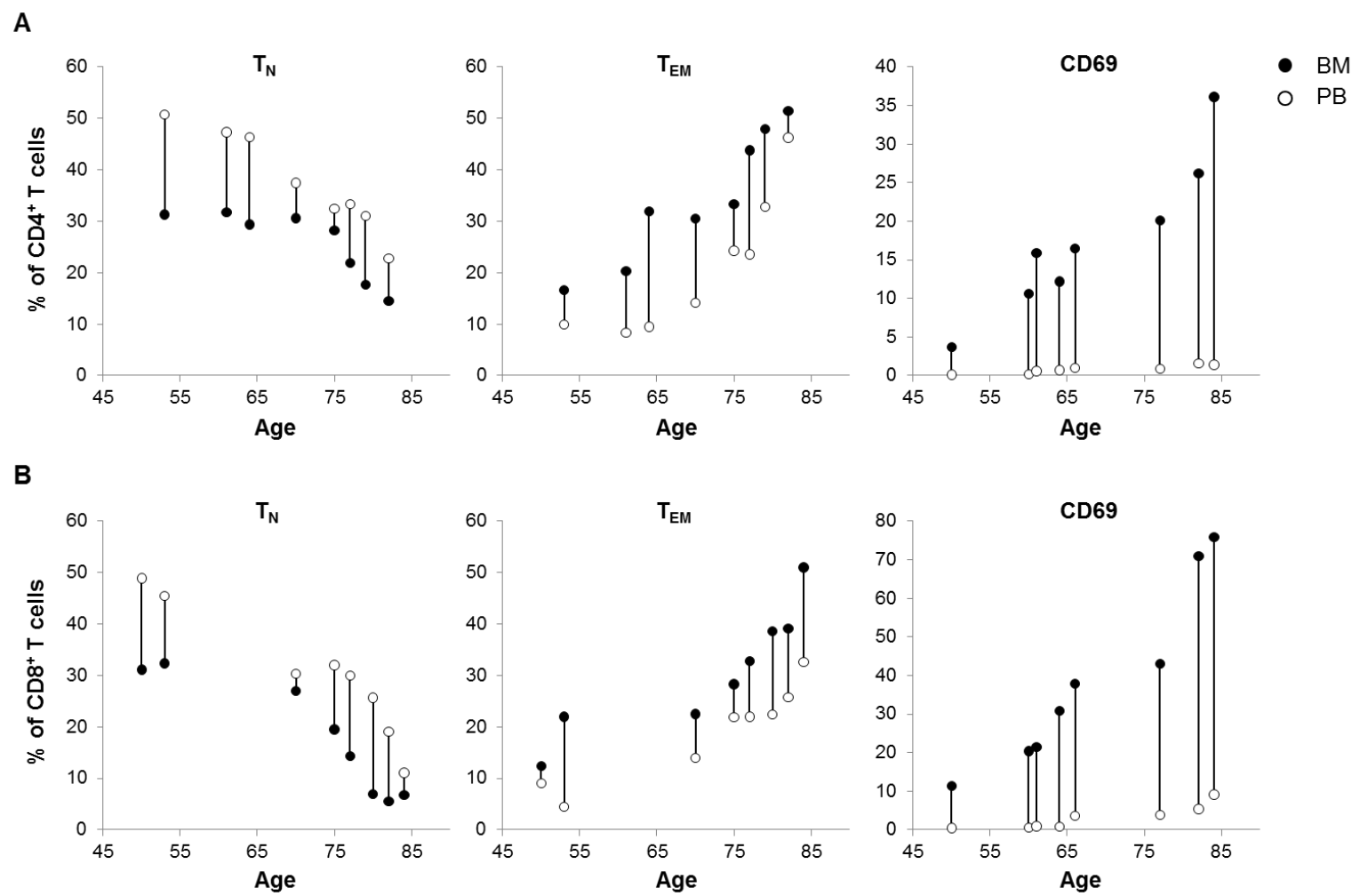

Figure 1. The impact of aging on $\mathrm{CD}^{+}$and $\mathrm{CD} 8^{+} \mathrm{T}$ cells in the $\mathrm{BM} . A, C D 4^{+} \mathrm{T}$ cells: the graphs show the impact of aging on the different subsets. Naïve $\left(T_{N}, C D 45 R A^{+} C C R 7^{+}\right)$, effector memory (TEM, CD45RA-CCR7-) as well as CD69 expressing T cells in BM from the femur (black dots, $n=8$ ) in comparison to autologous blood samples (white dots, $n=8$ ) are shown. $B, C^{2} 8^{+} T$ cells: the graphs show the impact of aging on the different subsets. Naïve $\left(T_{N}, C D 45 R A^{+} C C R 7^{+}\right)$, effector memory (TEM, CD45RA ${ }^{-C C R 7}{ }^{-}$) as well as CD69 expressing T cells in BM from the femur (black dots, $n=8$ ) in comparison to autologous blood samples (white dots, $n=8$ ) are shown. CD4 and CD8 staining were performed on samples from different donors.

$B M M C$ obtained from the femur and iliac crest have a similar cytokine production pattern

Intracellular cytokine staining was performed in order to assess possible differences in cytokine production in BMMC isolated from the femur or the iliac crest. In a first set of experiments the occurrence of polyfunctional $T$ cells was analyzed within the total $\mathrm{CD}^{+}$and $\mathrm{CD}^{+} \mathrm{T}$ cell populations. The occurrence of polyfunctional $T$ cells was similar in cells derived from either the femur or the iliac crest. In accordance with our previous results (Herndler-Brandstetter et al., 2011; Herndler-Brandstetter et al., 2012), the number of cells secreting three cytokines 
was higher in $T$ cells from the BM than from the PB $(p<0.05)$. Data on total CD8 ${ }^{+} T$ cells are depicted in Fig. 2A. Similar results were obtained for $\mathrm{CD} 4^{+} \mathrm{T}$ cells (data not shown). As higher numbers of BMMC were available from the femur than from the iliac crest, a more detailed analysis of cytokine production was possible using femur derived cells. The cytokine production profile of naïve, central memory, effector memory and TEMRA cells isolated from femur derived BM was compared to the cytokine production in corresponding subsets from the PB. Cytokine production by $\mathrm{CD}^{+} \mathrm{T}$ cell subsets is shown in Fig. 2B. Following stimulation, the majority of naïve $T$ cells from both sources produced only one cytokine, mostly IL2 or TNFa. The remaining cells produced either a combination of IL-2 and TNFa or of IFNy and TNFa, while the fraction of triple positive cells was relatively small in both types of naïve samples. In contrast, the percentage of cells producing only one cytokine was significantly lower in antigen experienced cells derived from the $B M$ than in corresponding populations from the PB $(p<0.05)$. In accordance with this, the percentage of double/triple positive cells was higher in antigen experienced cells from the BM than in the corresponding subpopulations from the $\mathrm{PB}(\mathrm{p}<0.05)$. Expectedly, the percentage of IL-2 producing cells decreased with $\mathrm{T}$ cell differentiation, while the percentage of IFNY/TNFa producing cells was highest in the TEMRA subsets and even further increased in the TEMRA population from the $B M$ compared to the PB $(p<0.05)$. Similar results were obtained for $C D 4^{+} T$ cells (data not shown). Our results demonstrate that $T$ cells from the BM are functionally more active than corresponding cells from the PB and that BM derived T cells of a high differentiation stage can produce a variety of different cytokines. 
A

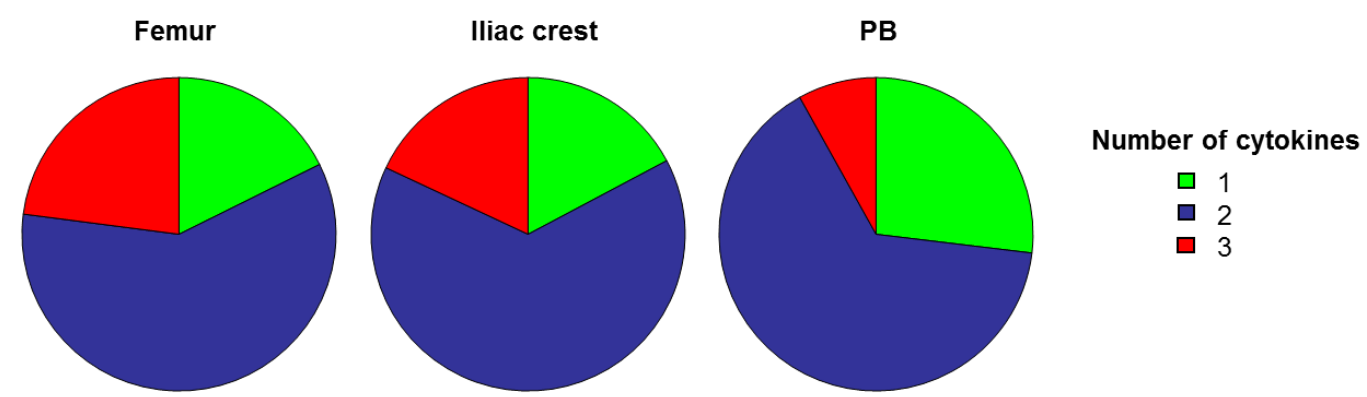

B

BM

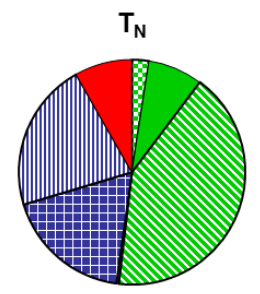

PB

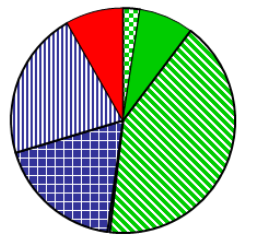

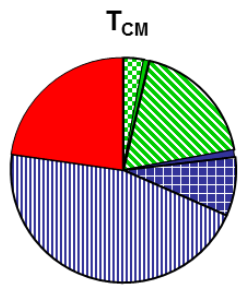

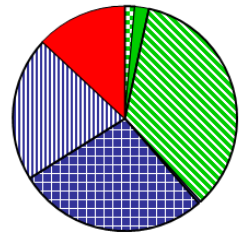

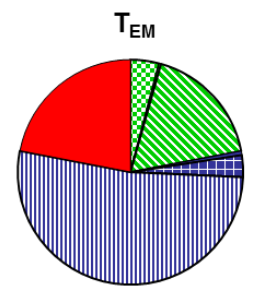

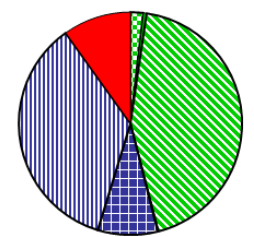

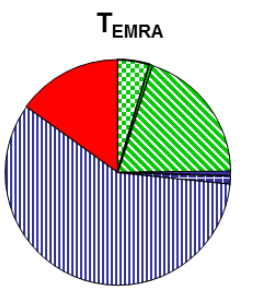

IFNY

$\square$ IL-2

$\nabla$ TNFa

口 IFNy/IL-2

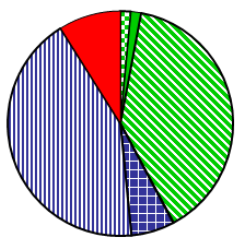

田 IL-2/TNFa

m IFNy/TNFa

$\square$ IFNy/IL-2/TNFa

Figure 2. Cytokine production by $\mathrm{CD}^{+} \mathrm{T}$ cell in the $\mathrm{BM}$ and the PB. BMMC from the femur $(n=14)$ or iliac crest $(n=5)$ and PBMC $(n=19)$ from healthy elderly persons were stimulated with PMA and ionomycin in the presence of brefeldin A for $4 \mathrm{~h}$ and the production of the cytokines IFN- $\gamma$, TNF- $\alpha$ and IL-2 was determined by intracellular FACS analysis. A, CD8 ${ }^{+} \mathrm{T}$ cells producing cytokines after stimulation are depicted and the pie charts show the percentages of $\mathrm{CD} 8^{+} \mathrm{T}$ cells producing one (green), two (blue) or three cytokines (red). B, Cytokine production of CD8 ${ }^{+}$naive $\left(T_{N}\right)$, central memory $\left(T_{C M}\right)$, effector memory $\left(T_{E M}\right)$, and TEMRA was analyzed in femur derived BMMC $(n=12)$ and PBMC $(n=12)$ from the same donors. The pie chart represents percentages of $T$ cells expressing different combinations of cytokines as indicated.

Generation of $T$ cell lines from BM samples by non-specific stimulation

For many functional tests, in particular studies on the interaction of $\mathrm{T}$ cells with other cell types such as stromal cells, the number of ex vivo obtainable T cells is not high enough, even when BM samples from the femur are used. We therefore expanded BM derived $\mathrm{T}$ cells from femur samples from two donors by stimulation with an anti-CD3 antibody and IL-2. After two weeks of culture we were able to increase the number of $T$ cells by approximately 20 -fold. We then analyzed the 
phenotype of the obtained lines in comparison to the original ex vivo populations. In accordance with our previous findings the BM samples contained more CD8 ${ }^{+}$ than $\mathrm{CD}^{+}{ }^{+} \mathrm{T}$ cells, which is in contrast to the situation in peripheral blood (Herndler-Brandstetter et al., 2011; Herndler-Brandstetter et al., 2012). After two weeks in culture the ratio of $\mathrm{CD} 4^{+} / \mathrm{CD} 8^{+} \mathrm{T}$ cells was further decreased. However, the percentage of CD28 $\mathrm{T}$ cells was relatively constant during the cultivation period and corresponded to the population obtained ex vivo (data not shown). Non-specifically expanded T cell lines are therefore a suitable model to study the function of BM derived T cells.

Effect of BM derived stromal cells on bone marrow derived $T$ cell lines

In addition to lymphocytes, stromal cells can be isolated from human BM. These stromal cells contain mesenchymal stem cells, which can be isolated and cultivated in vitro (Fehrer et al., 2007) and have suppressive effects on T cell function (Landgraf et al., 2011). However, the effect of other stromal cell types on $T$ cell function is less well studied and we therefore tested the suitability of BM derived $T$ cell lines for studies on the interaction of $T$ cells and stromal cells. BM derived T cell lines were stimulated with either IL-15 (homeostatic stimulation) or a combination of anti-CD3 antibody and IL-2 (antigenic stimulation) in the absence or presence of autologous stromal cells. The presence of stromal cells had no influence on the $T$ cell phenotype (data not shown). Our results additionally showed that BM stromal cells did not have a suppressive effect on the proliferation of BM derived T cell lines in response to stimulation (Fig. 3). 
A

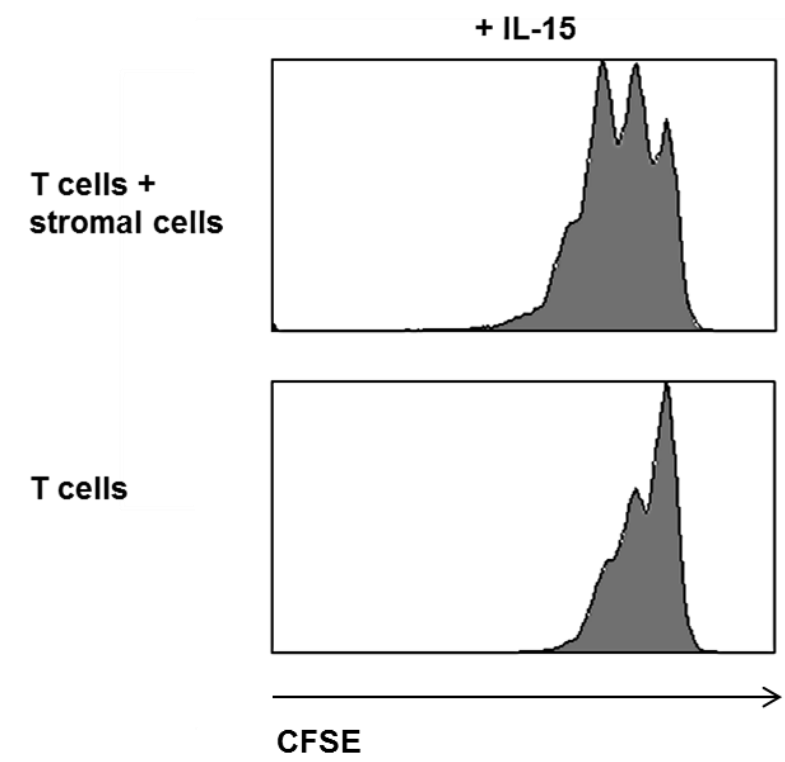

B
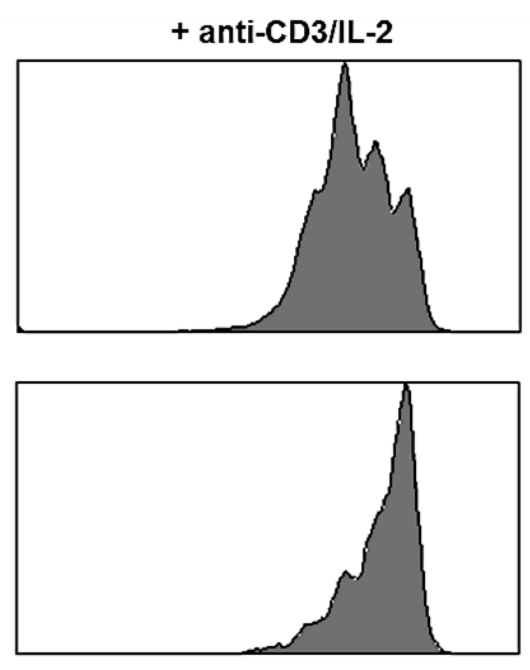

CFSE

Figure 3. Proliferation of $T$ cells in the presence or absence of stromal cells. $T$ cell lines generated from BMMC from the femur as described in Materials and Methods were stimulated with IL-15 $(50 \mathrm{ng} / \mathrm{ml})$ or anti-CD3 $(3 \mathrm{ng} / \mathrm{ml})$ and IL-2 $(20 \mathrm{ng} / \mathrm{ml})$ for four days in the presence or absence of stromal cells. T cells were labeled with CFSE and proliferation was measured on day 5 . One representative example of two independent experiments is shown.

The clonal composition of the $C D 8^{+} T$ cell pool in the BM in comparison to the $P B$ : The example of CMV specific cells

To analyze the clonal composition of BM derived T cells of a certain specificity, we stimulated BMMC as well as PBMC with the peptide CMVNLV for two weeks following a previously published protocol (Schwanninger et al., 2008; Weinberger et al., 2009). It was of interest that the starting population from the BM contained more $\mathrm{CMV}_{\mathrm{NLV}}$ specific cells than the corresponding population from the $\mathrm{PB}$ $(12.5 \% \pm 3.2, n=5$ : $B M$ versus $5.0 \% \pm 3.6 ; n=5$ : $P B ; p<0.01)$. A representative staining is shown in Fig. 4A. BMMC and PBMC from three donors were used for the establishment of antigen specific $T$ cell lines. After 14 days of culture CMV NLV specific $T$ cells were purified using allophycocyanin (APC)-conjugated CMVNLV pentamers, anti-APC-antibodies coupled with magnetic beads and MACS technology. The purity of the $6 \mathrm{~T}$ cell lines was above $95 \%$ after purification (Fig. 4A). RNA was isolated from the T cell lines and cDNA synthesis was performed 
using a reverse transcription system, as described in Materials and Methods. TCR fragments were amplified from cDNA for $24 \mathrm{~V} \beta$ families (BV) and complementarity determining region (CDR3) spectratyping was performed. While some CDNA clones, in particular within the $V \beta 8$ and $V \beta 13$ family, were identical in the $T$ cell lines derived from the BM and the PB (Fig. $4 \mathrm{~B}$, upper panel), other CDNA clones occurred exclusively in the BM or in the PB (Fig. 4B, lower panel). This fact is further underlined by the results depicted in Fig. 4C, in which the spectratyping data of the $6 \mathrm{CMV}_{\mathrm{NLV}}$ specific $\mathrm{T}$ cell lines obtained from three individual donors are summarized. The CMVNLV specific $T$ cell lines generated from donor 1 were both relatively polyclonal, which was most likely due to the fact that this donor was younger than the other two donors from whom we obtained material (donor 2 and 3). There were still $5 \vee \beta$ families $(1,4,5.3,15$ and 16), in which $c D N A$ clones were only found in the BM derived, but not in the peripheral $T$ cell line. On the other hand, $4 \mathrm{~V} \beta$ families $(5.1,11,20$ and 23) only contained $\mathrm{CDNA}$ clones in the peripheral, but not the BM derived $\mathrm{CMV}_{\mathrm{NLV}}$ specific $\mathrm{T}$ cell line. In comparison, the $T$ cell lines generated from donors 2 and 3 had a more restricted diversity and this restriction seemed to be even more pronounced in BM derived CMV NLV specific $T$ cell lines. Thus, $V \beta 20$ positive cDNA clones were only detected in the BM derived $T$ cell line, but not in the peripheral line, $V \beta$ 5.1, 5.3, 7, 9 and 14 cDNA clones were only found in the peripheral T cell line, but not in the BM derived one from donor 2 . The picture was similar in the CMV $\mathrm{NLV}_{\text {s }}$ specific $T$ cell lines derived from donor 3 : Two $V \beta$ families $(5.1,12)$ contained $C M V_{N L V}$ specific cDNA clones in the BM derived line only, while $7 \vee \beta$ families $(1,4,6.1,6.2,7,20,21)$ contained $c D N A$ clones in the peripheral, but not in the BM derived T cell line. 
A

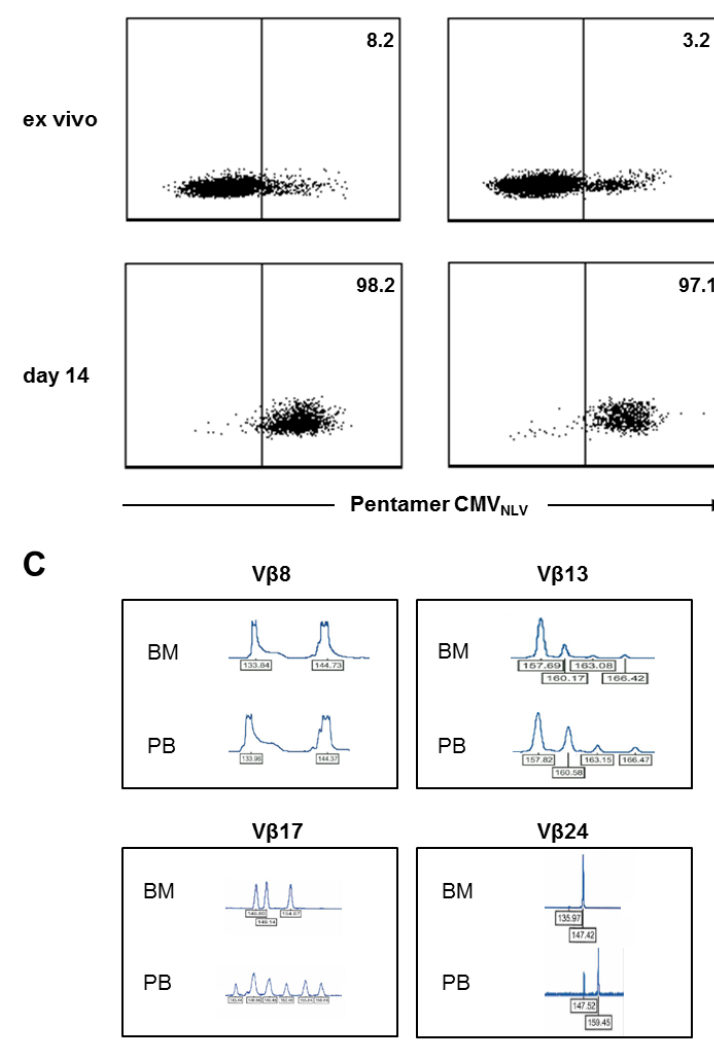

B

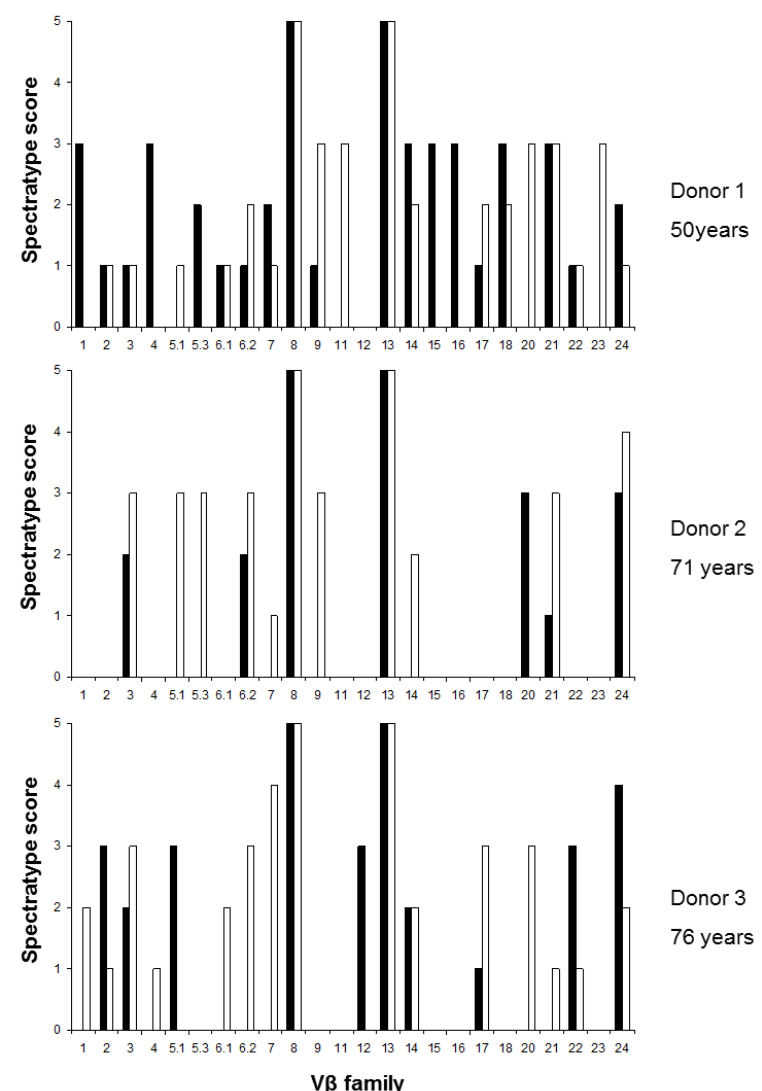

Figure 4. Analysis of $C_{M V} V_{N L V}$ specific $T$ cells ex vivo and after 14 days in culture. PBMC as well as femur derived BMMC from HLA-A2 positive donors were cultivated in the presence of $\mathrm{CMV}_{\mathrm{NLV}}$ peptide $(0.1 \mu \mathrm{g} / \mathrm{m})$ and IL-2 $(20 \mathrm{ng} / \mathrm{ml})$ for two weeks. $A$, T cells were stained with PerCPconjugated anti-CD8 antibody and APC-conjugated pentamers containing the CMVNLV peptide. Gating on $\mathrm{CD}^{+} \mathrm{T}$ cells was performed. A representative example is shown for $\mathrm{CMV}_{\mathrm{NLV}}$ peptide specific $\mathrm{CD}^{+} \mathrm{T}$ cells from the BM (left panel) and PB (right panel) before culture as well as after two weeks of culture with the peptide CMV NLV and IL-2 followed by the purification of the CMV NLV specific population with magnetic beads as described in Materials and Methods. The staining depicts one of three similar experiments. $B$, Spectratyping of the CDR3 region was performed on purified $\mathrm{CMV}_{\mathrm{NLV}}$ specific $T$ cells derived from $\mathrm{BM}$ and $\mathrm{PB}$. Representative results comparing the clonal composition of $\mathrm{CMV}_{\mathrm{NLV}}$ specific $\mathrm{T}$ cells derived from $\mathrm{BM}$ and $\mathrm{PB}$ for selected $\mathrm{V} \beta$ families are shown. The relative size of the CDR3-region fragments is indicated below the peaks. $C$, Clonality and intensity scores were determined for spectratyping results of 24 individual $V \beta$ families for $\mathrm{CMV}_{\mathrm{NLV}}$ specific $\mathrm{T}$ cells derived from BM (black) and PB (white). Results are depicted for three individual donors. The clonality score $(1=$ Gaussian distribution; $2=$ several peaks; $3=$ one peak) and intensity score $(0=<500 \mathrm{RFU}$ [relative fluorescence units]; $1=500-3000 \mathrm{RFU} ; 2=3000-8000$ RFU; $3=>8000$ RFU) were added. 


\section{Discussion}

In the present study we used femur as well as iliac crest to isolate BMMC from the $\mathrm{BM}$ of elderly persons and compared the phenotype and function of $T$ cells within these two preparations. In the past we used iliac crest samples from patients undergoing reconstructive surgery and bone remodeling of the jaw following accidents or for dental implants. These persons are known to be healthy and are not treated with any immunemodulatory drugs. In contrast, femur BM is obtained from patients undergoing hip replacement surgery. They suffer from inflammation of the joint and are frequently treated with anti-inflammatory drugs. Both factors might affect the composition of the T cell pool as well as the activation state of BM derived $T$ cells from the femur shaft region, which could compromise the suitability of this material for functional analyses of $\mathrm{BM}$ derived $\mathrm{T}$ cells. We clearly demonstrate that this is not the case, as the size of the different $T$ cell subsets, their activation state, and their cytokine production profile was not different between samples obtained from the two tissue sources. We can therefore conclude that BM from the femur shaft can be considered as healthy and suitable for physiological studies.

As the yield of BMMC from the femur is significantly larger than from the iliac crest, femur BMMC can be used for more sophisticated experimental approaches leading to more detailed results. In samples from the iliac crest was only possible to define the cytokine production of the total $\mathrm{CD}^{+}$and $\mathrm{CD} 4^{+} \mathrm{T}$ cell populations. However, using femur derived BMMC we were able to analyze the production of several cytokines separately in T cell subsets, namely naïve, central memory, effector memory and TemRA cells. These data were of interest, as T cells of late differentiation stages were more frequently polyfunctional in the BM than in the PB. These data support our concept that CCR7 cells, which are otherwise susceptible to apoptosis-inducing stimuli and destined to perish (Brunner et al., 2012), may not only survive, but also function in the $I L-15$ rich $B M$ microenvironment in old age (Herndler-Brandstetter et al., 2011; HerndlerBrandstetter et al., 2012). Whether these highly differentiated T cells in the BM of elderly people represent a useful line of defense in the absence of fully functioning naïve T cells (Johnson et al.; Li et al., 2012) or take up space otherwise reserved for $\mathrm{CD}^{+}{ }^{+} \mathrm{T}$ cells of an earlier differentiation stage or for long-lived plasma cells 
(Tokoyoda et al., 2010; Tokoyoda et al., 2009b) is not yet known. Further studies will be needed to clarify this open question.

One possible approach to address these issues is the in vitro modeling of the in vivo situation by co-culturing BM derived T cells and BM derived stromal cells. As in humans both cell types are not available in sufficiently high numbers for functional analysis in ex vivo samples, even in the relatively large BM samples from the femur, the generation of cell lines is a prerequisite to allow conclusive experimental setups. Our results show that $T$ cell lines generated from BMMC by non-specific stimulation maintain the characteristic phenotype of the original population. They also demonstrate that proliferation of the lines in response to stimulation with both, anti-CD3 antibody or IL-15, is not negatively affected by the presence of stromal cells. This may be surprising, as there are multiple reports in the literature that $B M$ derived mesenchymal stem cells have immunsuppressive effects on T cells (Abumaree et al., 2011). Because of their immunomodulatory properties mesenchymal stromal cells are already being used in clinical trials for preventing graft vs. host disease and other disorders going along with increased immune responsiveness (Le Blanc et al., 2004; Tolar et al., 2011). In view of our results it seems likely that only stromal cells of early differentiation stages, which may still be multipotent, are capable of immunosuppressive effects. Our in vitro model system will represent a useful tool to analyze how stromal cells of different phenotypes - from early differentiation stages to senescence - affect the function of different $T$ cell subsets.

In this context it will also be important to analyze how stromal cells affect $\mathrm{T}$ cell responses to different antigens. Our data clearly indicate that the clonal composition of a $\mathrm{CMV}_{\text {NLV }}$ specific $\mathrm{T}$ cell population is different in the $\mathrm{BM}$ and in the periphery. With the exception of $\mathrm{V} \beta 8^{+}$and $\mathrm{V} \beta 13^{+} \mathrm{T}$ cells, which are known to dominate CMV $\mathrm{NLV}_{\text {LV }}$ specific responses (Peggs et al., 2002; Schwanninger et al., 2008), a relatively large number of clones is found in the BM, but not in the PB and vice versa. Our data also suggest that the $\mathrm{CMV}_{\text {NLV }}$ specific $\mathrm{T}$ cell repertoire in the $\mathrm{BM}$ is more restricted than in the periphery. It will be a challenge to identify BM specific clones, isolate them and analyze their avidity and function. A similar approach using peripheral $T$ cells has in the past been successfully used by our group and others (Letsch et al., 2007; Saurwein-Teissl et al., 2002). As CMV is believed to accelerate the aging of the immune system (Almanzar et al., 2005; 
Pawelec et al., 2010; Pawelec et al., 2004), it will be of special interest to define the exact role of CMV specific clones which reside in the BM in the infection / reactivation process.

\section{Conclusion}

In conclusion, our results demonstrate that the BMMC population derived from the femur shaft provides a useful tool for a variety of immunological studies addressing questions of major importance. New insights thus obtained will improve our understanding of age-related changes of immune function in old age.

\section{Materials and Methods}

Sample collection and preparation

Paired blood and BM samples were obtained from systemically healthy elderly persons. Individuals who suffered from diseases known to influence the immune system, including autoimmune diseases and cancer, were excluded from the study. Femur derived BM and autologous blood samples were obtained from a total of 32 donors (19 females, 13 males, mean age \pm SEM: 68.6 \pm 2.1 years). CMV specific antibodies were measured in serum. 24 donors were sero-positive and 8 donors were sero-negative for CMV. Iliac crest material and blood were obtained from a total of 30 donors (22 females, 8 males, mean age $\pm S E M$ : $66 \pm 3.1$ years). The CMV serostatus was only known from seven patients, 4 donors were CMV sero-positive and 3 donors were CMV sero-negative. Informed written consent was obtained and the study was approved by the Ethics Committee of Innsbruck Medical University. Bone from the femur shaft was harvested at the Department of Orthopedic Surgery at Innsbruck Medical University from patients undergoing hip replacement surgery. A biopsy of substantia spongiosa ossium, which would otherwise have been discarded, was used to isolate BMMC. BMMC samples from the iliac crest of elderly persons were obtained as previously described (HerndlerBrandstetter et al., 2011; Herndler-Brandstetter et al., 2012). In brief, bone from the iliac crest was harvested at the Department of Cranio-Maxillofacial and Oral 
Surgery at Innsbruck Medical University for bone molding/recontouring prior to insertion into other areas of the body, in particular facial regions. A biopsy of substantia spongiosa ossium, which would otherwise have been discarded, was used to isolate BMMC. Results on some of the iliac crest derived samples used in this study have been described in a different context (Herndler-Brandstetter et al., 2011; Herndler-Brandstetter et al., 2012). Both types of bone biopsies were washed once with complete RPMI 1640 (Lonza) supplemented with 10\% FCS (Sigma Aldrich), 1\% Penicillin/Streptomycin (PAA). Bone biopsies were then fragmented and treated with sterile-filtered, chromatographically purified collagenase (CLSPA; Worthington; $20 \mathrm{U} / \mathrm{ml}$ in complete RPMI) for $2 \mathrm{~h}$ at $37^{\circ} \mathrm{C}$, $20 \% \mathrm{O}_{2}$ and $5 \% \mathrm{CO}_{2}$. Cells were centrifuged, and $\mathrm{BMMC}$ were purified by densitygradient centrifugation (Ficoll-Hypaque). Preparation of PBMC was also performed by density-gradient centrifugation.

Flow cytometric analysis

Immunofluorescence surface staining was performed by adding a panel of directly conjugated $\mathrm{mAb}$ to freshly prepared PBMC, BMMC or $\mathrm{T}$ cell lines, respectively. The Abs used were: CD3 (PE-Cy7 and APC-Cy7), CD4 (FITC, PerCP and PECy7), CD28 (APC), CD45RA (PE, PerCP and APC) CD69 (FITC and PE) (all BD Pharmingen), CD8 (PerCP; Biolegend) and CCR7 (FITC; R\&D Systems). Cells were incubated with the antibodies for $30 \mathrm{~min}$ at $4{ }^{\circ} \mathrm{C}$. The labeled cells were measured by a FACSCanto II Instrument (BD Biosciences), and the data were analyzed using FACSDiva software (BD Biosciences).

\section{Intracellular cytokine staining}

The production of cytokines by $\mathrm{T}$ cells from the BM and PB was assessed by stimulating the cells for $4 \mathrm{~h}$ with $30 \mathrm{ng} / \mathrm{ml}$ PMA and $500 \mathrm{ng} / \mathrm{ml}$ ionomycin in the presence of $10 \mu \mathrm{g} / \mathrm{ml}$ brefeldin A (all Sigma-Aldrich). Cells were permeabilized using the Cytofix/Cytoperm kit (BD Pharmingen) and intracellular staining of IFN- $y$ (FITC), TNF- $\alpha$ (PE) and IL-2 (PE-Cy7) (all BD Pharmingen) was performed 
following manufacturer's instructions. In intracellular cytokine staining experiments naïve cells were defined as $\mathrm{CD}^{2} 5 \mathrm{RA}^{+} \mathrm{CD}^{+} 8^{+}$, central memory cells as CD45RA' $\mathrm{CD}^{-} 8^{+}$, effector memory cells as CD45RA- CD28- and TEMRA as CD45RA+ CD28-

\section{Pentamer Staining}

For the detection of CMV pp65 NLVPMVATV (CMVNLV) peptide specific CD8 ${ }^{+} \mathrm{T}$ cells in HLA-A2 positive, CMV positive persons, the cells were stained with $\mathrm{CMV}_{\text {NLV }}$ Pro5 ${ }^{\circledR}$ MHC Pentamer (Proimmune) and incubated for $10 \mathrm{~min}$ at RT in the dark before staining for other surface markers was performed.

\section{Cell culture}

Cell culture experiments were performed with RPMI 1640 (Lonza) supplemented with 10\% FCS (Sigma-Aldrich) and 1\% Penicillin/Streptomycin (PAA).

For non-specific expansion, femur derived BMMC and PBMC from two HLA-A2 positive donors were stimulated with anti-CD3 $(3 \mathrm{ng} / \mathrm{ml})$ (BD Pharmingen) and IL-2 $(20 \mathrm{ng} / \mathrm{ml})$ (Novartis) for 2 weeks. During this time they were restimulted once a week with anti-CD3 antibody and every third day with IL-2.

To generate $\mathrm{CMV}_{\mathrm{NLV}}$ peptide-specific $\mathrm{CD}^{+} \mathrm{T}$ cell populations, femur derived BMMC and PBMC from three HLA-A2 positive CMV positive elderly donors were incubated with $0.1 \mu \mathrm{g} / \mathrm{ml}$ pp65 CMV NLV peptide (NLVPMVATV; Bachem) for two weeks. During this time they were restimulated with IL-2 $(20 \mathrm{ng} / \mathrm{ml})$ (Novartis) every three days and with peptide once on day 7 . After 14 days $\mathrm{CMV}_{\text {NLV }}$ specific $\mathrm{CD}^{+} \mathrm{T}$ cells were purified using MACS technology, as previously described (Weinberger et al., 2009). Briefly, CMV specific $C D 8^{+} T$ cells were positively selected using

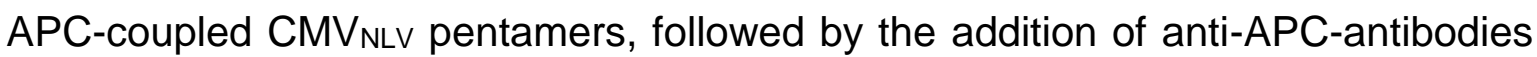
coupled with magnetic beads (all (BD Pharmingen) and a LS column (Miltenyi Biotec). The purity of the $\mathrm{CMV}_{\mathrm{NLV}}$ specific $\mathrm{CD}^{+} \mathrm{T}$ cell lines was $>95 \%$ after purification. 
TCR V $\beta$ CDR3 spectratyping analysis

TCR V $\beta$ transcripts of CMVNLV specific T cells from the femur derived BM and PB were amplified by PCR using HotStarTaq Master Mix Kit (Qiagen), primers (MWG Biotech) specific for each of the 24 human $V \beta$ families and a specific primer for the $C$ region of the $\beta$-chain (labeled with the fluorescent dye marker 6-FAM) as previously described (Herndler-Brandstetter et al., 2005; Peggs et al., 2002). An aliquot of the PCR product was diluted in $20 \mu \mathrm{l}$ deionized formamide and $1.2 \mathrm{fmol}$ internal lane standard GeneScan-350 Tamra (PerkinElmer). The samples were denatured at $90^{\circ} \mathrm{C}$ for $2 \mathrm{~min}$ and loaded on a CE 3100 Genetic Analyzer (PerkinElmer). Each sample was injected for $5 \mathrm{~s}$ at $15 \mathrm{kV}$ and electrophoresed for $24 \mathrm{~min}$ at $10 \mathrm{kV}$ using a $36-\mathrm{cm}$ capillary and POP46 (PerkinElmer). Analysis of the raw data was performed applying the GeneScan 3.7 analysis software package (Applies Biosyststems) using the Local Southern method for fragment size estimation. For each $V \beta$ family the occurrence of dominant clonal expansions was quantified by assigning scores for clonality and intensity as previously described (Schwanninger et al., 2008). The clonality score ( $1=$ Gaussian distributed; $2=$ several peaks; $3=$ one peak) and intensity score $(0=<500$ RFU [relative fluorescence units]; $1=500-3000 \mathrm{RFU} ; 2=3000-8000 \mathrm{RFU} ; 3=>8000 \mathrm{RFU}$ ) were added.

\section{Stromal cell culture}

Following density gradient centrifugation the BMMC samples were incubated overnight at $37^{\circ} \mathrm{C}, 5 \% \mathrm{CO}_{2}$. After this time stromal cells had adhered to plastic, the non-adherent $\mathrm{T}$ cell enriched population was removed and was used for analysis or further culture. The adherent cells were further incubated in RPMI 1640 (Lonza) supplemented with 10\% FCS (Sigma-Aldrich) and 1\% Penicillin/Streptomycin (PAA) for one to two weeks and then removed from the plastic by trypsin/EDTA (Sigma). They were a heterogeneous population consisting of morphologically defined classical stromal cells, monocytes, dendritic cells and fibroblasts. 
To measure proliferation of T cells were stained with CFSE (Carboxyfluorescein succinimidyl ester). Briefly, cells were washed with PBS and stained with CFSE (Molecular Probes) for $10 \mathrm{~min}$ at $37^{\circ} \mathrm{C}$. T cells were washed twice with RPMI 1640 (Lonza) supplemented with $10 \%$ FCS (Sigma-Aldrich) and $1 \%$ Penicillin/Streptomycin (PAA). Proliferation was measured after 5 days using a FACSCanto II Instrument (BD Biosciences), and the data were analyzed using FACSDiva software (BD Biosciences).

\section{Statistical analysis}

Differences between samples and groups were evaluated using paired or unpaired $\mathrm{t}$ tests, respectively. $p$ values $<0.05$ were considered as statistically significant.

\section{Competing interests}

None of the authors has competing interests.

\section{Authors' contributions}

TP, BW and KLR performed experiments and analyzed the data. RR, JL, RG and MK provided bone marrow samples. DHB provided the iliac crest-derived samples as well as some of his staining results. DHB and BGL designed the study protocol. TP, BW and BGL wrote the manuscript.

\section{Acknowledgement}

We thank Brigitte Jenewein, Michael Keller and Daniela Niederwieser for excellent technical assistance. 


\section{References to manuscript I}

Abrahamsen, J.F., Lund-Johansen, F., Laerum, O.D., Schem, B.C., Sletvold, O., Smaaland, R., 1995. Flow cytometric assessment of peripheral blood contamination and proliferative activity of human bone marrow cell populations. Cytometry 19:77-85.

Abumaree, M., Al Jumah, M.,. Pace, R.A, Kalionis, B., 2011. Immunosuppressive properties of mesenchymal stem cells. Stem Cell Rev 8:375-392.

Almanzar, G., Schwaiger, S., Jenewein, B., Keller, M., Herndler-Brandstetter, D., Wurzner, R., Schonitzer, D., Grubeck-Loebenstein, B., 2005. Long-term cytomegalovirus infection leads to significant changes in the composition of the CD8+ T-cell repertoire, which may be the basis for an imbalance in the cytokine production profile in elderly persons. J Virol 79:3675-3683.

Brunner, S., Herndler-Brandstetter, D., Arnold, C.R., Wiegers, G.J., Villunger, A., Hackl, M., Grillari, J., Moreno-Villanueva, M., Burkle, A., GrubeckLoebenstein, B., 2012. Upregulation of miR-24 is associated with a decreased DNA damage response upon etoposide treatment in highly differentiated CD8(+) T cells sensitizing them to apoptotic cell death. Aging Cell 11:579-587.

Di Rosa, F., Pabst, R., 2005. The bone marrow: a nest for migratory memory $T$ cells. Trends Immunol 26:360-366.

Fehrer, C., Brunauer, R., Laschober, G., Unterluggauer, H., Reitinger, S., Kloss, F., Gully, C., Gassner, R., Lepperdinger, G., 2007. Reduced oxygen tension attenuates differentiation capacity of human mesenchymal stem cells and prolongs their lifespan. Aging Cell 6:745-757.

Geiger, H., de Haan, G., Florian, M.C., 2013. The ageing haematopoietic stem cell compartment. Nature reviews. Immunology 13:376-389.

Herndler-Brandstetter, D., Landgraf, K., Jenewein, B., Tzankov, A., Brunauer, R., Brunner, S., Parson, W., Kloss, F.,. Gassner, R, Lepperdinger, G., GrubeckLoebenstein, B., 2011. Human bone marrow hosts polyfunctional memory CD4+ and CD8+ T cells with close contact to IL-15-producing cells. $J$ Immunol 186:6965-6971. 
Herndler-Brandstetter, D., Landgraf, K., Tzankov, A., Jenewein, B., Brunauer, R., Laschober, G.T., Parson, W., Kloss, F., Gassner, R.,. Lepperdinger, G, Grubeck-Loebenstein, B., 2012. The impact of aging on memory $\mathrm{T}$ cell phenotype and function in the human bone marrow. J Leukoc Biol 91:197205.

Herndler-Brandstetter, D., Schwaiger, S., Veel, E., Fehrer, C., Cioca, D.P., Almanzar, G., Keller, M., Pfister, G., Parson, W., Wurzner, R., Schonitzer, D., Henson, S.M., Aspinall, R., Lepperdinger, G., Grubeck-Loebenstein, B., 2005. CD25-expressing CD8+ T cells are potent memory cells in old age. $J$ Immunol 175:1566-1574.

Johnson, P.L., Yates, A.J., Goronzy, J.J., Antia, R., Peripheral selection rather than thymic involution explains sudden contraction in naive CD4 T-cell diversity with age. Proc Natl Acad Sci U S A

Landgraf, K., Brunauer, R., Lepperdinger, G., Grubeck-Loebenstein, B., 2011. The suppressive effect of mesenchymal stromal cells on $\mathrm{T}$ cell proliferation is conserved in old age. Transpl Immunol 25:167-172.

Le Blanc, K., Rasmusson, I., Sundberg, B., Gotherstrom, C., Hassan, M., Uzunel, M., Ringden, O., 2004. Treatment of severe acute graft-versus-host disease with third party haploidentical mesenchymal stem cells. Lancet 363:14391441.

Letsch, A., Knoedler, M., Na, I.K., Kern, F., Asemissen, A.M., Keilholz, U., Loesch, M., Thiel, E., Volk, H.D., Scheibenbogen, C., 2007. CMV-specific central memory T cells reside in bone marrow. Eur J Immunol 37:3063-3068.

Li, G., Yu, M., Lee, W.W., Tsang, M., Krishnan, E., Weyand, C.M., Goronzy, J.J., 2012. Decline in miR-181a expression with age impairs $T$ cell receptor sensitivity by increasing DUSP6 activity. Nat Med 18:1518-1524.

Pawelec, G., Akbar, A., Beverley, P., Caruso, C., Derhovanessian, E., Fulop, T., Griffiths, P., Grubeck-Loebenstein, B., Hamprecht, K., Jahn, G., Kern, F., Koch, S.D., Larbi, A., Maier, A.B., Macallan, D., Moss, P., Samson, S., Strindhall, J., Trannoy, E., Wills, M., 2010. Immunosenescence and Cytomegalovirus: where do we stand after a decade? Immun Ageing 7:13. 
Pawelec, G., Akbar, A., Caruso, C., Effros, R., Grubeck-Loebenstein, B., Wikby, A., 2004. Is immunosenescence infectious? Trends Immunol 25:406-410.

Peggs, K., Verfuerth, S., Pizzey, A., Ainsworth, J., Moss, P., Mackinnon, S., 2002. Characterization of human cytomegalovirus peptide-specific CD8(+) T-cell repertoire diversity following in vitro restimulation by antigen-pulsed dendritic cells. Blood 99:213-223.

Saurwein-Teissl, M., Lung, T.L., Marx, F., Gschosser, C., Asch, E., Blasko, I., Parson, W., Bock, G., Schonitzer, D., Trannoy, E., Grubeck-Loebenstein, B., 2002. Lack of antibody production following immunization in old age: association with CD8(+)CD28(-) T cell clonal expansions and an imbalance in the production of Th1 and Th2 cytokines. J Immunol 168:5893-5899.

Schwanninger, A., Weinberger, B., Weiskopf, D., Herndler-Brandstetter, D., Reitinger, S., Gassner, C., Schennach, H., Parson, W., Wurzner, R., Grubeck-Loebenstein, B., 2008. Age-related appearance of a CMV-specific high-avidity CD8+ $\mathrm{T}$ cell clonotype which does not occur in young adults. Immun Ageing 5:14.

Shen, Y., Wang, W., Li, X., Liu, Z., Markel, D.C., Ren, W., 2012. Impacts of age and gender on bone marrow profiles of BMP7, BMPRs and Stro-1(+) cells in patients with total hip replacement. Int Orthop 36:879-886.

Tokoyoda, K., Hauser, A.E., Nakayama, T., Radbruch, A., 2010. Organization of immunological memory by bone marrow stroma. Nat Rev Immunol 10:193200.

Tokoyoda, K., Zehentmeier, S., Chang, H.D., Radbruch, A., 2009a. Organization and maintenance of immunological memory by stroma niches. Eur $J$ Immunol 39:2095-2099.

Tokoyoda, K., Zehentmeier, S., Hegazy, A.N., Albrecht, I., Grun, J.R., Lohning, M., Radbruch, A., 2009b. Professional memory CD4+ T lymphocytes preferentially reside and rest in the bone marrow. Immunity 30:721-730.

Tolar, J., Villeneuve, P., Keating, A., 2011. Mesenchymal stromal cells for graftversus-host disease. Hum Gene Ther 22:257-262. 
Weinberger, B., Welzl, K., Herndler-Brandstetter, D., Parson, W., GrubeckLoebenstein, B., 2009. CD28(-)CD8(+) T cells do not contain unique clonotypes and are therefore dispensable. Immunol Lett 127:27-32. 


\section{Introduction to manuscript II}

While the first paper of the thesis addresses the question if femur-shaft derived BM samples are a useful tool for a variety of immunological studies with the main focus on $T$ cells, the second part investigates the impact of aging on the frequency, phenotype and antigen-specificity of BM and PB derived $B$ cells.

Over the last decades it has also become clear from mice studies that long-lived plasma cells are maintained in the BM (McHeyzer-Williams and Ahmed, 1999; Radbruch et al., 2006). Interaction of the chemokine receptor CXCR4 and its ligand CXCL12 allows plasmablasts to home to the BM and differentiate into plasma cells (Chu and Berek, 2013). Plasma cells are in close contact with CXCL12+IL7-VCAM1+ stromal cells and survive in distinct survival niches in the BM for a long period of time (Tokoyoda et al., 2009a; Zehentmeier et al., 2014). Furthermore, it has been demonstrated that inflammation suppresses CXCL12 expression and, as a consequence the homing of plasmablasts to the BM (Ueda et al., 2004). Therefore, a low-grade inflammatory background induced by proinflammatory cytokines (Franceschi et al., 2000) could be associated with a decline of CXCL12 expression as well as plasma cell numbers in old age.

So far less is known about these processes in humans. Therefore, the second paper aimed to study $B$ cell subpopulations from the BM and PB, potential agerelated changes as well as antigen-specificity of BM plasma cells and PB memory B cells. 


\section{Manuscript II}

The impact of aging on plasma cells and memory B cells in the human bone marrow

Theresa Pritz ${ }^{1}$, Julian Lair², Michael Ban², Michael Keller ${ }^{1}$, Birgit Weinberger ${ }^{1}$, Martin Krismer ${ }^{2}$, Beatrix Grubeck-Loebenstein ${ }^{1 \S}$

1 Institute for Biomedical Aging Research, Universität Innsbruck, Rennweg 10, Innsbruck, Austria

2 Department of Orthopedic Surgery, Innsbruck Medical University, Anichstrasse 35, Innsbruck, Austria

$\S$ Corresponding author

Revised version submitted to the European Journal of Immunology 


\section{List of abbreviations}

BM bone marrow

PB peripheral blood

BMMC bone marrow mononuclear cells

PBMC peripheral blood mononuclear cells

CMV Cytomegalovirus

SFC spot forming cells

PE phycoerythrin 


\section{Abstract}

The bone marrow (BM) is well understood to play a key role in plasma cell homing and survival in mice. In humans, BM plasma cells and their functions are less well characterized. In the present study, we used paired bone biopsies from the femur shaft and blood samples from persons of different age to analyze age-related changes of plasma and memory $B$ cells. Our results demonstrated that plasma cells were mainly located in the BM, while a higher percentage of memory $B$ cells was in the peripheral blood (PB). The frequency of plasma and memory $B$ cells from both sources decreased with age, while immature and naïve $B$ cells were unaffected. An age-related decline of tetanus- and diphtheria-specific BM plasma cells was observed, whereas influenza A- and Cytomegalovirus (CMV)-specific BM plasma cells were not affected. With the exception of CMV, peripheral antibody concentrations correlated with BM plasma cells of the same specificity, but were independent of antigen-specific PB memory B cells.

Our results demonstrate that the BM houses decreased numbers of plasma cells in old age. The number of cells of a certain specificity may reflect the number and time point of previous antigen encounters as well as intrinsic age-related changes in the BM.

Key words: bone marrow, plasma cells, memory B cells, aging 


\section{Introduction}

Immunologic memory is a hallmark of the adaptive immune system. Previous studies indicate that the bone marrow $(B M)$ is a secondary lymphoid organ and a major reservoir of memory $\mathrm{CD} 4^{+}$and $\mathrm{CD} 8^{+} \mathrm{T}$ cells (Pritz et al., 2014). In mice it has been demonstrated that memory $\mathrm{CD}^{+}{ }^{+} \mathrm{T}$ cells migrate to the $\mathrm{BM}$ utilizing CD69 and CD49b, an alpha 2 integrin, and are in close contact with CXCL12-IL$7^{+} \mathrm{VCAM} 1^{+}$stromal cells that support their maintenance in the BM (Hanazawa et al., 2013b; Tokoyoda and Radbruch, 2012).

Memory $\mathrm{T}$ cells from the BM are resting in terms of proliferation, transcription, mobility and maintain antigen-specific memory over long periods of time. The repertoire of $\mathrm{CD} 4^{+} \mathrm{BM} T$ cells compared with the peripheral blood (PB) is enriched for memory $\mathrm{CD}^{+}{ }^{+} \mathrm{T}$ cells and provides long-term memory for systemic pathogens (Okhrimenko et al., 2014).

Most BM T cell studies were performed in mice and less is known in humans as well as about potential alterations in old age. Recently, our group contributed to this topic and showed that during aging total $\mathrm{CD} 4^{+}$and $\mathrm{CD} 8^{+} \mathrm{T}$ cells in the $\mathrm{BM}$ are not affected, but that the size of $\mathrm{CD} 4^{+}$and $\mathrm{CD} 8^{+} \mathrm{T}$ cell subsets in the $\mathrm{BM}$ changes (Herndler-Brandstetter et al., 2012). Similar to the situation in the PB (Arnold et al., 2011), naïve $C D 4^{+}$and $C D 8^{+} T$ cells decrease and an age-dependent increase of polyfunctional effector memory $T$ cells occurs in the BM.

Over the last decades it has also become clear that long-lived plasma cells are maintained in the murine BM (Radbruch et al., 2006). High affinity memory B and plasma cells are generated in the germinal centers of secondary lymphoid organs in response to antigenic stimulation. While memory B cells are mainly located in the spleen, plasmablasts migrate via the blood stream to the BM. Interaction of the chemokine receptor CXCR4 and its ligand CXCL12 allows plasmablasts to home to the BM and differentiate into plasma cells. Plasma cells are in close contact with CXCL12+IL7-VCAM1+ stromal cells and survive in distinct niches in the BM for a long period of time without DNA synthesis and cell division, but are highly activated in terms of protein synthesis as they constitutively produce antibodies. They obtain survival factors for their long-term maintenance from CXCL12expressing stromal cells, a proliferation-inducing ligand (APRIL)- and IL-6 expressing megakaryozytes as well as BM-derived eosinophils (Chu and Berek, 
2013; Tokoyoda et al., 2009a). Little information is available about plasma cells in the human BM, their response against specific pathogens as well as age-related changes. To increase our knowledge on human plasma cells, memory B cells and their function in old age, we collected bone biopsies from the femur shaft and PB of healthy persons of different age and analyzed the impact of aging on the frequency and function of BM plasma cells and PB memory B cells.

\section{Results}

The impact of aging on the frequency of plasma cells and memory $B$ cells in the human $B M$ and $P B$

We first analyzed $B$ cell subsets from human bone marrow mononuclear cells (BMMC) and peripheral blood mononuclear cells (PBMC). We used the surface molecules CD19, CD27 and CD38 to characterize B cell subsets: Within the $\mathrm{CD}^{-} 9^{+}$gate we defined $\mathrm{CD} 27^{-} \mathrm{CD} 38^{+}$immature and CD27-CD38- naïve $\mathrm{B}$ cells, as well as $\mathrm{CD} 27^{+} \mathrm{CD} 38^{-}$memory $\mathrm{B}$ cells and $\mathrm{CD} 27^{+} \mathrm{CD} 38^{+}$plasma cells in the $\mathrm{BM}$ and $\mathrm{PB}$ by flow cytometric analysis (Fig. $1 A, B$ ). The percentage of $\mathrm{CD} 27^{+} \mathrm{CD} 38^{+}$ plasma cells was increased in the $\mathrm{BM}$ compartment in comparison to the $\mathrm{PB}$, whereas $C D 27^{+} \mathrm{CD} 38^{-}$memory $\mathrm{B}$ cells were mainly located in the $\mathrm{PB}$. However, only a small proportion of plasma cells was observed in the PB as well as a low percentage of memory $\mathrm{B}$ cells in the $\mathrm{BM}$. While the percentage of $\mathrm{CD} 27^{-} \mathrm{CD} 38^{+}$ immature $B$ cells was higher in the $B M, C D 27^{-} C D 38^{-}$naïve $B$ cells were more frequent in the PB. 
A
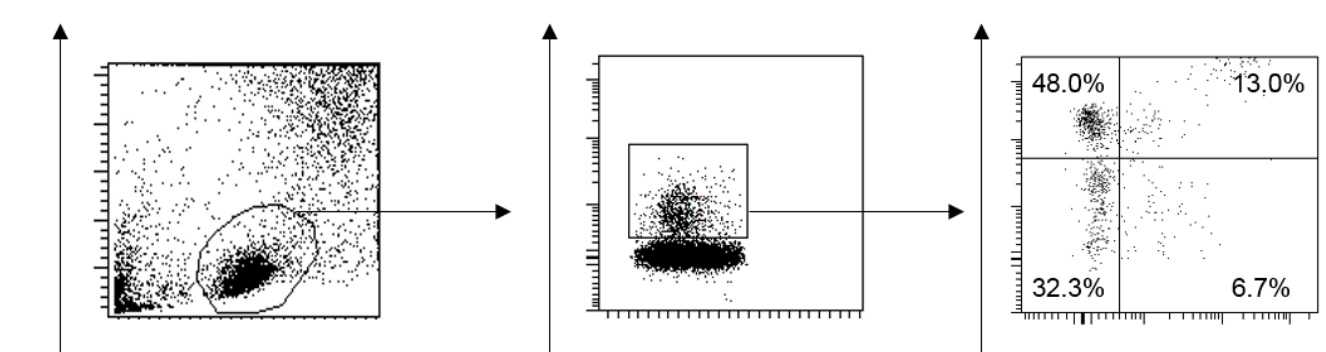

BM
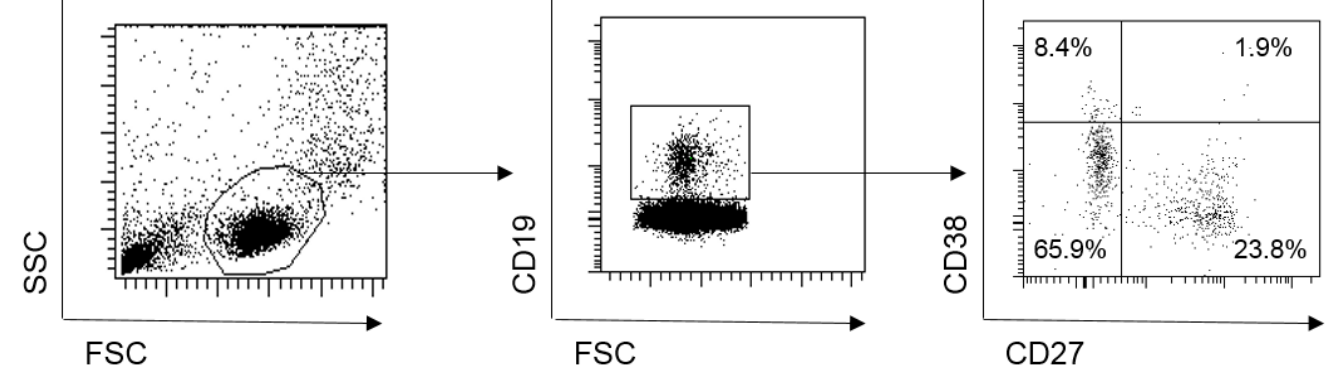

PB

B

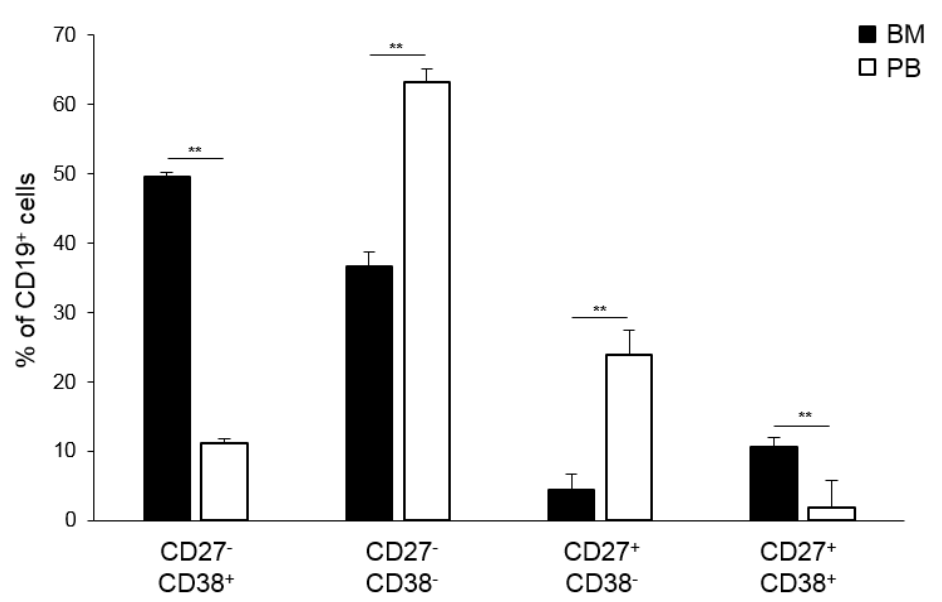

Figure 1. B cell subsets in the bone marrow and peripheral blood. $A$, The dot plots show the gating strategy by FACS analysis in the bone marrow (BM) and peripheral blood (PB). From the

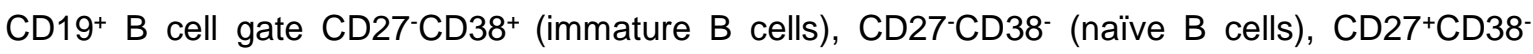
(memory $B$ cells) and $\mathrm{CD} 27^{+} \mathrm{CD} 38^{+}$(plasma cells) in paired BM and PB samples are shown. One representative experiment (59 year old donor) is shown. $B$, The bar graph shows the statistical analysis of the percentages of CD27+CD38- immature, CD27-CD38- naïve, CD27+CD38- memory $B$ cells and of $\mathrm{CD} 27^{+} \mathrm{CD} 38^{+}$plasma cells in paired BM (black) and $\mathrm{PB}$ (white) samples within the CD19 gate. CD19+ cells are considered as $100 \%$. Data are presented as mean values \pm SEM $(\mathrm{n}=8)$. Statistical analysis was performed using paired $t$ test; ${ }^{* *} p \leq 0.01$.

To investigate whether age affects the frequency of plasma and memory $B$ cells in the $\mathrm{BM}$ and $\mathrm{PB}$, we performed flow cytometric analysis of paired BMMC and PBMC samples of persons aged $\leq$ and $>65$ years, respectively. The relative proportions of plasma and memory B cells within the CD19+ population were 
significantly decreased in the BMMC in the older age group, whereas the percentages of immature and naïve B cells were similar in both age groups (Fig. $2 A, C$ ). Similar results to BMMC were observed for PBMC (Fig. $2 B, D$ ).

A

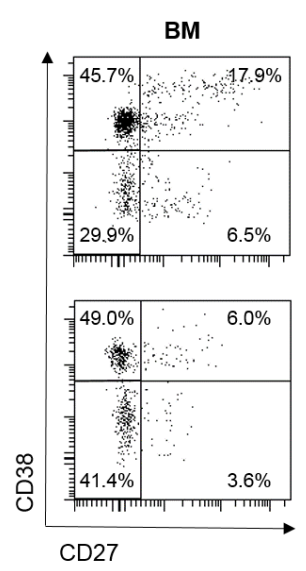

C

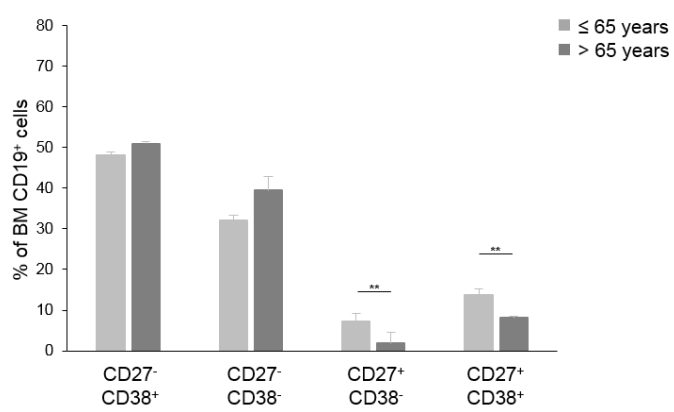

B

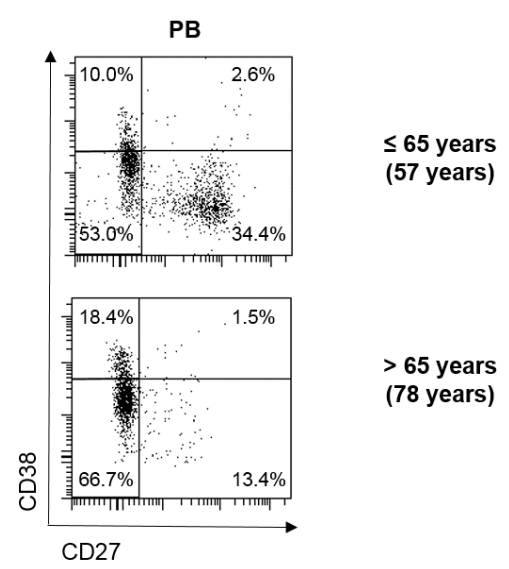

D

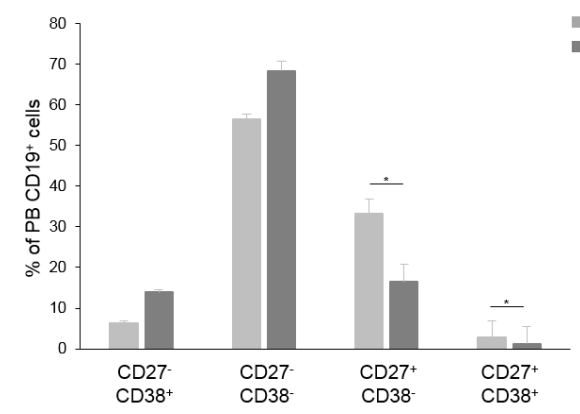

Figure 2. Impact of age on $B$ cell subsets in the bone marrow and peripheral blood. $A$, The dot plots show the impact of age on $A$, bone marrow (BM)- and $B$, peripheral blood (PB)-derived CD27-CD38+ (immature B cells), CD27-CD38- (naïve B cells), CD27 ${ }^{+}$CD38- B cells (memory B cells) and CD27+CD38+ (plasma cells). Each subset was expressed as percentage of CD19+ cells. The gating strategy was the same as described in Figure 1. Representative examples from a 57 year old donor and a 78 year old one are shown. $B$, The bar graphs represent the statistical analysis of the percentages of CD27-CD38+ immature, CD27-CD38- naïve, CD27+CD38- memory $B$ cells and of $\mathrm{CD} 27^{+} \mathrm{CD} 38^{+}$plasma cells from $C$, the $\mathrm{BM}$ and $D$, the $\mathrm{PB}$. Data are presented as mean values \pm SEM ( $n=4$ in each age group; $\leq 65$ years light grey; $>65$ years dark grey). Statistical analysis was performed using impaired $t$ test. * $p \leq 0.05 ;{ }^{* *} p<0.01$ 
Next, we analyzed the impact of aging on the frequency of antigen-specific BM plasma cells, PB-derived memory B cells as well as on peripheral antibody concentrations. Tetanus and diphtheria represent antigens against which most of our donors had been immunized in the past, but for which natural exposure is unlikely. In contrast, influenza $A$ is a pathogen which is encountered frequently by natural exposure and/or vaccination. Cytomegalovirus (CMV) is a persistent virus which during latent infection chronically stimulates immune responses.

The frequencies of tetanus- and diphtheria-specific BM plasma cells correlated negatively with age (Fig. $3 A$ ). In contrast, no correlation between influenza Aspecific BM plasma cells and age was observed. The frequency of CMV-specific BM plasma cells did not change with age in persons with a positive serotype, but correlated with age in the whole cohort due to the fact that young persons were more frequently CMV sero-negative.

To assess age-related alterations of PB-derived memory B cells of a certain specificity, isolated PBMC were pre-activated with pokeweed mitogen (PWM), ODN2006 and Staphylococcus aureus Cowan (SAC) to stimulate antibody production. The percentage of antibody secreting cells (ASC) was analyzed by ELISPOT analysis, as described in Materials and Methods (Fig. 3B). Peripheral antibody concentrations were analyzed by ELISA (Fig. $3 C$ ). The correlations between age and antibody production by memory $B$ cells and between age and peripheral antibody concentrations were weaker than between age and antibody production by BM plasma cells. There was still a significant correlation for the relationship between age and diphtheria-specific memory $B$ cells and between age and tetanus-specific peripheral antibody concentrations. 
A

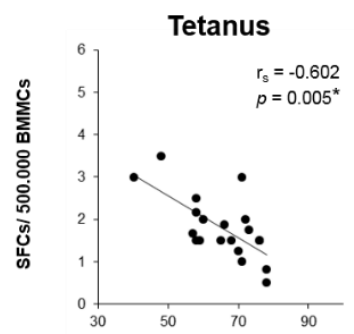

B

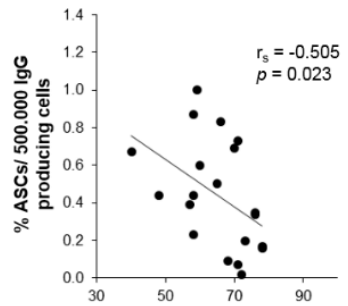

C

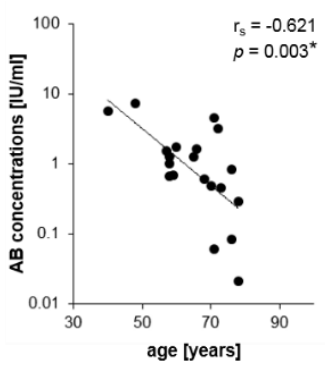

Diphtheria
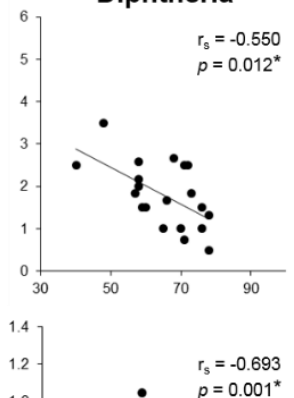

$\begin{aligned} \mathrm{r}_{\mathrm{s}} & =-0.693 \\ \mathrm{p} & =0.001^{*}\end{aligned}$
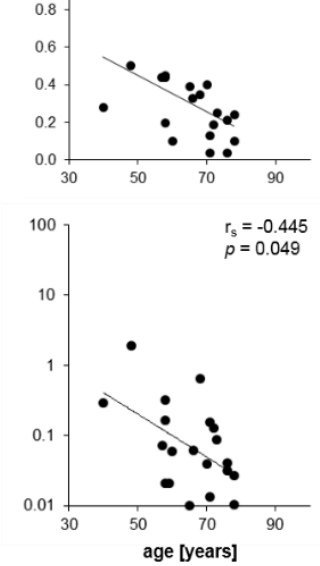
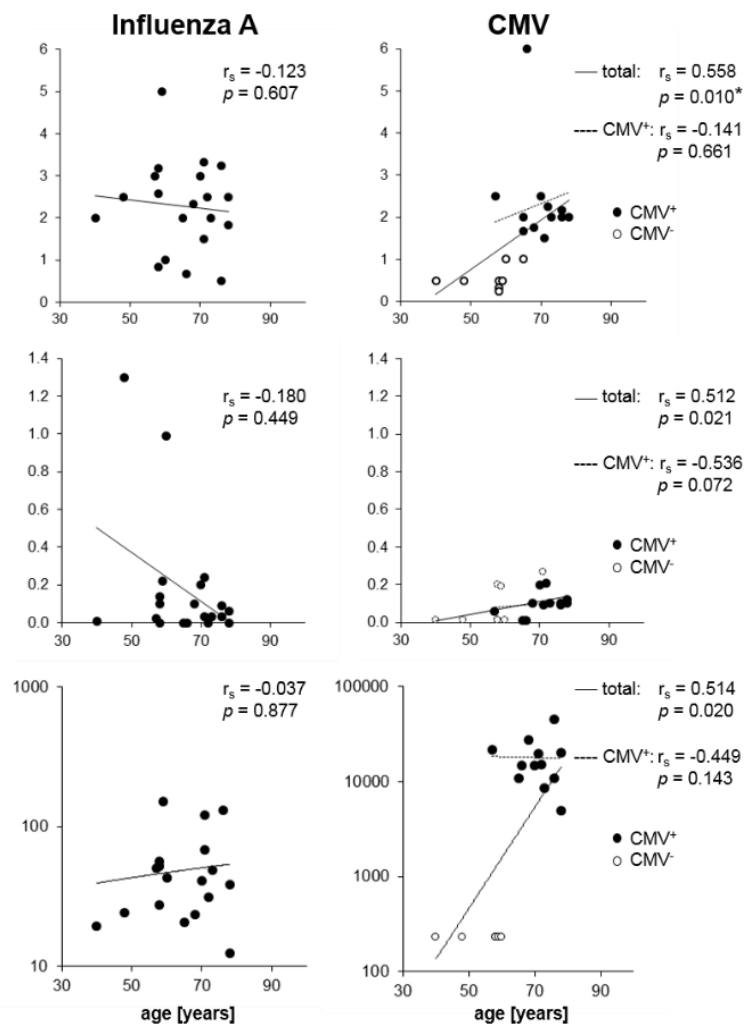

Figure 3. Impact of age on antigen-specific bone marrow plasma cells, peripheral blood memory $B$ cells and peripheral antibody concentrations. $A$, The graphs show the impact of age on tetanus-, diphtheria-, influenza A- and Cytomegalovirus (CMV)-specific bone marrow (BM) plasma cells (spot forming cells (SFC)) analyzed by ELISPOT. $B$, The graphs represent the correlation between age and the percentage of tetanus-, diphtheria-, influenza A- and CMV-specific peripheral blood (PB)-derived antibody secreting memory B cells (ASC). PB mononuclear cells were stimulated for 6 days with pokeweed mitogen (PWM), Staphylococcus aureus Cowan (SAC) and ODN2600 and analyzed by ELISPOT analysis as described in Materials and Methods. $C$, The graphs show the impact of age on tetanus-, diphtheria-, influenza A- and CMV-specific peripheral IgG antibody ( $A B)$ concentrations which were measured by ELISA as described in Materials and Methods. The results for CMV show results from CMV sero-positive (black dots; $n=12$ ) as well as from CMV sero-negative donors (white dots; $n=8$ ). The dashed lines represent the trend line for CMV sero-positive donors, the solid lines for all donors. $r_{s}=S$ pearman correlation coefficients were calculated; $p$ values are shown in the graphs, the ones which were significant following BonferroniHolm correction for multiple testing are indicated by asterisks. 
To make sure that the assessment of antibody producing cells by FACS (Figs. 1 and 2) and ELISPOT (Figs. 3 and 4) corresponded, we additionally analyzed the number of antibody producing cells in BMMC and PBMC from three donors by both methods and the ratio between the results obtained with either, FACS or ELISPOT, was calculated. The ratio was approximately 1 in all experiments, confirming that the two methods gave corresponding results (Supplementary Table 1).

\begin{tabular}{|c|c|c|c|c|c|c|}
\hline & \multicolumn{2}{|c|}{ FACS } & \multicolumn{2}{c|}{$\begin{array}{c}c \mid \\
\text { Ranti-IgG ELISPOT } \\
\% \text { IgG specific spots/well }\end{array}$} \\
\hline Donor & BM CD19+ IgG+ cells in BMMC/PBMC gate & PB & BM & PB & BM & PB \\
\hline $\mathbf{1}$ & $0.31 \%$ & $0.07 \%$ & $0.32 \%$ & $0.06 \%$ & 1.0 & 1.2 \\
\hline $\mathbf{2}$ & $0.42 \%$ & $0.08 \%$ & $0.44 \%$ & $0.07 \%$ & 1.0 & 1.1 \\
\hline $\mathbf{3}$ & $0.31 \%$ & 0.06 & $0.35 \%$ & $0.07 \%$ & 0.9 & 0.9 \\
\hline
\end{tabular}

Supplementary Table 1: Assessment of number of antibody producing cells by FACS and ELISPOT technique. Freshly isolated bone marrow mononuclear cells (BMMC) and peripheral blood mononuclear cells (PBMC) were used for the analysis of IgG producing plasma cells by antiIgG ELISPOT or FACS analysis as described in Materials and Methods. The table summarizes the percentage of IgG producing plasma cells analyzed by FACS and the results of an anti-lgG ELISPOT analysis in three donors in bone marrow (BM)- and peripheral blood (PB)-derived samples. To make FACS and ELISPOT data comparable, plasma cells were defined by staining with anti-CD19 and anti-lgG in this experiment. IgG-producing cells were defined as percent of total cells in the BMMC/PBMC gate in FACS experiments and as percent of total cells per well $(50.000=$ $100 \%$ ) in ELISPOT experiments. Finally the ratio between the percentage of $\mathrm{CD}^{2} 9^{+} \operatorname{lgG}{ }^{+}$plasma cells assessed by FACS and the percentage of IgG-producing cells assessed by ELIPSOT was calculated.

\section{Plasma cells maintain antigen-specific antibody concentrations}

Previous studies reported that BM plasma cells have the capacity to generate persistent high-affinity antibodies and are therefore important in providing longlasting immune protection (Hofer et al., 2006). Thus, we next analyzed the relationship between plasma cells and memory $B$ cells with peripheral antigen- 
specific IgG antibody concentrations. Fig. $4 A$ demonstrates a positive correlation between tetanus-, diphtheria- and influenza A-specific BM plasma cells and peripheral antigen-specific $\lg G$ antibodies of the same specificity. The frequency of CMV-specific BM-derived plasma cells did not correlate with peripheral CMVspecific antibody concentrations in CMV sero-positive persons. The percentage of diphtheria-, influenza A- and CMV-specific PB-derived ASC did not significantly correlate with peripheral antibody concentrations (Fig. 4B).

A
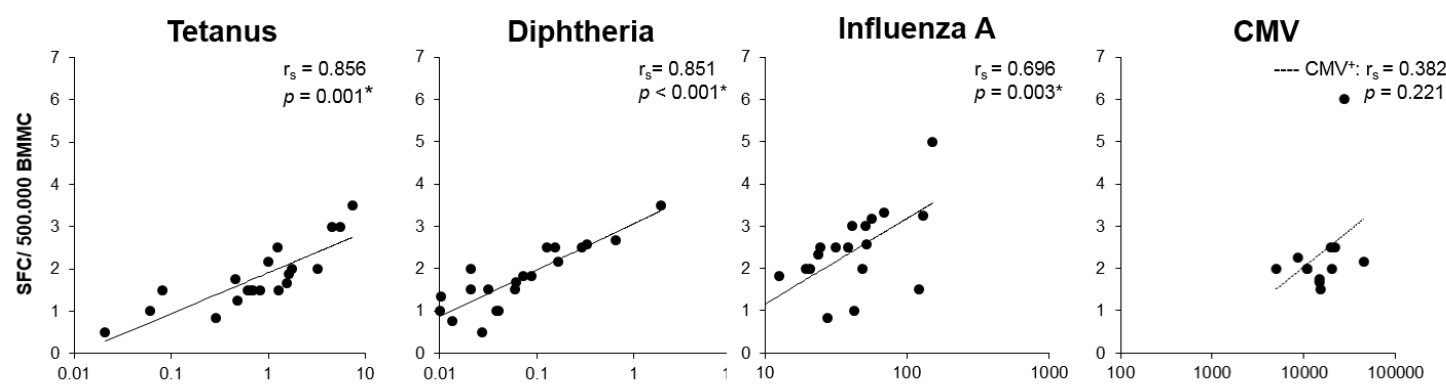

B
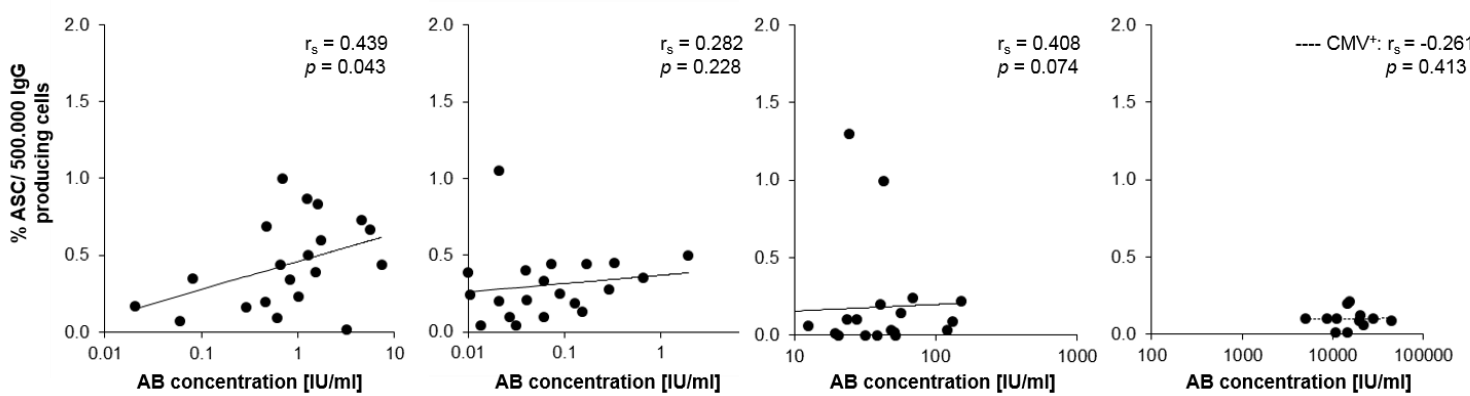

Figure 4. BM plasma cells correlate with antigen-specific antibody concentrations. The graphs show the correlations of tetanus-, diphtheria-, influenza A- and Cytomegalovirus (CMV)specific $\lg G$ antibody $(\mathrm{AB})$ concentrations and antigen-specific $A$, bone marrow (BM) plasma cells (spot forming cells (SFC); upper panel) and $B$, peripheral blood (PB)-derived antibody secreting memory $B$ cells (ASC) (lower panel). The frequency of antigen-specific BM plasma cells and PBderived memory $B$ cells was analyzed by ELISPOT, whereas peripheral antibody concentrations were measured by ELISA as described in Materials and Methods. The results for samples from CMV sero-positive $(n=12)$ but not from sero-negative persons are shown. $r_{s}=S p e a r m a n$ correlation coefficients were calculated; $p$ values are shown in the graphs, the ones which were significant following Bonferroni-Holm correction for multiple testing are indicated by asterisks. 


\section{Discussion}

As the murine BM has been attributed a key role in the survival of plasma cells in distinct survival niches (Tokoyoda et al., 2009a), we studied plasma and memory $B$ cells as well as age-related changes of these populations in the human BM and PB. The flow cytometric analysis of BMMC and PBMC revealed that plasma cells are mainly located in the $\mathrm{BM}$, whereas a higher frequency of memory $\mathrm{B}$ cells was observed in the periphery. Previous studies showed that memory $B$ cells circulate in the PB, but many also reside in places of antigen drainage such as the spleen and tonsils (Tangye et al., 1998; Tangye and Tarlinton, 2009). In contrast, peripheral plasma cells are believed to correspond to newly generated plasmablasts migrating to the BM, mucosa associated lymphoid tissue (MALT) or chronically inflamed tissue (Odendahl et al., 2005). Under steady state conditions only low numbers of these cells are detected in the PB. Studies in mice have shown that plasma cells are also enriched in survival niches in the BM, where they are in close contact with CXCL12+IL7-VCAM1+ stromal cells and receive survival factors from stromal cells, megakaryozytes as well as BM-derived eosinophils (reviewed in (Tokoyoda et al., 2010)).

In accordance with others, who used the same marker molecules as we for the definition of B cell subsets (Caraux et al., 2010), we demonstrate that during aging the relative frequency of memory $B$ and plasma cells decreases in the $\mathrm{PB}$, while immature and naïve $B$ cells seem unaffected by donor age. The finding of decreased percentages of memory $B$ and plasma cells in the PB of humans has also been demonstrated by other groups (Breitbart et al., 2002; Chong et al., 2005; Frasca et al., 2008a; Shi et al., 2005), while a few studies also show the opposite (Colonna-Romano et al., 2003; Veneri et al., 2009). This discrepancy may be due to the use of different markers to define $B$ cell subsets. Thus, memory/plasma cells have been defined by different combinations of CD10, CD19, CD23, CD27, CD38, $\lg \mathrm{D}$ and $\operatorname{lgM}$. Furthermore, differences in the techniques used for analysis and variations in the age groups and cohort sizes could explain varying results. The situation seems to be different in mice, as most murine studies show a decrease of newly generated $B$ cells and an increase of antigen-experienced cells (reviewed in (Kogut et al., 2012; Miller and Cancro, 2007)). The decreased percentage of peripheral memory $\mathrm{B}$ and plasma cells observed in humans may be due to age- 
related defects in the T helper cell system (Zhang et al., 2014) leading to decreased germinal center responses, as shown in old mice (Han et al., 2003).

Decreased germinal center responses in the lymph nodes may also explain our finding of decreased numbers of plasma cells in the aged human BM. Additional factors may, however, also influence BM plasma cell numbers. Human aging has for instance been associated with a chronic, low-grade proinflammatory status, leading to age-associated diseases and increased mortality, termed "inflammaging" (Franceschi et al., 2000). Previous studies demonstrated that TNF- $\alpha$ mediated inflammation suppresses CXCL12 expression and as a consequence the homing of plasmablasts to the BM in mice (Ueda et al., 2004). "Inflamm-aging" could therefore be associated with a decrease of CXCL12 expression leading to a diminished survival of plasma cells in the aged BM.

In this context the antigen-specificity of plasma cells in the aged BM is of interest. Our results demonstrate that tetanus- and diphtheria-specific BM plasma cells correlate with age, whereas this was not the case for influenza A- and CMVspecific BM plasma cells.

The observation that influenza A-specific BM plasma cells and antibody concentrations were independent of age might be explained by the fact that frequent re-exposure with influenza occurs. Presumably for the same reason, CMV-specific BM plasma cells, PB memory B cells and peripheral antibody concentration from CMV sero-positive donors did not show a relationship with age, but CMV-specific BM plasma cells correlated with age in the whole cohort due to the fact that young persons were more frequently CMV sero-negative.

It was of interest that our data additionally demonstrate that tetanus-, diphtheria-, and influenza A-specific peripheral antibody concentrations correlated with the frequency of BM plasma cells, but less well with peripheral memory B cells. These results are in accordance with mice studies which show that long-lasting antibody production is provided by long-lived plasma cells, independent of memory B cells (Manz et al., 1998). They also confirm data in humans which demonstrate that memory B cells do not correlate with peripheral antibody concentrations (MamaniMatsuda et al., 2008). CMV-specific BM plasma cells from sero-positive donors did not show a correlation with peripheral antibody concentrations. This may indicate that other lymphoid organs are more important to generate immune responses to $\mathrm{CMV}$ reactivation and in particular the production of antibodies. 
The finding that BM plasma cell numbers specific for influenza and CMV are unaffected with age suggests that the recruitment of plasma cells is still possible in old age. It is, however, still not clear whether plasma cells generated late in life have the same functional properties as the ones generated during childhood in response to diseases such as mumps or measles known to induce life-long immunity (Amanna et al., 2007). The possibility that plasma cells which produce antibodies with decreased avidity predominate in old age has been discussed but the results are conflicting (de Bruijn et al., 1999; Kolibab et al., 2005; Sasaki et al., 2011; Stiasny et al., 2012). Recently, however, there seems to be more consensus that antibody avidity and affinity are not affected by aging, at least in humans (Sasaki et al., 2011; Stiasny et al., 2012). Thus, we have found no age-related differences in the avidity and functional activity of antibodies induced by Tickborne encephalitis (TBE) vaccination in elderly persons (Stiasny et al., 2012) and Sasaki et al come to the same conclusion for influenza (Sasaki et al., 2011). However, these studies have been performed on PB following vaccination and not on BM plasma cells. Future studies will have to show whether plasma cells immigrating into the $\mathrm{BM}$ in old age have altered functional characteristics and whether these are due to changes of the plasma cells themselves, of the BM niche, or both. In contrast to influenza A- and CMV-specific plasma cells, tetanusand diphtheria-specific cells in the BM decrease with age. Peripheral antibodies to tetanus and diphtheria have been shown to have a relatively short half-life of 10 20 years, which is much shorter than that observed for antibodies against viruses (Amanna et al., 2007). In view of this fact our data on tetanus- and diphtheriaspecific antibodies have to be interpreted with caution, as no reliable vaccination history was obtainable from our cohort. In view of the vast literature demonstrating that antibody concentrations in elderly persons with a known vaccination history are still decreased (reviewed in (Boraschi et al., 2013)), it seems likely that intrinsic age-related changes as well as vaccination history affect plasma cell numbers specific for tetanus and diphtheria in the BM.

As for both antigens there are strong correlations between BM plasma cell numbers and peripheral antibody concentrations, it is, for whatever reason, to be expected that too low plasma cell numbers in the BM endanger protection against certain antigens in old age. As intrinsic age-related changes can hardly be avoided, it seems of importance to assure regular booster vaccinations against 
both antigens in adults. Whether low plasma cell numbers in the human BM also reflect small memory pools of $B$ cells specific to a certain antigen would be of interest. However, our data do not allow definite conclusions in this direction, as due to the relatively small cohort we had to use stringent statistical analyses. We thus found no significant correlation between peripheral memory $B$ cells and age for tetanus, but a significant correlation between memory $B$ cells and age for diphtheria and no correlation between peripheral memory B cells and BM plasma cells (data not shown). Future studies on a larger cohort will help to solve this open question.

In conclusion, our results suggest that BM plasma cells do still play an important role for antibody production in elderly persons. It has to be kept in mind that due to intrinsic aging processes in the BM niche and/or plasma cells themselves and due to too long intervals in antigen exposure, protection cannot be taken for granted in old age. Regular booster immunizations, at least against certain pathogens, seem therefore of great relevance.

\section{Materials and Methods}

\section{Sample collection and preparation}

Paired blood and BM samples were obtained from systemically healthy persons who were scheduled for hip replacement surgery at the Department of Orthopedic Surgery at the Innsbruck Medical University. Individuals who suffered from diseases known to influence the immune system, including autoimmune diseases and cancer, were excluded from the study. The study was approved by the Ethics Committee of the Innsbruck Medical University. Bone from the femur shaft was harvested during surgery. Femur-derived BM and autologous blood samples were obtained from a total of 31 persons (age \pm SEM: $65.7 \pm 1.92$, range: 40 to 86 years; 16 females, 15 males). CMV sero-positivity was assessed by ELISA.

BMMC were isolated from bone, as previously described (Pritz et al., 2013). Briefly, bone biopsies were washed once with complete RPMI 1640 (Sigma Aldrich; St. Louis, MO, USA) supplemented with 10\% FCS (Sigma Aldrich), and 1\% Penicillin/Streptomycin (PAA; Pasching, Austria). Bone biopsies were 
fragmented and treated with $20 \mathrm{U} / \mathrm{ml}$ sterile-filtered, chromatographically purified collagenase (CLSPA; Worthington, Lakewood, NJ, USA) diluted in complete RPMI 1640 for $2 \mathrm{~h}$ at $37^{\circ} \mathrm{C}, 20 \% \mathrm{O}_{2}$ and $5 \% \mathrm{CO}_{2}$. Cells were centrifuged, and $\mathrm{BMMC}$ purified by density-gradient centrifugation (Ficoll-Hypaque). Preparation of PBMC was performed by density-gradient centrifugation and plasma samples were stored at $-20^{\circ} \mathrm{C}$.

Flow cytometric analysis

Immunofluorescence surface staining was performed by adding a panel of directly conjugated $\mathrm{mAb}$ to $\mathrm{BMMC}$ or $\mathrm{PBMC}$, respectively. The following Abs used were: CD19 (PE), CD38 (APC), anti-lgG (PE) (all BD Pharmingen; San Jose, CA, USA) and CD27 (APC-Cy7; Biolegend; San Diego, CA, USA). Cells were incubated with the antibodies for $30 \mathrm{~min}$ at $4^{\circ} \mathrm{C}$. The labeled cells were measured by using a FACSCanto II Instrument (BD Biosciences; San Jose, CA, USA), and the data were analyzed using FACSDiva Software (BD Biosciences).

Analysis of antigen-specific antibody secreting cells

ELISPOT assays were used for the detection of antigen-specific antibody secreting cells. The assays were performed following the manufacturer's instructions (Mabtech; Nacka Strand, Sweden). Briefly, for the analysis of BM plasma cells of a certain specificity, ELISPOT multiscreen IP Filtration Plates (MAIPS4510; Millipore; Temecula, CA, USA) were pre-wetted with $70 \%$ ethanol and coated with $10 \mu \mathrm{g} / \mathrm{ml}$ anti-lgG antibody (Mabtech) over night at $4^{\circ} \mathrm{C}$. The plates were washed with PBS and blocked with complete RPMI 1640 (Sigma Aldrich; St. Louis, MO, USA) supplemented with 10\% FCS (Sigma Aldrich), 1\% Penicillin/Streptomycin (PAA; Pasching, Austria) at least for 1 h at $37^{\circ} \mathrm{C}, 20 \% \mathrm{O}_{2}$ and $5 \% \mathrm{CO}_{2} .500 .000$ isolated $\mathrm{BMMC}$ were cultured in triplicates for $24 \mathrm{~h}$ at $37^{\circ} \mathrm{C}$, $20 \% \mathrm{O}_{2}$ and $5 \% \mathrm{CO}_{2}$. After the plates were washed with PBS, the detection of antigen-specific antibody secreting cells was performed using $0.05 \mu \mathrm{g} / \mathrm{ml}$ tetanus or diphtheria toxoid (Statens Serum Institute; Copenhagen, Denmark), $0.10 \mu \mathrm{g} / \mathrm{ml}$ 
influenza A virus preparation (H1N1; BioScience, Orth, Austria) or CMV lysate (Virion-Serion; Würzburg, Germany) (for $90 \mathrm{~min}$ at $37^{\circ} \mathrm{C}, 20 \% \mathrm{O}_{2}$ and $5 \% \mathrm{CO}_{2}$ ). Detection with bovine serum albumin (BSA) was used as a negative control. All antigens were biotinylated using the EZ-Link Sukfo-NHS-LC-Biotinylation Kit (Pierce Biotechnology; Rockford, IL, USA). After washing with PBS, detection was performed using Streptavidin alkaline phosphatase (Mabtech) (for 90min at room temperature) and the colorimetric substrate BCIP/NBT (Moss Inc.; Pasadena, MA, USA). Spots were counted using a CTL reader (CTL; Bonn, Germany).

For the analysis of peripheral memory $B$ cells of a certain specificity, isolated PBMC were pre-activated for 6 days with pokeweed mitogen (PWM; 10ng/ml;

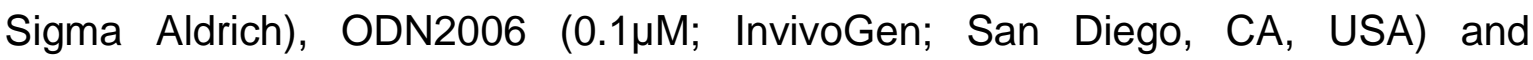
Staphylococcus aureus Cowan (SAC; 1:10000; Sigma Aldrich) to stimulate antibody production. The number of antigen-specific antibody producing cells was analyzed by ELISPOT assay, as described above.

\section{Detection of antibody concentrations}

For the analysis of antibodies against influenza A (Immunolab; Kassel, Germany) and CMV (Siemens; Erlangen, Germany) commercially available ELISA kits were used. The assays were performed following the manufacturer's instructions.

For the determination of tetanus- and diphtheria-specific antibody concentrations, microtiter plates were coated with $1 \mu \mathrm{g} / \mathrm{ml}$ tetanus or diphtheria toxoid (Statens Serum Institute; Copenhagen, Denmark). For tetanus and diphtheria, standards of the NIBSC (National Institute for Biological Standards and Control; Potters Bar, UK) were used. By definition, each tetanus ampoule contains 120 IU of human tetanus Ig. A titer of more than $0.01 \mathrm{IU} / \mathrm{ml}$ of anti-tetanus antibodies is considered to be protective. For diphtheria each ampoule contains $0.8 \mathrm{IU}$ of diphtheria antitoxin, as measured by toxin neutralization in vivo against the British Standard for diphtheria antitoxin (Ipsen, 1946). Anti-diphtheria antibody concentrations of more than $0.01 \mathrm{IU} / \mathrm{ml}$ are considered as protective. After blocking with $0.01 \mathrm{M}$ Glycin, sera and standards were tested in duplicates (for $1 \mathrm{~h}$ at $37^{\circ} \mathrm{C}, 20 \% \mathrm{O}_{2}$ and $5 \% \mathrm{CO}_{2}$ ). After washing, Peroxidase-labeled rabbit anti-human $\lg \mathrm{G}$ antibody 
(Chemicon/Millipore; Temecula, CA, USA) was used as secondary antibody. IgG antibodies were quantified in $\mathrm{IU} / \mathrm{ml}$.

Statistical analysis

Differences between BM and PB were evaluated using paired $t$ tests. For the comparison of samples from younger and older persons impaired $t$ test was used. For both analyses, $p$ values of $\leq 0.05$ were considered as statistically significant.

For correlations between plasma cells, memory B cells, peripheral antibody concentrations and age, the Spearman's rank correlation coefficient $\left(r_{s}\right)$ was calculated. The statistical analyses were performed using the software package IBM SPSS Statistics 21 (SPSS Inc.; Armonk, NY, USA). To make statistical analysis more stringent, a Bonferroni-Holm correction for multiple testing was performed (Streiner and Norman, 2011).

\section{Acknowledgment}

We thank Caroline Linhart from the Department of Medical Statistics, Innsbruck Medical University, for statistical support.

The work has been supported by D. Swarovski KG.

\section{Conflict of interest}

The authors declare no conflicts of interest. 


\section{References to manuscript II}

Amanna, I.J., Carlson, N.E.,. Slifka, M.K, 2007. Duration of humoral immunity to common viral and vaccine antigens. The New England journal of medicine 357:1903-1915.

Arnold, C.R., Wolf, J., Brunner, S., Herndler-Brandstetter, D., GrubeckLoebenstein, B., 2011. Gain and loss of T cell subsets in old age--agerelated reshaping of the $\mathrm{T}$ cell repertoire. Journal of clinical immunology 31:137-146.

Boraschi, D., Aguado, M.T., Dutel, C., Goronzy, J., Louis, J., GrubeckLoebenstein, B., Rappuoli, R., Del Giudice, G., 2013. The gracefully aging immune system. Science translational medicine 5:185ps188.

Breitbart, E., Wang, X., Leka, L.S., Dallal, G.E., Meydani, S.N., Stollar, B.D., 2002. Altered memory B-cell homeostasis in human aging. The journals of gerontology. Series A, Biological sciences and medical sciences 57:B304311.

Caraux, A., Klein, B., Paiva, B., Bret, C., Schmitz, A., Fuhler, G.M., Bos, N.A., Johnsen, H.E., Orfao, A., Perez-Andres, M., Myeloma Stem Cell, N., 2010. Circulating human $B$ and plasma cells. Age-associated changes in counts and detailed characterization of circulating normal CD138- and CD138+ plasma cells. Haematologica 95:1016-1020.

Chong, Y., Ikematsu, H., Yamaji, K., Nishimura, M., Nabeshima, S., Kashiwagi, S., Hayashi, J., 2005. CD27(+) (memory) B cell decrease and apoptosisresistant CD27(-) (naive) B cell increase in aged humans: implications for age-related peripheral B cell developmental disturbances. International immunology 17:383-390.

Chu, V.T., Berek, C., 2013. The establishment of the plasma cell survival niche in the bone marrow. Immunological reviews 251:177-188.

Colonna-Romano, G., Bulati, M., Aquino, A., Scialabba, G., Candore, G., Lio, D., Motta, M., Malaguarnera, M., Caruso, C., 2003. B cells in the aged: CD27, CD5, and CD40 expression. Mechanisms of ageing and development 124:389-393. 
de Bruijn, I.A., Remarque, E.J., Jol-van der Zijde, C.M., van Tol, M.J., Westendorp, R.G., Knook, D.L. , 1999. Quality and quantity of the humoral immune response in healthy elderly and young subjects after annually repeated influenza vaccination. The Journal of infectious diseases 179:3136.

Franceschi, C., Bonafe, M., Valensin, S., Olivieri, F., De Luca, M., Ottaviani, E., De Benedictis, G., 2000. Inflamm-aging. An evolutionary perspective on immunosenescence. Annals of the New York Academy of Sciences 908:244-254.

Frasca, D., Landin, A.M., Lechner, S.C., Ryan, J.G., Schwartz, R., Riley, R.L., Blomberg, B.B., 2008. Aging down-regulates the transcription factor E2A, activation-induced cytidine deaminase, and Ig class switch in human B cells. Journal of immunology 180:5283-5290.

Han, S., Yang, K., Ozen, Z., Peng, W., Marinova, E., Kelsoe, G., Zheng, B., 2003. Enhanced differentiation of splenic plasma cells but diminished long-lived high-affinity bone marrow plasma cells in aged mice. Journal of immunology 170:1267-1273.

Hanazawa, A., Lohning, M., Radbruch, A., Tokoyoda, K., 2013. CD49b/CD69Dependent Generation of Resting $\mathrm{T}$ Helper Cell Memory. Frontiers in immunology 4:183.

Herndler-Brandstetter, D., Landgraf, K., Tzankov, A., Jenewein, B., Brunauer, R., Laschober, G.T., Parson, W., Kloss, F., Gassner, R., Lepperdinger, G., Grubeck-Loebenstein, B., 2012. The impact of aging on memory $T$ cell phenotype and function in the human bone marrow. Journal of leukocyte biology $91: 197-205$.

Hofer, T., Muehlinghaus, G., Moser, K., Yoshida, T., H, E.M., Hebel, K., Hauser, A., Hoyer, B., E, O.L., Dorner, T., Manz, R.A., Hiepe, F., Radbruch, A., 2006. Adaptation of humoral memory. Immunological reviews 211:295-302.

Ipsen, J., 1946. Circulating antitoxin at the onset of diphtheria in 425 patients. Journal of immunology 54:325-347. 
Kogut, I., Scholz, J.L., Cancro, M.P., Cambier, J.C., 2012. B cell maintenance and function in aging. Seminars in immunology 24:342-349.

Kolibab, K., Smithson, S.L., Shriner, A.K., Khuder, S., Romero-Steiner, S., Carlone, G.M., Westerink, M.A., 2005. Immune response to pneumococcal polysaccharides 4 and 14 in elderly and young adults. I. Antibody concentrations, avidity and functional activity. Immunity \& ageing : I \& $A$ 2:10.

Mamani-Matsuda, M., Cosma, A., Weller, S., Faili, A., Staib, C., Garcon, L., Hermine, O., Beyne-Rauzy, O., Fieschi, C., Pers, J.O., Arakelyan, N., Varet, B., Sauvanet, A., Berger, A., Paye, F., Andrieu, J.M., Michel, M., Godeau, B., Buffet, P., Reynaud, C.A., Weill, J.C., 2008. The human spleen is a major reservoir for long-lived vaccinia virus-specific memory $B$ cells. Blood 111:4653-4659.

Manz, R.A., Lohning, M., Cassese, G.,. Thiel, A, Radbruch, A., 1998. Survival of long-lived plasma cells is independent of antigen. International immunology 10:1703-1711.

McHeyzer-Williams, M.G., Ahmed, R., 1999. B cell memory and the long-lived plasma cell. Current opinion in immunology 11:172-179.

Miller, J.P., Cancro, M.P., 2007. B cells and aging: balancing the homeostatic equation. Experimental gerontology 42:396-399.

Odendahl, M., Mei, H.,. Hoyer, B.F, Jacobi, A.M., Hansen, A., Muehlinghaus, G., Berek, C., Hiepe, F., Manz, R., Radbruch, A., Dorner, T., 2005. Generation of migratory antigen-specific plasma blasts and mobilization of resident plasma cells in a secondary immune response. Blood 105:1614-1621.

Okhrimenko, A., Grun, J.R., Westendorf, K., Fang, Z., Reinke, S., von Roth, P., Wassilew, G., Kuhl, A.A., Kudernatsch, R., Demski, S., Scheibenbogen, C., Tokoyoda, K., McGrath, M.A., Raftery, M.J., Schonrich, G., Serra, A., Chang, H.D., Radbruch, A., Dong, J. , 2014. Human memory T cells from the bone marrow are resting and maintain long-lasting systemic memory. Proceedings of the National Academy of Sciences of the United States of America 
Pritz, T., Landgraf-Rauf, K., Herndler-Brandstetter, D., Rauf, R., Lair, J., Gassner, R., Weinberger, B., Krismer, M., Grubeck-Loebenstein, B., 2013. Bone marrow $T$ cells from the femur are similar to iliac crest derived cells in old age and represent a useful tool for studying the aged immune system. Immunity \& ageing : I \& A 10:17.

Pritz, T., Weinberger, B., Grubeck-Loebenstein, B., 2014. The aging bone marrow and its impact on immune responses in old age. Immunology letters

Radbruch, A., Muehlinghaus, G., Luger, E.O., Inamine, A., Smith, K.G., Dorner, T., Hiepe, F., 2006. Competence and competition: the challenge of becoming a long-lived plasma cell. Nature reviews. Immunology 6:741-750.

Sasaki, S., Sullivan, M., Narvaez, C.F., Holmes, T.H., Furman, D., Zheng, N.Y., Nishtala, M., Wrammert, J., Smith, K., James, J.A., Dekker, C.L., Davis, M.M., Wilson, P.C., Greenberg, H.B., He, X.S., 2011. Limited efficacy of inactivated influenza vaccine in elderly individuals is associated with decreased production of vaccine-specific antibodies. The Journal of clinical investigation 121:3109-3119.

Shi, Y., Yamazaki, T., Okubo, Y., Uehara, Y., Sugane, K., Agematsu, K., 2005. Regulation of aged humoral immune defense against pneumococcal bacteria by IgM memory B cell. Journal of immunology 175:3262-3267.

Stiasny, K., Aberle, J.H., Keller, M., Grubeck-Loebenstein, B., Heinz, F.X., 2012. Age affects quantity but not quality of antibody responses after vaccination with an inactivated flavivirus vaccine against tick-borne encephalitis. PloS one $7: \mathrm{e} 34145$.

Streiner, D.L., Norman, G.R., 2011. Correction for multiple testing: is there a resolution? Chest 140:16-18.

Tangye, S.G., Liu, Y.J., Aversa, G., Phillips, J.H., de Vries, J.E., 1998. Identification of functional human splenic memory $B$ cells by expression of CD148 and CD27. The Journal of experimental medicine 188:1691-1703.

Tangye, S.G., Tarlinton, D.M., 2009. Memory B cells: effectors of long-lived immune responses. European journal of immunology 39:2065-2075. 
Tokoyoda, K., Hauser, A.E., Nakayama, T., Radbruch, A., 2010. Organization of immunological memory by bone marrow stroma. Nature reviews. Immunology 10:193-200.

Tokoyoda, K., Radbruch, A., 2012. Signals controlling rest and reactivation of $T$ helper memory lymphocytes in bone marrow. Cellular and molecular life sciences : CMLS 69:1609-1613.

Tokoyoda, K., Zehentmeier, S., Chang, H.D., Radbruch, A., 2009. Organization and maintenance of immunological memory by stroma niches. European journal of immunology 39:2095-2099.

Ueda, Y., Yang, K., Foster, S.J., Kondo, M., Kelsoe, G., 2004. Inflammation controls B lymphopoiesis by regulating chemokine CXCL12 expression. The Journal of experimental medicine 199:47-58.

Veneri, D., Ortolani, R., Franchini, M., Tridente, G., Pizzolo, G., Vella, A., 2009. Expression of CD27 and CD23 on peripheral blood $B$ lymphocytes in humans of different ages. Blood transfusion = Trasfusione del sangue 7:2934.

Zehentmeier, S., Roth, K., Cseresnyes, Z., Sercan, O., Horn, K., Niesner, R.A., Chang, H.D., Radbruch, A., Hauser, A.E., 2014. Static and dynamic components synergize to form a stable survival niche for bone marrow plasma cells. European journal of immunology

Zhang, W., Brahmakshatriya, V., Swain, S.L., 2014. CD4 T cell defects in the aged: causes, consequences and strategies to circumvent. Experimental gerontology 54:67-70. 
CHAPTER III GENERAL DISCUSSION AND CONCLUSION 


\section{Discussion and conclusion}

Most studies on the adaptive immune system in the BM have been performed in mice (Radbruch et al., 2006; Tokoyoda et al., 2010) and there are very few data available on humans (Di Rosa and Pabst, 2005), in particular in the context of aging.

Recently our group contributed to the topic of BM T cells from young and elderly persons (Herndler-Brandstetter et al., 2011; Herndler-Brandstetter et al., 2012). For these studies BM biopsies from iliac crest from young and elderly persons were used. The major advantage of this BM source is that it is obtained from healthy donors of different age groups. However, few samples and only small amounts of this tissue type are available from patients undergoing reconstructive surgery and bone remodeling of the jaw. Furthermore, the samples are generally very small with a low yield of BMMC. For many immunological analyses and studies on aging, higher cell numbers are needed. Therefore, we tested a different source of BM, namely the femur shaft. The frequent availability of BM tissue from patients undergoing hip replacement surgery and the bigger yield of BMMC from femur shaft-derived tissue samples allow a more detailed analysis of BM lymphocytes as well as of their interactions with other BM-derived cells in old age. A disadvantage of this BM source is the relatively rare availability of BM tissue from younger donors. Another potential problem may be the close vicinity of the femur shaft to the inflamed joint in patients who undergo hip replacement surgery, or the fact that these patients are treated with anti-inflammatory drugs. For studies on the physiology of the aging immune system, a possible influence of inflammatory processes and/or drugs on adaptive immune cells needs to be excluded. Thus, the first aim of this study was to demonstrate that the size of different $T$ cell subsets as well as their phenotype were not different when iliac crest or femur shaft-derived bone biopsies were studied. In accordance with previous studies (Herndler-Brandstetter et al., 2012) we now demonstrate that the number of naïve $T$ cells decreased in both types of $B M$, while there was an increase in the number of effector memory $T$ cells during aging. A large percentage of CD69-expressing BM T cells was also observed. Recently, mice studies demonstrated that memory $\mathrm{CD} 4^{+} \mathrm{T}$ cells migrating to the $\mathrm{BM}$ utilize $\mathrm{CD} 49 \mathrm{~b}$ 
and CD69 and survive in the BM as resting but highly reactive cells (Hanazawa et al., 2013). We showed that human BM T cells also express CD69.

With the bigger yield of BMMC from the femur shaft we were also able to analyze the cytokine production by BM T cell subsets in greater detail. It has already been demonstrated that a higher percentage of polyfunctional CD4 ${ }^{+}$and $\mathrm{CD}^{+} \mathrm{T}$ cells accumulate in the BM from aged persons (Herndler-Brandstetter et al., 2011; Herndler-Brandstetter et al., 2012). Using the new tissue source we were now able to demonstrate that specific BM $\mathrm{T}$ cell subsets, namely $\mathrm{T}$ cells of late differentiation stages, were frequently more polyfunctional than in the periphery. These results support the concept that CD28- T cells survive and function in the IL15-rich BM niche in old age (Herndler-Brandstetter et al., 2011). Whether these highly differentiated polyfunctional T cells in the BM of elderly people represent a compensatory line of defense in the absence of naïve $T$ cells is not yet clear. Further studies will be needed to clarify this question.

To better understand the adaptive immune system in the aged human BM, in vitro modeling of the in vivo situation by co-culturing BM-derived $\mathrm{T}$ and stromal cells is one possible approach. We showed that $\mathrm{T}$ cell proliferation is not negatively affected by the presence of BM-derived stromal cells. This may be unexpected, as there are reports that describe an immunosuppressive effect of BM-derived MSCs on T cells (Landgraf et al., 2011). From our results we conclude that only BMderived multipotent stromal cells are capable of immunosuppressive effects, while differentiated stromal cells support T cell function. Therefore, our in vitro model system will represent a useful tool to analyze how BM stromal cells from early differentiation stages to senescence affect the function of different $T$ and $B$ cell subsets in the human BM.

Usage of BMMC from the femur shaft also allowed a detailed analysis of B cell subsets. While it is well understood that long-lived plasma cells survive in distinct survival niches in the BM of mice (Tokoyoda et al., 2010), relatively little is still known on plasma cell survival in the human BM and virtually nothing on the effects of aging.

Our study is therefore the first which analyzes B cell subsets in the aged human BM. Our results revealed that BM and PB contained fewer memory and plasma cells in older persons, while immature and naïve B cells were unaffected by age. 
This decrease might be related to a defect in $\mathrm{CD} 4^{+}$helper $\mathrm{T}$ cell function in old age, as impaired cognate helper function of $\mathrm{CD} 4^{+}$helper $\mathrm{T}$ cells would lead to a decline in GC responses (Zhang et al., 2014), as already demonstrated in old mice (Han et al., 2003). Alternatively, age-related chronic inflammatory processes could also be deleterious (Franceschi et al., 2000). Thus, it has been demonstrated in mice that TNF- $\alpha$ mediated inflammation suppresses CXCL12 expression and as a consequence the homing of plasmablasts to the BM (Ueda et al., 2004). Therefore, aging could be associated with an impaired CXCL12 expression also in humans, leading to a diminished survival of plasma cells in the human BM.

The antigen-specificity of plasma cells in the aged BM is also of interest. Our results demonstrate that tetanus- and diphtheria-specific BM plasma cells correlate with age, while this was not the case for influenza A- and CMV-specific $\mathrm{BM}$ plasma cells. The latter finding suggests that the recruitment of plasma cells to the BM is principally possible in old age. It is, however, still not clear whether plasma cells generated later in life have the same functional properties as the ones generated during childhood in response to diseases (Amanna et al., 2007). While there has been disagreement about age-related changes in antibody avidity and affinity, there is now mostly consensus that peripheral antibody avidity and affinity seem not to be affected by age (Sasaki et al., 2011; Stiasny et al., 2012). Future studies will have to clarify whether the same holds true for antibodies produced by BM plasma cells.

Additionally, we could confirm previous results that antibody production against tetanus, diphtheria and influenza A in the BM is independent of PB memory B cells (Mamani-Matsuda et al., 2008). Antibody production by BM plasma cells correlated well with peripheral antibody concentrations in the case of tetanus, diphtheria and influenza A. However, CMV-specific BM plasma cells from seropositive persons did not correlate with peripheral antibodies. This may indicate that other lymphoid organs are more important to generate immune responses to CMV reactivation.

As mentioned above, tetanus- and diphtheria-specific plasma cells decrease with age. Peripheral antibody concentrations against tetanus and diphtheria have only a half-life of 10-20 years, which is much shorter than that observed for antibodies against viruses, such as measles and mumps (Amanna et al., 2007). This may suggest that low antibody responses against the former antigens result - at least 
partly - from irregular vaccination intervals (Boraschi et al., 2013). Intrinsic agerelated alterations of the quality of adaptive immune cells and/or the BM niche are still likely to exert additional influence. Both factors may thus contribute to an agerelated loss of protection against some antigens. As intrinsic age-related changes cannot yet be prevented or healed, regular booster vaccinations against tetanus and diphtheria in adults are of importance to ensure continuous protection in old age.

In conclusion, the studies described in this $\mathrm{PhD}$ thesis contribute to a better understanding of memory $\mathrm{T}$ and plasma cells in the human BM as well as their function in young and elderly persons. This knowledge may help to design improved vaccination strategies for elderly persons. 


\section{References to chapter III}

Amanna, I.J., Carlson, N.E., Slifka, M.K., 2007. Duration of humoral immunity to common viral and vaccine antigens. The New England journal of medicine 357:1903-1915.

Boraschi, D., Aguado, M.T., Dutel, C., Goronzy, J., Louis, J., GrubeckLoebenstein, B., Rappuoli, R., Del Giudice, G., 2013. The gracefully aging immune system. Science translational medicine 5:185ps188.

Di Rosa, F., Pabst, R., 2005. The bone marrow: a nest for migratory memory T cells. Trends Immunol 26:360-366.

Franceschi, C., Bonafe, M., Valensin, S., Olivieri, F., De Luca, M., Ottaviani, E., De Benedictis, G., 2000. Inflamm-aging. An evolutionary perspective on immunosenescence. Annals of the New York Academy of Sciences 908:244-254.

Han, S., Yang, K., Ozen, Z., Peng, W., Marinova, E., Kelsoe, G., Zheng, B., 2003. Enhanced differentiation of splenic plasma cells but diminished long-lived high-affinity bone marrow plasma cells in aged mice. Journal of immunology 170:1267-1273.

Hanazawa, A., Lohning, M., Radbruch, A., Tokoyoda, K., 2013. CD49b/CD69Dependent Generation of Resting $\mathrm{T}$ Helper Cell Memory. Frontiers in immunology 4:183.

Herndler-Brandstetter, D., Landgraf, K.,. Jenewein, B, Tzankov, A., Brunauer, R., Brunner, S., Parson, W., Kloss, F., Gassner, R., Lepperdinger, G., Grubeck-Loebenstein, B., 2011. Human bone marrow hosts polyfunctional memory CD4+ and CD8+ T cells with close contact to IL-15-producing cells. Journal of immunology 186:6965-6971.

Herndler-Brandstetter, D., Landgraf, K., Tzankov, A., Jenewein, B., Brunauer, R., Laschober, G.T., Parson, W., Kloss, F., Gassner, R., Lepperdinger, G., Grubeck-Loebenstein, B., 2012. The impact of aging on memory $T$ cell phenotype and function in the human bone marrow. Journal of leukocyte biology 91:197-205. 
Landgraf, K., Brunauer, R., Lepperdinger, G., Grubeck-Loebenstein, B., 2011. The suppressive effect of mesenchymal stromal cells on $\mathrm{T}$ cell proliferation is conserved in old age. Transpl Immunol 25:167-172.

Mamani-Matsuda, M., Cosma, A., Weller, S., Faili, A., Staib, C., Garcon, L., Hermine, O., Beyne-Rauzy, O., Fieschi, C., Pers, J.O., Arakelyan, N., Varet, B., Sauvanet, A., Berger, A., Paye, F., Andrieu, J.M., Michel, M., Godeau, B., Buffet, P., Reynaud, C.A., Weill, J.C., 2008. The human spleen is a major reservoir for long-lived vaccinia virus-specific memory $B$ cells. Blood 111:4653-4659.

Radbruch, A., Muehlinghaus, G., Luger, E.O., Inamine, A., Smith, K.G., Dorner, T., Hiepe, F., 2006. Competence and competition: the challenge of becoming a long-lived plasma cell. Nature reviews. Immunology 6:741-750.

Sasaki, S., Sullivan, M., Narvaez, C.F., Holmes, T.H., Furman, D., Zheng, N.Y., Nishtala, M., Wrammert, J., Smith, K., James, J.A., Dekker, C.L., Davis, M.M., Wilson, P.C., Greenberg, H.B., He, X.S., 2011. Limited efficacy of inactivated influenza vaccine in elderly individuals is associated with decreased production of vaccine-specific antibodies. The Journal of clinical investigation 121:3109-3119.

Stiasny, K., Aberle, J.H., Keller, M., Grubeck-Loebenstein, B., Heinz, F.X., 2012. Age affects quantity but not quality of antibody responses after vaccination with an inactivated flavivirus vaccine against tick-borne encephalitis. PloS one $7: \mathrm{e} 34145$.

Tokoyoda, K., Hauser, A.E., Nakayama, T., Radbruch, A., 2010. Organization of immunological memory by bone marrow stroma. Nature reviews. Immunology 10:193-200.

Ueda, Y., Yang, K., Foster, S.J., Kondo, M., Kelsoe, G., 2004. Inflammation controls B lymphopoiesis by regulating chemokine CXCL12 expression. The Journal of experimental medicine 199:47-58.

Zhang, W., Brahmakshatriya, V., Swain, S.L., 2014. CD4 T cell defects in the aged: causes, consequences and strategies to circumvent. Experimental gerontology 54:67-70. 
CHAPTER IV APPENDIX 


\section{Methodological details}

\section{Sequences of TCR V $\beta$ primers}

Primer sequence of $\mathrm{V} \beta$ primer ( $5^{\prime}-3^{\prime}$ direction)

\begin{tabular}{|c|c|}
\hline Vß1 & CAG TTC CCT GAC TTG GAC TC \\
\hline VB2 & GCT TCT ACA TCT GCA GTG C \\
\hline Vß3 & GAG AGA AGA AGG AGC GCT TC \\
\hline VB4 & GCA GCA TAT ATC TCT GCA GC \\
\hline Vß5.1. & CTC GGC CCT TTA TCT TTG CG \\
\hline Vß5.3. & CCC TAA CTA TAG CTC TGA GC \\
\hline Vß6.1. & GAT CCA GCG CAC AGA GC \\
\hline Vß6.2. & GAT CCA GCG CAC AGA GC \\
\hline Vß7 & CCT GAA TGC CCC AAC AGC \\
\hline Vß8 & GAA CCC AGG GAC TCA GC \\
\hline V $\beta 9$ & GGA GCT TGG TGA CTC TGC TG \\
\hline Vß11 & CAG GCC CTC ACA TAC CTC TCA \\
\hline VB12 & CAA AGA CAG AGG ATT TCC TCC \\
\hline Vß13 & GTC GGC TGC TCC CTC CC \\
\hline Vß14 & GTC TCT CGA AAA GAG AAG AGG \\
\hline Vß15 & GTC TCT CGA CAG GCA CAG GC \\
\hline Vß16 & GAA CTG GAG GAT TCT GGA GTT \\
\hline Vß17 & CCA AAA GAA CCC GAC AGC TTT C \\
\hline Vß18 & GTG CGA GGA GAT TCG GCA GCA GC \\
\hline VB20 & CAC ACC CAA GGA CCG GCA G \\
\hline VB21 & GGC TCA AAG GAG TAG ACT CC \\
\hline VB22 & GTT GAA AGG CCT GAT GGA TC \\
\hline VB23 & CAG TTC AGT GAC TAT CAT TCT G \\
\hline Vß24 & GGG GAC GCA GCC ATC TAC C \\
\hline constant primer & GCT TCT GAT GGC TCA AAC ACA G \\
\hline
\end{tabular}




\section{Buffers}

\section{Cell number determination}

Trypan blue

Trypan blue stock solution (0.5\%) $\quad 1 \mathrm{ml}$

PBS 9ml

\section{Cell culture}

RPMI 1640 complete

RPMI 1640 with 25mM Hepes and L-glutamine FCS

$10 \%$

Penicillin/Streptomycin

$1 \%$

MACS buffer

BSA

$5 \mathrm{~g}$

EDTA

$0.7445 \mathrm{~g}$

PBS

11

PBS (pH 7.3)

Aqua bidest

101

$\mathrm{KCl}$

$2 \mathrm{~g}$

$\mathrm{KH}_{2} \mathrm{PO}_{4}$

$2 \mathrm{~g}$

$\mathrm{NaCl}$

$80 \mathrm{~g}$

$\mathrm{Na}_{2} \mathrm{HPO}_{4}{ }^{*} 2 \mathrm{H}_{2} \mathrm{O}$

$14.5 \mathrm{~g}$ 


\section{ELISPOT analysis}

$\mathrm{CO}_{3}$ - buffer ( $\mathrm{pH}$ 9.6)

$\mathrm{Na}_{2} \mathrm{CO}_{3}$

$0.318 \mathrm{~g}$

$\mathrm{NaHCO}_{3}$

$0.586 \mathrm{~g}$

FACS analysis

FACS Sheath

Aqua bidest

201

$\mathrm{KCl}$

$5.6 \mathrm{~g}$

$\mathrm{KH}_{2} \mathrm{PO}_{4}$

$5.2 \mathrm{~g}$

$\mathrm{NaCL}$

$162.4 \mathrm{~g}$

$\mathrm{Na}_{2} \mathrm{HPO}_{4}{ }^{*} 2 \mathrm{H}_{2} \mathrm{O}$

$47 \mathrm{~g}$

Lithium chloride

$8.6 \mathrm{~g}$

Thiomersal

$2 \mathrm{~g}$

Triplex III

$7.2 \mathrm{~g}$ 


\section{Reagents}

Anti-CD3

Anti-lgG

Anti-lgG mAb

BCIP/NBT Chromogen

Brefaldin A

BSA

CCR7 mAb

CD3 mAb

CD4 mAb

CD8 mAb

CD19 mAb

CD27 mAb

CD28 mAb

CD38 mAb

CD45RA mAb

CD69 mAb

Carboxyfluorescein succinimidyl ester

CMV ELISA Kit

CMV NLVPMVATV peptide

CMV pp65 Pro5 ${ }^{\circledR}$ MHC Pentamer

Collagenase

Cytofix/Cytoperm Kit

Diphtheria Toxoid

Ethylenediamine tetraacetic acid (EDTA)

Ethanol

EZ-Link Sukfo-NHS-LC-Biotinylation Kit

Fetal Calf Serum (FCS)

Ficoll Hypaque

Heparin
BD Pharmingen, USA

BD Pharmingen, USA

Mabtech, Sweden

Moss Inc., USA

Sigma Aldrich, Austria

Sigma Aldrich, Austria

R\&D Systems, USA

eBioscience, Austria

BD Pharmingen, USA

BD Pharmingen, USA

BD Pharmingen, USA

Biolegend, USA

BD Pharmingen, USA

BD Pharmingen, USA

BD Pharmingen, USA

BD Pharmingen, USA

Molecular Probes, Austria

Siemens, Germany

Bachem, Switzerland

Proimmune, United Kingdom

Worthington Biochemical Corp., USA

BD Pharmingen, USA

Statens Serum Institute, Denmark

Merck, Germany

Invitrogen, Austria

Pierce, USA

Sigma Aldrich, Austria

GE Healthcare Biosciences AB,

Sweden

Baxter, USA 
HLA-A2 mAb

HotStarTaq Master Mix Kit

IL-2

IL-2 mAb

IL-15

IFN-Y mAb

Influenza A ELISA Kit

lonomycin

Measles ELISA Kit

Mumps ELISA Kit

Nuclease free water

PBS

Penicillin/Streptomycin 100x

Peroxidase-labeled rabbit anti-human IgG

PMA

PWM

Oligodeoxynucleotides (ODN) 2006 control

RNeasy Plus Mini Kit

RPMI 1640

SAC

Streptavidin-ALP

Tetanus Toxoid

Thiomersal

Titriplex III

TNF- $a$ mAb

Tris-HCL

Trypan blue

Tween 20
BD Pharmingen, USA

Quiagen, Germany

Novartis, Switzerland

BD Pharmingen, USA

Merck Millipore, Germany

BD Pharmingen, USA

Immunolab, Germany

Sigma Aldrich, Austria

Virion\Serion, Germany

Virion\Serion, Germany

Promega, USA

Gibco, USA

PAA Laboratories, Austria

Merck Millipore, Germany

Sigma Aldrich, Austria

Sigma Aldrich, Austria

InvivoGen, France

Quiagen, Germany

Sigma Aldrich, Austria

Sigma Aldrich, Austria

Mabtech, Sweden

Statens Serum Institute, Denmark

Merck, Germany

Merck, Germany

BD Pharmingen, USA

Sigma-Aldrich, Austria

Serva, Germany

Merck, Germany 


\section{Additional manuscript I}

The aging bone marrow and its impact on immune responses in old age.

Theresa Pritz ${ }^{\mathrm{a}}$, Birgit Weinberger ${ }^{\mathrm{a}}$, Beatrix Grubeck-Loebenstein ${ }^{\mathrm{a}}{ }$

a Institute for Biomedical Aging Research, Universität Innsbruck, Rennweg 10, Innsbruck, Austria

$\S$ Corresponding author

Immunology Letters 2014, pii: S0165-2478(14)00129-1. doi: 10.1016/j.imlet. 2014.06.016

This article is available from http://www.sciencedirect.com/science/article/pii/S016524781400129 
The aging bone marrow and its impact on immune responses in old age.

Theresa Pritz $^{\mathrm{a}}$, Birgit Weinberger ${ }^{\mathrm{a}}$, Beatrix Grubeck-Loebenstein ${ }^{\text {a }}$

a Institute for Biomedical Aging Research, Universität Innsbruck, Rennweg 10, Innsbruck, Austria

§ Corresponding author: beatrix.grubeck@uibk.ac.at

Rennweg 10

6020 Innsbruck, Austria

+4351250750810 


\section{Abstract}

With aging the immune system undergoes significant age-related changes. These age-dependent changes are referred to as immunosenescence and are partially responsible for the poor immune response to infections and the low efficacy of vaccination in elderly persons. Immunosenescence is characterized by a decrease in innate and adaptive cell-mediated immune function in the peripheral blood and the bone marrow. The aging of bone marrow cells and in particular, of adaptive immune cells in the bone marrow has been addressed relatively rarely. It is therefore the goal of this review to summarize what is known about the effect of age on bone marrow immune cells and their precursors in mice and humans. 


\section{Immunosenescence: where do we stand?}

The aged immune system undergoes significant age-related changes and numerous of its physiological functions decrease, leading to the increased incidence and severity of infections, poor responses to vaccination as well as an increased susceptibility to cancer [1-4]. These alterations of the immune system are being referred to as immunosenescence [5]. Immunosenescence affects many components of the innate and adaptive immune system.

The innate immune system represents the first line of defense against pathogens. Aging of the innate immune system is associated with a diminished function of epithelial barriers of the skin, lung or gastrointestinal tract, which enables pathogens to more reliably invade mucosal tissues, resulting in an increased challenge for the innate immune system in old age [6,7]. Beside phagocytic cells and NK cells, Interleukin-6 (IL-6), IL-1 $\beta$ and tumor-necrosis factor-alpha (TNF- $\alpha$ ) have been postulated as predictive markers of functional disability, frailty and mortality in elderly people $[8,9]$.

Whereas the innate immune system is less affected by aging, the adaptive immune system experiences significant alterations in lymphocyte population composition in the periphery and secondary lymphoid organs [10]. Within the adaptive immune system aging leads to substantial alterations of the B and the T cell compartment in humans and mice $[9,11]$. While age-dependent alterations of the B cell pool are less pronounced [12], changes of the $\mathrm{T}$ cell pool have been well studied and are one hallmark of immunosenescence. Naïve $T$ cell counts are reduced in the periphery and lymphoid organs $[13,14]$, whereas the numbers of memory and terminally differentiated effector cells increase with age. The initial trigger responsible for agerelated changes of the $T$ cell pool is the involution of the thymus, the $T$ cell maturation 
organ. With aging the functional thymic mass decreases which results in a diminished output of naïve T cells. As a consequence, homeostatic forces have to assure cell survival and to maintain T cell numbers $[11,15]$.

These alterations are more pronounced in $\mathrm{CD}^{+}$than in $\mathrm{CD} 4^{+} \mathrm{T}$ cells and can be accelerated by pathogens themselves, such as for instance the Cytomegalovirus (CMV) $[16,17]$. Although latent persistent CMV infection is systemically controlled by the immune system and only during times of reactivation viral particles are detectable, life-long exposure to CMV severely impairs the T cell system. Due to repeated reactivation of the virus followed by rounds of division of CMV-specific $T$ cells, the number of highly differentiated $C D 4^{+}$and $C D 8^{+} T$ cells increases $[11,18,19]$. Terminally differentiated effector $T$ cells lack the costimulatory molecule CD28, a member of the tumor necrosis family that interacts with CD80 and/or CD86 expressed on activated antigen-presenting cells. Along with an appropriate TCR/MHC interaction, CD28 signaling provides the stimulus to achieve full $\mathrm{T}$ cell activation [20]. The loss of CD28 signaling has also been associated with decreased telomerase activity [21], which further contributes to the exhaustion of CD28- $\mathrm{T}$ cells. The loss of the co-stimulatory molecule CD28 is associated with a change of cellular function in T cells including decreased activation and proliferation as well as impaired ability to secrete IL-2, but high levels of cytotoxic mediators (granzymes and perforine) as well as proinflammatory cytokines that enable these cells to exhibit effector functions [11,22]. Due to their pro-inflammatory properties, terminally differentiated CD28- $\mathrm{T}$ cells are believed to contribute to a low-grade inflammatory background commonly observed in old persons, which has been referred to as "inflamm-aging" [23]. 
So far, most studies on the aging of the immune system have been performed on spleen and lymph node cells in mice and on peripheral blood (PB) in humans. The aging of bone marrow (BM) cells, and in particular, of adaptive immune cells in the BM has been addressed relatively rarely. In this review we will therefore specifically focus on the BM and its role for the maintenance of immunological memory in old age. 


\section{The bone marrow: The hematopoietic organ and age-related changes}

The BM is the primary organ of hematopoiesis and is responsible for the generation of precursors to innate and adaptive immune cells. It is well understood that the amount of hematopoietic tissue decreases in the BM with age and is gradually replaced by fat tissue [24]. Hematopoietic stem cells (HSC) reside in the BM within a specialized microenvironment, the HSC niche. Human and animal studies have demonstrated that HSCs, which have a high potential for self-renewal and differentiation, are affected by age. Aged HSCs have an impaired ability to proliferate and have shortened telomeres, which may affect their proliferative and developmental capacity [25]. Furthermore, with age, the hematopoietic microenvironment changes and processes such as hematopoiesis become quiescent, while the deposition of adipose tissue increases. As a result of these changes B and T lymphopoiesis is decreased [10]. In contrast, the output of myeloid cells is maintained or even increases with age [10,25-27].

Defects in B cell generation have been described, as age has an impact on B cell development [12]. In mice, it has been shown that fewer pro-B cells are generated and their transition to pre-B cells is decreased due to impaired V-D-J heavy chain gene recombination [28]. This results, at least partly, from changes in the expression and activity of the E2A encoded transcription factors E12 and E47. E12 and E47 are key regulators of B cell function. They promote early pre-B cell survival, initiate Ig rearrangement and are involved in class switching of mature B cells in the periphery. It has been shown that aged BM pro-B/pre-B cell precursors exhibit a reduced expression of E2A proteins and have a reduced ability to bind DNA [29]. Another explanation for a decreased overall transit from pro- to pre-B cells with age could be 
due to a suboptimal expression of Interleukin-7 (IL-7) in old age. IL-7 is expressed by stromal cells and induces proliferation and transition induction of pre-B cell differentiation $[10,30,31]$.

\section{The bone marrow: a secondary lymphoid organ and age-related changes}

Over the last decades it has become clear that the BM also plays an important role as a secondary lymphoid organ [32]. While its capacity to house long-lived plasma cells $[33,34]$ and its role in supporting memory $T$ cell survival $[35-38]$ have been studied in mice and humans, less is known about changes during aging [39].

Upon stimulation of the immune system with a T cell-dependent antigen, high affinity memory B cells and plasma cells are generated in the germinal centers (GC) of secondary lymphoid organs. Within the GC, the variable region gene segments of the antibody genes undergo hypermutation and cells with high affinity receptors are selected to differentiate into memory B cells and plasma cells. While memory B cells mainly relocate and remain in the spleen, plasmablasts leave the GC, enter the blood stream and home to the BM guided by a chemotactic response. CXCR4 is a chemokine receptor for stromal cell-derived factor 1 (SDF-1) and thereby regulates B lymphopoiesis [40]. However, interaction of CXCR4 with its ligand CXCL12 allows plasmablasts to lodge in the BM and differentiate into plasma cells [41]. Studies in chimeric mice demonstrate that, in mice which were reconstituted with CXCR4deficient fetal liver cells, plasma cells fail to accumulate in the BM [42].

BM eosinophils are also an important factor for the proper development of plasmablasts to plasma cells $[41,43]$. It has been shown in GATA 1-depleted mice, 
which lack eosinophils, that the maturation of plasmablasts into plasma cells is impaired [43]. Plasma cells can survive in distinct BM survival niches for a long period of time, probably years, without DNA synthesis, or cell division, but highly activated in terms of protein synthesis as they constitutively produce antibodies [44]. A study by Manz et al. demonstrated that $60 \%$ of OVA-specific plasma cells survive up to 120 days in the murine BM [45].

It has been demonstrated in mice that plasma cells of both low and high affinity are diminished in the BM of aged mice compared to young animals. These results suggest that two mechanisms contribute to an impaired humoral immune response in old age: (1) Due to the diminished germinal center activity, lower numbers of high affinity antibody-secreting cells are generated, (2) The long-term survival of antibodysecreting cells in the BM is impaired due to alterations of the BM environment [46]. Ueda et al. also demonstrated that TNF- $\alpha$ mediated inflammation suppresses CXCL12 expression and, as a consequence the homing of plasmablasts to the BM [47]. Therefore, a low-grade inflammatory background induced by pro-inflammatory cytokines ("inflamm-aging") [23] could be associated with a decrease of CXCL12 expression as well as plasma cell numbers in the aged BM. Still, little is known about age-related changes of plasma cells in the human BM. Recent data from our group suggest that the percentage of BM plasma cells decreases with age in humans. We also observed that CXCL12 mRNA expression declines in human BM in an agedependent manner (Pritz et al., manuscript submitted).

It has been postulated that the BM also plays a major role in the long-term survival of memory $\mathrm{T}$ cells. First studies demonstrated that murine primed $\mathrm{CD} 4^{+} \mathrm{T}$ cells migrate to the BM and contribute to the development of memory antibody responses [48]. A study in mice demonstrated that animals which were tracked with LCMV-specific 
CD4 ${ }^{+} \mathrm{CD} 44^{\mathrm{hi}} \mathrm{T}$ cells were mainly present in spleen and lymph nodes but not in BM after 4 days. The number of $C D 4{ }^{+} C D 44^{\text {hi }} T$ cells decreased in the spleen and lymph nodes from day 28 onwards, whereas in the BM their number increased. More than $80 \%$ of total $\mathrm{CD}^{+}{ }^{+} \mathrm{T}$ cells resided in the BM from day 60 onwards. They persisted in the $\mathrm{BM}$ at constant numbers for more than 134 days which was the period of observation. In another experiment, which was performed to analyze the immune response to ovalbumin as well as KLH and complete Freund's adjuvant, antigenspecific memory $\mathrm{CD} 4^{+} \mathrm{T}$ cells migrated to the $\mathrm{BM}$ with similar kinetics and remained there constant for more than 90 days [35].

Further studies showed that memory $\mathrm{CD}^{+} \mathrm{T}$ cells relocated to the BM and survived there $[32,49]$. It was shown that the BM contained one of the largest pool of antigenspecific $\mathrm{CD}^{+} \mathrm{T}$ cells. In one of these studies memory responses using P14 transgenic $T$ cells, which are specific for the DbGP33-41 LCMV epitope, were analyzed. Transgenic T cells were transferred into B6 mice one day before LCMV infection and memory $\mathrm{CD} 8^{+} \mathrm{T}$ cells were analyzed at $\sim 60$ days post infection. P14 memory $\mathrm{CD}^{+} \mathrm{T}$ cells were still detectable in the BM at this time point [49].

Additionally it has been demonstrated that murine memory $\mathrm{CD} 4^{+} \mathrm{T}$ cells migrating to the $\mathrm{BM}$ utilize $\mathrm{CD} 49 \mathrm{~b}$ and $\mathrm{CD} 69$ and survive in the BM as resting but highly reactive cells [35]. CD49b (alpha 2 integrin) forms the adhesion molecule very late activation antigen-2 (VLA-2), which serves as a collagen receptor (collagens I, II and XI) and is involved in cell adhesion [36,50-53]. Hanazawa et al. demonstrated that CD49b is required for murine memory $C D 4^{+} \mathrm{T}$ cell trafficking to the $\mathrm{BM}$ survival niche $[36,50]$. CD69 is a type II membrane protein and belongs to the C-type lectin family $[54,55]$. CD69 is considered to be an activation marker, expressed by activated $T$ cells [50,54-56]. However, in the murine system CD69-deficient CD4 T cells fail to facilitate 
the generation of BM long-lived plasma cells in the late phase of immune responses. Therefore, CD49b and CD69 are essential to the homing of memory $\mathrm{CD} 4^{+} \mathrm{T}$ cells to the BM $[36,50,54]$.

Little is also known about the relocation of human memory $\mathrm{T}$ cells to the BM and their survival. First studies in humans demonstrated that a large number of mature, indigenous $\mathrm{T}$ cells with a predominantly cytotoxic phenotype are located in the BM [57]. Years later, it was documented by Vavassor et al. that human BM grafts from donors immunized against tetanus contain anti-tetanus memory $\mathrm{CD} 4^{+} \mathrm{T}$ cells which persist in the recipients for many years following transplantation [58]. Later it was demonstrated that the number of $\mathrm{CD} 45 \mathrm{RA}{ }^{+} \mathrm{CD} 27^{-} \mathrm{CD} 4{ }^{+} \mathrm{T}$ cells increases in the $\mathrm{BM}$ of persons latently infected with CMV [59]. As CMV-specific T cells frequently have this particular phenotype, this observation may be regarded as another indication that memory $T$ cells accumulate in the BM.

Our group could recently show that total numbers of $\mathrm{CD} 4^{+}$and $\mathrm{CD} 8^{+} \mathrm{T}$ cells in the $\mathrm{BM}$ are not affected, but that the size of $\mathrm{CD}^{+}$and $\mathrm{CD} 8^{+} \mathrm{T}$ cell subsets in the $\mathrm{BM}$ changes with age [39]. Similar to the situation in the PB [11,13], naïve $C D 4^{+}$and $\mathrm{CD}^{+} \mathrm{T}$ cells decrease and an age-dependent increase of $\mathrm{CD} 4^{+}$effector memory $\mathrm{T}$ cells (TEM) and CD8 ${ }^{+}$effector memory RA+ $T$ (TEMRA) cells occur in the BM (Figure 1) $[39,60]$. In contrast, the frequency of central memory (Tсм) as well as CD4+ TEMRA and $\mathrm{CD} 8^{+}$effector memory $\mathrm{T}$ cells does not change in the BM with age. The ratios of T cell subsets between PB and BM show characteristic age-related changes. During aging the $\mathrm{PB} / \mathrm{BM}$ ratio of naïve $\mathrm{CD} 4^{+} \mathrm{T}$ cells $(1.3 \pm 0.1$ and $1.9 \pm 0.3 ; p<0.05)$, naïve CD8 ${ }^{+} T$ cells $(1.3 \pm 0.1$ and $2.2 \pm 0.4 ; p<0.05)$ and CD4 ${ }^{+}$TemRA cells $(0.8 \pm 0.1$ and $1.2 \pm 0.1 ; p<0.05)$ increases [39]. These results suggest that the age-related decline of naïve T cells is more pronounced in the BM than in the PB. Furthermore, a higher 
number of polyfunctional $\mathrm{CD} 4^{+}$and $\mathrm{CD} 8^{+} \mathrm{T}$ cells, which produce IFN- - , TNF- $\alpha$ and Interleukin (IL)-2 simultaneously, resides in the BM than in the PB. The relatively high percentage of polyfunctional T cells in the BM is characteristically maintained during aging (Figure 2) [39].

As the BM has been shown to support homeostatic $\mathrm{T}$ cell activation and proliferation in humans and mice $[37,49]$, the impact of aging on the activation state of $C D 4^{+}$and $\mathrm{CD}^{+} \mathrm{T}$ cells in the human BM has been investigated by our group. The frequency of CD69-expressing $C D 4^{+} \mathrm{T}$ cells is not influenced by age, while the number of CD69expressing $\mathrm{CD}^{+} \mathrm{T}$ cells is increased in the BM of elderly persons [39]. Data on the comparison of the BM and PB T cell receptor (TCR) repertoire using immunoscope technique revealed that the BM TCR repertoire is of similar diversity as the PB one. In particular, by classifying the TCR CD3 length profiles as monoclonal, oligoclonal and polyclonal, no significant differences were observed between unstimulated $T$ cells from the BM and PB. Thus, the relatively diverse TCR repertoire in the BM suggests that the heightened activation state of $T$ cells and the accumulation of CD69-expressing $\mathrm{T}$ cells in the BM is not due to an excessive antigen-driven $\mathrm{T}$ cell immune response and clonal expansion [37].

In PB CD8 ${ }^{+} \mathrm{T}$ cell aging is associated with the loss of CD28 and the acquisition of CD57 [61-63]. CD57 is a late differentiation marker and CD57 expression on human T cells has been described as marker of in vitro replicative senescence [62]. High CD57 expression can be found in memory $C D 8^{+} T$ cells specific for persistent viral infections, such as CMV [64]. Our group could show that the percentage of $\mathrm{CD}^{+}{ }^{+} \mathrm{CD} 28^{-} \mathrm{T}$ cells increases in the $\mathrm{BM}$ and in $\mathrm{PB}$ during aging. In contrast, $\mathrm{CD}^{+} \mathrm{CD} 57^{+} \mathrm{T}$ cells increase in the $\mathrm{PB}$, whereas only a low number of highly differentiated $\mathrm{CD} 8{ }^{+} \mathrm{CD} 57^{+} \mathrm{T}$ cells accumulate in the $\mathrm{BM}$ of elderly persons. This 
indicates that the life-long homeostatic renewal of memory $\mathrm{CD}^{+} \mathrm{T}$ cells in the $\mathrm{BM}$ leads to the accumulation of $\mathrm{CD} 8^{+} \mathrm{CD} 28^{-} \mathrm{T}$ cells but not of $\mathrm{CD}^{+}{ }^{+} \mathrm{CD} 57^{+} \mathrm{T}$ cells [39].

First studies on age-related changes of the human BM T cell pool and T cell function were performed on samples derived from iliac crest. lliac crest BM samples were obtained from patients undergoing reconstructive surgery and bone remodeling of the jaw following accidents or surgical dental implantation. This approach is satisfactory because, BM cells can be obtained from healthy young and elderly donors. However, a disadvantage lies in the fact that the samples are generally very small, with a low yield $\left(\sim 5 \times 10^{6}\right)$ of bone marrow mononuclear cells (BMMC) [37,39]. For many research questions, higher cell numbers are needed. Therefore, BM from the femur shaft was obtained from patients undergoing total hip replacement and was compared to BM from iliac crest. The results show no differences in the characteristics of $T$ cell subpopulations in the BM from either tissue source. BMMCs from the femur shaft can therefore be used in order to obtain higher cell numbers

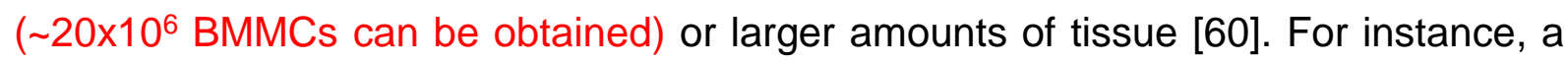
more detailed description of the cytokine profile of BM T cells can be performed using this approach. Thus, in addition to previous data $[37,39]$, we could now show that in the BM of elderly persons, naïve CD4+ and CD8 ${ }^{+} \mathrm{T}$ cells produce only IL-2 or TNF- $\alpha$, while more differentiated T cells produce either a combination of IFN- $\gamma$ and TNF- $\alpha$ or IL-2 and TNF- $\alpha[60]$.

Furthermore, larger sample sizes allow the generation of $T$ cell lines using nonspecific and specific stimulation. Such $T$ cell lines do not change their phenotype after anti-CD3 antibody and IL-2 stimulation during long term culture and can be used for studies on the interaction of T cells with different types of BM cells. We showed that BM stromal cells do not have a suppressive effect on the proliferation of BM 
derived $\mathrm{T}$ cell lines in the presence of IL-15 or a combination of anti-CD3 antibody and IL-2 [60].

Moreover, our group could demonstrate that $\mathrm{CMV}_{\mathrm{NLV}}$-specific $\mathrm{T}$ cell lines can be used for studies on the clonal composition of antigen-specific BM T cells. For this analysis, BMMCs and peripheral blood mononuclear cells (PBMCs) were stimulated with CMVNLV peptide for two weeks. The obtained data indicated that the clonal composition of a CMVNLV-specific T cell population is different in the BM and PB, with the exception of $V \beta 8^{+}$and $V \beta 13^{+} \mathrm{T}$ cells $[65,66]$, which are known to dominate $\mathrm{CMV}_{\mathrm{NLV}}$-specific responses. These data also suggest that, in spite of overall similarity of the $\mathrm{T}$ cell receptor pool the $\mathrm{CMV}_{\mathrm{NLV}}$-specific $\mathrm{T}$ cell repertoire in the $\mathrm{BM}$ is more restricted than in the PB [60].

\section{The bone marrow niche}

In the BM different microenvironmental niches are present, including those for HSCs. The HSC niche in the BM is formed by HSCs and non-HSCs, such as subendosteal osteoblasts, sinusoidal endothelial cells, adipocytes and mesenchymal stromal cells (MSC) $[25,38,67,68]$. The HSC niche undergoes several age-related changes. With age, the number of osteoblasts declines, resulting in decreased osteogenesis in elderly persons. Furthermore, the number of adipocytes increases as a result of a skewed differentiation potential of aged MSCs. MSCs are characterized by the expression of CXCL12 $[69,70]$ which is reduced in elderly persons and during inflammation [25]. This loss of CXCL12 disturbs the delicate balance of regulatory networks necessary to govern tissue-specific regeneration and remodeling, as well as the migration of plasmablasts to the BM $[47,69]$. 
A specific subpopulation of MSCs expresses vascular cell adhesion molecule 1 (VCAM1) and platelet-derived growth factor receptor- $\alpha$ (PDGFRa), but not stem cell antigen 1 and platelet endothelial cell adhesion molecule 1 (PECAM1). In contrast to other MSCs, these cells do not have the developmental potential to differentiate into osteoblasts, chondrocytes or adipocytes. Their high CXCL12 expression and their developmental stability suggest that they may provide a survival niche for plasma cells, although no data are available to support this claim [38].

Recently, an interesting new concept for the organization of adaptive immune cells in the BM has been put forward $[38,50]$. On the basis of murine data, it was suggested that plasmablasts home to the BM and differentiate into plasma cells, which are in close contact with $\mathrm{CXCL} 12^{+} \mathrm{IL7}$-VCAM1+ stromal cells and survive in distinct BM survival niches. BM plasma cells obtain survival factors from CXCL12-expressing stromal cells [70,71], A proliferation-inducing ligand (APRIL)- and IL-6-expressing megakaryozytes [72] as well as BM-derived eosinophils which are necessary for the proper development of plasmablasts to plasma cells and provide survival factors for long-term maintenance of plasma cells in the BM $[38,41,73]$.

Moreover, studies in mice demonstrated that memory $\mathrm{CD}^{+} \mathrm{T}$ cells relocate to the $\mathrm{BM}$ and survive in distinct survival niches for a prolonged period of time. As mentioned above, memory $\mathrm{CD} 4{ }^{+} \mathrm{T}$ cells migrate to the BM utilizing CD49b and CD69 $[36,50,54]$ and interact with CXCL12-IL-7+VCAM1+ stromal cells that support their maintenance by expressing IL-7. Moreover memory CD4+ $T$ cells express $\mathrm{Bcl}-2$ [38]. $\mathrm{Bcl}-2$ is an anti-apoptotic molecule, the expression which is upregulated in response to IL-7 during a 6 day culture period of murine cells [74]. Therefore, IL-7 and Bcl-2 are required for survival of memory $\mathrm{CD} 4^{+} \mathrm{T}$ cells in the BM [75]. 
In humans, memory CD4+ $\mathrm{T}$ cells also rely on IL-7. However, controversial data have been published on IL-7 production in old age. While one study demonstrated that compared with the young, the elderly had decreased serum IL-7 levels which positively correlated with the frequency of effector memory $\mathrm{CD} 4^{+} \mathrm{T}$ cells [76], another study showed that IL-7 and IL-7 receptor alpha chain (CD127) levels were the same at all ages [77]. However, our group could demonstrate that IL-6 and IL-15 production in the BM is increased in elderly persons [37]. IL- 6 and IL-15 support memory CD8+ cell activation, proliferation and differentiation and may therefore induce the accumulation of $\mathrm{CD}^{+}{ }^{+} \mathrm{CD} 28^{-} \mathrm{T}$ cells in the BM $[37,49,78]$. IL-15 is produced by a variety of stroma-like cell types in the human BM, such as stromal cells, monocytes and dendritic cells [79-81]. In mice it has been shown that IL-15 is primarily expressed by BM VCAM1+ stromal cells [82]. But whether this is also the case in humans, is not yet clear. IL-15 producing cells with a stromal cell-like morphology have been shown to be in close vicinity of $\mathrm{CD}^{+} \mathrm{T}$ cells in the human BM. The increased expression of IL-15 responsive genes, such as the anti-apoptotic molecule

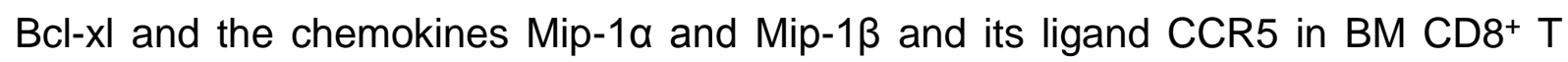
cells, supports the notion that IL-15 actually interacts with CD8 ${ }^{+} \mathrm{T}$ cells and that IL-15 producing cells may serve as a niche for the maintenance of $\mathrm{CD} 8^{+} \mathrm{T}$ cells in the BM [37]. In this context it is also of interest that IL-15 signaling increases with $\mathrm{T}$ cell differentiation and that IL-15 rescues $\mathrm{CD}^{+}{ }^{+} \mathrm{CD} 28^{-} \mathrm{T}$ cells from apoptosis [83].

\section{Do altered bone marrow niches contribute to impairments of}

\section{immunological memory in old age?}

In conclusion, the BM is a primary and secondary lymphoid organ that is affected by aging. Age alters hematopoiesis in the BM, and affects HSC as well as B and T 
lymphopoiesis. Furthermore, the BM provides survival niches for plasma cells and memory $\mathrm{T}$ cells and functions as a secondary lymphoid organ. The composition of BM niches seems to be affected by aging. The age-related increase in the production of IL-15 seems to support the accumulation of memory CD8 ${ }^{+} \mathrm{T}$ cells, which frequently have a highly differentiated phenotype. This may lead to a displacement and/or functional impairment of other BM niches and their resident lymphocytes, such as $\mathrm{CD}^{+} \mathrm{T}$ cells and plasma cells. A reduction in the number of long-lived plasma cells in the BM may thus result in decreased antibody production. 


\section{Conflict of interest}

The authors declare no conflicts of interest.

\section{Acknowledgment}

We thank Kai Kosog for critically reading the manuscript.

The work is supported by D. Swarovski KG.

\section{Vitae}

\section{THERESA PRITZ}

Theresa Pritz studied Molecular Biology in Vienna, Austria. Since 2011 she is doing her $\mathrm{PhD}$ at the Institute for Biomedical Aging Research in Innsbruck, Austria. Her research focuses on the aging bone marrow and its impact on adaptive immune responses in old age.

\section{BIRGIT WEINBERGER}

Birgit Weinberger studied biology in Regensburg, Germany and Boulder, CO, USA, and holds a PhD from the Institute for Medical Microbiology and Hygiene of the University of Regensburg, where she worked on the role of Epstein-Barr Virus in transplant recipients. Since 2005 she has been working at the Institute for Biomedical Aging Research as a senior scientist. Her research focuses on the role of Cytomegalovirus in T cell senescence and on vaccine-induced immune responses in the elderly. 


\section{BEATRIX GRUBECK-LOEBENSTEIN}

Beatrix Grubeck-Loebenstein is Professor for Immunogerontology at the University of Innsbruck, Austria, and Head of its Institute for Biomedical Aging Research. Her main research goal is to find new ways to prevent $T$ cell function from declining as a person grows older and to optimize vaccinations in elderly people. Dr. GrubeckLoebenstein received her medical doctoral degree from Vienna University and her training in Basic Immunology at Prof. Marc Feldmann's laboratory at the Kennedy Institute of Rheumatology, London, UK. She has published more than 200 research papers and book chapters and is an editorial board member of numerous scientific journals. 


\section{Figure legends}

Figure 1: The impact of aging on $\mathrm{CD}^{+}$and $\mathrm{CD}^{+} \mathrm{T}$ cells in the $\mathrm{BM}$. $A$, The graphs show the impact of aging on $B M C D 4^{+}$naïve $T$ cells $\left(T_{N} ; C D 45 R A^{+} C C R 7^{+}\right)$ and BM-derived effector memory CD4 ${ }^{+} \mathrm{T}$ cells (TEM; CD45RA-CCR7-). $\mathrm{CD}^{+}{ }^{+} \mathrm{CD} 4^{+}{ }^{+} \mathrm{T}$ cells were considered as $100 \%$. $B$, The graphs show the impact of aging on $\mathrm{CD}^{+} \mathrm{T}_{\mathrm{N}}$ $\left(\mathrm{CD} 45 \mathrm{RA}^{+} \mathrm{CCR} 7^{+}\right)$and $\mathrm{CD}^{2} 5 \mathrm{RA}^{+}$expressing effector memory $\mathrm{T}$ cells (TEMRA; $\mathrm{CD}^{2} \mathrm{RA}^{+}{ }^{+} \mathrm{CCR} 7^{-}$) from the BM. $\mathrm{CD}^{+}{ }^{+} \mathrm{CD}^{+}{ }^{+} \mathrm{T}$ cells were considered as $100 \%$. BMMCs were analyzed by flow cytometric analysis. Unpublished data from 8 donors are shown which confirm previous results from our group [39].

Figure 2: The frequency of polyfunctional $\mathrm{CD}^{+}$and $\mathrm{CD} 8^{+} \mathrm{T}$ cells in the $\mathrm{BM}$ and PB of young and elderly healthy persons. The pie charts show the percentage of $\mathrm{CD}^{+}$and $\mathrm{CD}^{+} \mathrm{T}$ cells producing one (white), two (grey) or three cytokines (black). The cells were stimulated for 15 hours with PMA and lonomycin in the presence of Brefaldin A and the production of IFN- $\mathrm{y}, \mathrm{IL}-2$ and TNF- $\alpha$ was analyzed. Mean values from seven young and five elderly donors are shown.

From Herndler-Brandstetter et al., J Leuk Biol 2012 [39], reproduced with the kind permission of Elsevier. 


\section{References}

[1] Boraschi D, Aguado MT, Dutel C, Goronzy J, Louis J, Grubeck-Loebenstein B, et al. The gracefully aging immune system. Sci Transl Med 2013;5:185ps188.

[2] Gavazzi G, Krause KH. Ageing and infection. Lancet Infect Dis 2002;2:659666.

[3] Grubeck-Loebenstein B, Berger P, Saurwein-Teissl M, Zisterer K, Wick G. No immunity for the elderly. Nat Med 1998;4:870.

[4] Pawelec G, Lustgarten J, Ruby C, Gravekamp C. Impact of aging on cancer immunity and immunotherapy. Cancer Immunol Immunother 2009;58:19071908.

[5] McElhaney JE, Effros RB. Immunosenescence: what does it mean to health outcomes in older adults? Curr Opin Immunol 2009;21:418-424.

[6] Gomez CR, Boehmer ED, Kovacs EJ. The aging innate immune system. Curr Opin Immunol 2005;17:457-462.

[7] Nomellini V, Gomez CR, Kovacs EJ. Aging and impairment of innate immunity. Contrib Microbiol 2008;15:188-205.

[8] Shaw AC, Joshi S, Greenwood H, Panda A, Lord JM. Aging of the innate immune system. Curr Opin Immunol 2010;22:507-513.

[9] Cancro MP, Hao Y, Scholz JL, Riley RL, Frasca D, Dunn-Walters DK, et al. B cells and aging: molecules and mechanisms. Trends Immunol 2009;30:313318.

[10] Linton PJ, Dorshkind K. Age-related changes in lymphocyte development and function. Nat Immunol 2004;5:133-139.

[11] Arnold CR, Wolf J, Brunner S, Herndler-Brandstetter D, Grubeck-Loebenstein B. Gain and loss of T cell subsets in old age--age-related reshaping of the T cell repertoire. J Clin Immunol 2011;31:137-146. 
[12] Ademokun A, Wu YC, Dunn-Walters D. The ageing B cell population: composition and function. Biogerontology 2010;11:125-137.

[13] Fagnoni FF, Vescovini R, Passeri G, Bologna G, Pedrazzoni M, Lavagetto G, et al. Shortage of circulating naive CD8(+) T cells provides new insights on immunodeficiency in aging. Blood 2000;95:2860-2868.

[14] Lazuardi L, Jenewein B, Wolf AM, Pfister G, Tzankov A, Grubeck-Loebenstein B. Age-related loss of naive T cells and dysregulation of T-cell/B-cell interactions in human lymph nodes. Immunology 2005;114:37-43.

[15] Aspinall R, Andrew D. Thymic involution in aging. J Clin Immunol 2000;20:250-256.

[16] Nikolich-Zugich J. Ageing and life-long maintenance of T-cell subsets in the face of latent persistent infections. Nat Rev Immunol 2008;8:512-522.

[17] Brunner S, Herndler-Brandstetter D, Weinberger B, Grubeck-Loebenstein B. Persistent viral infections and immune aging. Ageing Res Rev 2011;10:362369.

[18] Sylwester AW, Mitchell BL, Edgar JB, Taormina C, Pelte C, Ruchti F, et al. Broadly targeted human cytomegalovirus-specific CD4+ and CD8+ T cells dominate the memory compartments of exposed subjects. J Exp Med 2005;202:673-685.

[19] Pawelec G. Immunosenenescence: role of cytomegalovirus. Exp Gerontol 2014;54:1-5.

[20] Bjorgo E, Tasken K. Novel mechanism of signaling by CD28. Immunol Lett 2010;129:1-6.

[21] Plunkett FJ, Franzese O, Finney HM, Fletcher JM, Belaramani LL, Salmon M, et al. The loss of telomerase activity in highly differentiated CD8+CD28-CD27- 
T cells is associated with decreased Akt (Ser473) phosphorylation. J Immunol 2007;178:7710-7719.

[22] Kovaiou RD, Weiskirchner I, Keller M, Pfister G, Cioca DP, Grubeck-

Loebenstein B. Age-related differences in phenotype and function of CD4+ T cells are due to a phenotypic shift from naive to memory effector CD4+ T cells. Int Immunol 2005;17:1359-1366.

[23] Franceschi C, Bonafe M, Valensin S, Olivieri F, De Luca M, Ottaviani E, et al. Inflamm-aging. An evolutionary perspective on immunosenescence. Ann NY Acad Sci 2000;908:244-254.

[24] Hartsock RJ, Smith EB, Petty CS. Normal Variations with Aging of the Amount of Hematopoietic Tissue in Bone Marrow from the Anterior lliac Crest. A Study Made from 177 Cases of Sudden Death Examined by Necropsy. Am J Clin Pathol 1965;43:326-331.

[25] Geiger H, de Haan G, Florian MC. The ageing haematopoietic stem cell compartment. Nat Rev Immunol 2013;13:376-389.

[26] Montecino-Rodriguez E, Berent-Maoz B, Dorshkind K. Causes, consequences, and reversal of immune system aging. J Clin Invest 2013;123:958-965.

[27] Kogut I, Scholz JL, Cancro MP, Cambier JC. B cell maintenance and function in aging. Semin Immunol 2012;24:342-349.

[28] Szabo P, Shen S, Telford W, Weksler ME. Impaired rearrangement of IgH V to DJ segments in bone marrow Pro-B cells from old mice. Cell Immunol 2003;222:78-87.

[29] Frasca D, Nguyen D, Riley RL, Blomberg BB. Decreased E12 and/or E47 transcription factor activity in the bone marrow as well as in the spleen of aged mice. J Immunol 2003;170:719-726. 
[30] Allman D, Miller JP. B cell development and receptor diversity during aging. Curr Opin Immunol 2005;17:463-467.

[31] Stephan RP, Lill-Elghanian DA, Witte PL. Development of B cells in aged mice: decline in the ability of pro-B cells to respond to IL-7 but not to other growth factors. J Immunol 1997;158:1598-1609.

[32] Di Rosa F, Santoni A. Bone marrow CD8 T cells are in a different activation state than those in lymphoid periphery.Eur J Immunol 2002;32:1873-1880.

[33] McHeyzer-Williams MG, Ahmed R. B cell memory and the long-lived plasma cell. Curr Opin Immunol 1999;11:172-179.

[34] Radbruch A, Muehlinghaus G, Luger EO, Inamine A, Smith KG, Dorner T, et al. Competence and competition: the challenge of becoming a long-lived plasma cell. Nat Rev Immunol 2006;6:741-750.

[35] Tokoyoda K, Zehentmeier S, Hegazy AN, Albrecht I, Grun JR, Lohning M, et al. Professional memory CD4+ T lymphocytes preferentially reside and rest in the bone marrow. Immunity 2009;30:721-730.

[36] Hanazawa A, Hayashizaki K, Shinoda K, Yagita H, Okumura K, Lohning M, et al. CD49b-dependent establishment of T helper cell memory. Immunol Cell Biol 2013;91:524-531.

[37] Herndler-Brandstetter D, Landgraf K, Jenewein B, Tzankov A, Brunauer R, Brunner S, et al. Human bone marrow hosts polyfunctional memory CD4+ and CD8+ T cells with close contact to IL-15-producing cells. J Immunol 2011;186:6965-6971.

[38] Tokoyoda K, Hauser AE, Nakayama T, Radbruch A. Organization of immunological memory by bone marrow stroma. Nat Rev Immunol 2010;10:193-200. 
[39] Herndler-Brandstetter D, Landgraf K, Tzankov A, Jenewein B, Brunauer R, Laschober GT, et al. The impact of aging on memory $T$ cell phenotype and function in the human bone marrow. J Leuk Biol 2012;91:197-205.

[40] Ma Q, Jones D, Springer TA. The chemokine receptor CXCR4 is required for the retention of $B$ lineage and granulocytic precursors within the bone marrow microenvironment. Immunity 1999;10:463-471.

[41] Chu VT, Berek C. The establishment of the plasma cell survival niche in the bone marrow. Immunol Rev 2013;251:177-188.

[42] Hargreaves DC, Hyman PL, Lu TT, Ngo VN, Bidgol A, Suzuki G, et al. A coordinated change in chemokine responsiveness guides plasma cell movements. J Exp Med 2001;194:45-56.

[43] Yu C, Cantor AB, Yang H, Browne C, Wells RA, Fujiwara Y, et al. Targeted deletion of a high-affinity GATA-binding site in the GATA-1 promoter leads to selective loss of the eosinophil lineage in vivo. J Exp Med 2002;195:13871395.

[44] Tokoyoda K, Zehentmeier S, Chang HD, Radbruch A. Organization and maintenance of immunological memory by stroma niches. Eur J Immunol 2009;39:2095-2099.

[45] Manz RA, Thiel A, Radbruch A. Lifetime of plasma cells in the bone marrow. Nature 1997;388:133-134.

[46] Han S, Yang K, Ozen Z, Peng W, Marinova E, Kelsoe G, et al. Enhanced differentiation of splenic plasma cells but diminished long-lived high-affinity bone marrow plasma cells in aged mice. J Immunol 2003;170:1267-1273.

[47] Ueda Y, Yang K, Foster SJ, Kondo M, Kelsoe G. Inflammation controls B lymphopoiesis by regulating chemokine CXCL12 expression. J Exp Med 2004;199:47-58. 
[48] Benner R, Meima F, van der Meulen GM. Antibody formation in mouse bone marrow. II. Evidence for a memory-dependent phenomenon. Cell Immunol 1974;13:95-106.

[49] Becker TC, Coley SM, Wherry EJ, Ahmed R. Bone marrow is a preferred site for homeostatic proliferation of memory CD8 T cells. J Immunol 2005;174:1269-1273.

[50] Hanazawa A, Lohning M, Radbruch A, Tokoyoda K. CD49b/CD69-Dependent Generation of Resting T Helper Cell Memory. Front Immunol 2013;4:183.

[51] Tuckwell D, Calderwood DA, Green LJ, Humphries MJ. Integrin alpha 2 Idomain is a binding site for collagens. J Cell Sci 1995;108 ( Pt 4):1629-1637.

[52] Heino J. The collagen family members as cell adhesion proteins. BioEssays 2007;29:1001-1010.

[53] Hynes RO. Integrins: versatility, modulation, and signaling in cell adhesion. Cell 1992;69:11-25.

[54] Shinoda K, Tokoyoda K, Hanazawa A, Hayashizaki K, Zehentmeier S, Hosokawa $\mathrm{H}$, et al. Type II membrane protein CD69 regulates the formation of resting T-helper memory. Proc Natl Acad Sci USA 2012;109:7409-7414.

[55] Ziegler SF, Ramsdell F, Alderson MR. The activation antigen CD69. Stem Cells 1994;12:456-465.

[56] Testi R, D'Ambrosio D, De Maria R, Santoni A. The CD69 receptor: a multipurpose cell-surface trigger for hematopoietic cells. Immunol Today 1994;15:479-483.

[57] Clark P, Normansell DE, Innes DJ, Hess CE. Lymphocyte subsets in normal bone marrow. Blood 1986;67:1600-1606.

[58] Vavassori M, Maccario R, Moretta A, Comoli P, Wack A, Locatelli F, et al. Restricted TCR repertoire and long-term persistence of donor-derived antigen- 
experienced CD4+ T cells in allogeneic bone marrow transplantation recipients. J Immunol 1996;157:5739-5747.

[59] Libri V, Azevedo RI, Jackson SE, Di Mitri D, Lachmann R, Fuhrmann S, et al. Cytomegalovirus infection induces the accumulation of short-lived, multifunctional CD4+CD45RA+CD27+ T cells: the potential involvement of interleukin-7 in this process. Immunology 2011;132:326-339.

[60] Pritz T, Landgraf-Rauf K, Herndler-Brandstetter D, Rauf R, Lair J, Gassner R, et al. Bone marrow T cells from the femur are similar to iliac crest derived cells in old age and represent a useful tool for studying the aged immune system. Immun Ageing 2013;10:17.

[61] Focosi D, Bestagno M, Burrone O, Petrini M. CD57+ T lymphocytes and functional immune deficiency. J Leuk Biol 2010;87:107-116.

[62] Brenchley JM, Karandikar NJ, Betts MR, Ambrozak DR, Hill BJ, Crotty LE, et al. Expression of CD57 defines replicative senescence and antigen-induced apoptotic death of CD8+ T cells. Blood 2003;101:2711-2720.

[63] Effros RB, Dagarag M, Spaulding C, Man J. The role of CD8+ T-cell replicative senescence in human aging. Immunol Rev 2005;205:147-157.

[64] Kern F, Khatamzas E, Surel I, Frommel C, Reinke P, Waldrop SL, et al. Distribution of human CMV-specific memory T cells among the CD8pos. subsets defined by CD57, CD27, and CD45 isoforms. Eur J Immunol 1999;29:2908-2915.

[65] Schwanninger A, Weinberger B, Weiskopf D, Herndler-Brandstetter D, Reitinger S, Gassner C, et al. Age-related appearance of a CMV-specific highavidity CD8+ T cell clonotype which does not occur in young adults. Immun Ageing 2008;5:14. 
[66] Peggs K, Verfuerth S, Pizzey A, Ainsworth J, Moss P, Mackinnon S. Characterization of human cytomegalovirus peptide-specific CD8(+) T-cell repertoire diversity following in vitro restimulation by antigen-pulsed dendritic cells. Blood 2002;99:213-223.

[67] Wilson A, Trumpp A. Bone-marrow haematopoietic-stem-cell niches. Nat Rev Immunol 2006;6:93-106.

[68] Morrison SJ, Scadden DT. The bone marrow niche for haematopoietic stem cells. Nature 2014;505:327-334.

[69] Lepperdinger G. Inflammation and mesenchymal stem cell aging. Curr Opin Immunol 2011;23:518-524.

[70] Tokoyoda K, Egawa T, Sugiyama T, Choi BI, Nagasawa T. Cellular niches controlling B lymphocyte behavior within bone marrow during development. Immunity 2004;20:707-718.

[71] Hauser AE, Debes GF, Arce S, Cassese G, Hamann A, Radbruch A, et al. Chemotactic responsiveness toward ligands for CXCR3 and CXCR4 is regulated on plasma blasts during the time course of a memory immune response. J Immunol 2002;169:1277-1282.

[72] Winter O, Moser K, Mohr E, Zotos D, Kaminski H, Szyska M, et al. Megakaryocytes constitute a functional component of a plasma cell niche in the bone marrow. Blood 2010;116:1867-1875.

[73] Chu VT, Frohlich A, Steinhauser G, Scheel T, Roch T, Fillatreau S, et al. Eosinophils are required for the maintenance of plasma cells in the bone marrow. Nat Immunol 2011;12:151-159.

[74] Kondrack RM, Harbertson J, Tan JT, McBreen ME, Surh CD, Bradley LM. Interleukin 7 regulates the survival and generation of memory CD4 cells. $\mathrm{J}$ Exp Med 2003;198:1797-1806. 
[75] Tokoyoda K, Radbruch A. Signals controlling rest and reactivation of T helper memory lymphocytes in bone marrow. Cell Mol Life Sci 2012;69:1609-1613.

[76] Kang I, Hong MS, Nolasco H, Park SH, Dan JM, Choi JY, et al. Ageassociated change in the frequency of memory CD4+ $T$ cells impairs long term CD4+ T cell responses to influenza vaccine. J Immunol 2004;173:673-681.

[77] Nasi M, Troiano L, Lugli E, Pinti M, Ferraresi R, Monterastelli E, et al. Thymic output and functionality of the IL-7/L-7 receptor system in centenarians: implications for the neolymphogenesis at the limit of human life. Aging Cell 2006;5:167-175.

[78] Parretta E, Cassese G, Barba P, Santoni A, Guardiola J, Di Rosa F. CD8 cell division maintaining cytotoxic memory occurs predominantly in the bone marrow. J Immunol 2005;174:7654-7664.

[79] Doherty TM, Seder RA, Sher A. Induction and regulation of IL-15 expression in murine macrophages. J Immunol 1996;156:735-741.

[80] Ruckert R, Brandt K, Bulanova E, Mirghomizadeh F, Paus R, Bulfone-Paus S. Dendritic cell-derived IL-15 controls the induction of CD8 T cell immune responses. Eur J Immunol 2003;33:3493-3503.

[81] Sandau MM, Schluns KS, Lefrancois L, Jameson SC. Cutting edge: transpresentation of IL-15 by bone marrow-derived cells necessitates expression of IL-15 and IL-15R alpha by the same cells. J Immunol 2004;173:6537-6541.

[82] Cui G, Hara T, Simmons S, Wagatsuma K, Abe A, Miyachi H, et al. Characterization of the IL-15 niche in primary and secondary lymphoid organs in vivo. Proc Natl Acad Sci USA 2014;111:1915-1920.

[83] Brunner S, Herndler-Brandstetter D, Arnold CR, Wiegers GJ, Villunger A, Hackl M, et al. Upregulation of miR-24 is associated with a decreased DNA 
damage response upon etoposide treatment in highly differentiated CD8(+) T cells sensitizing them to apoptotic cell death. Aging Cell 2012;11:579-587. 
Figure 1:

A

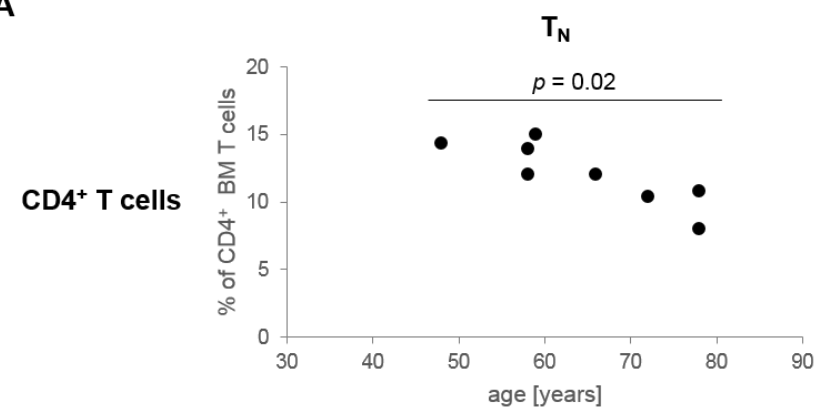

B

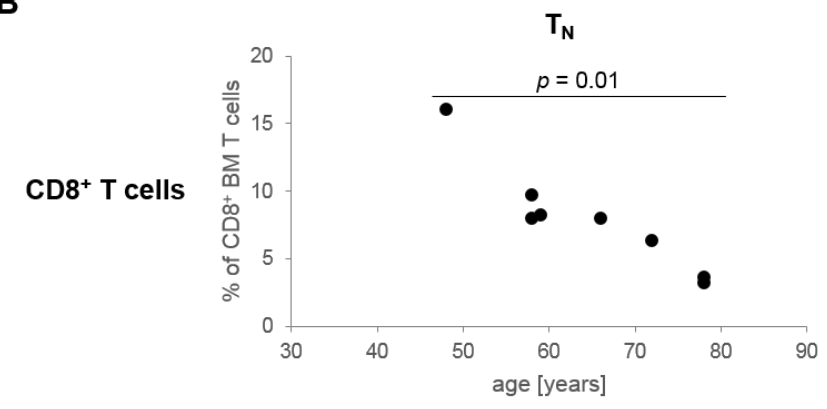

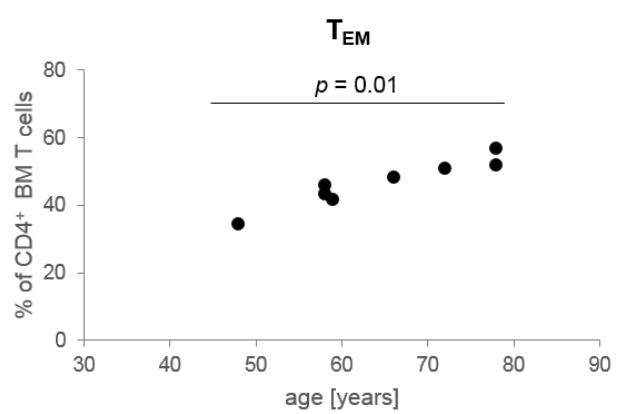

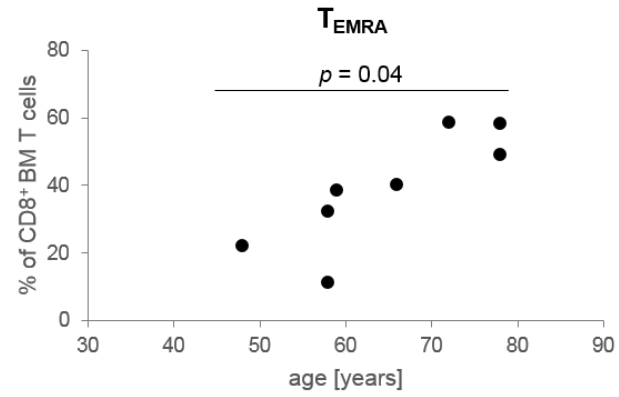


Figure 2:

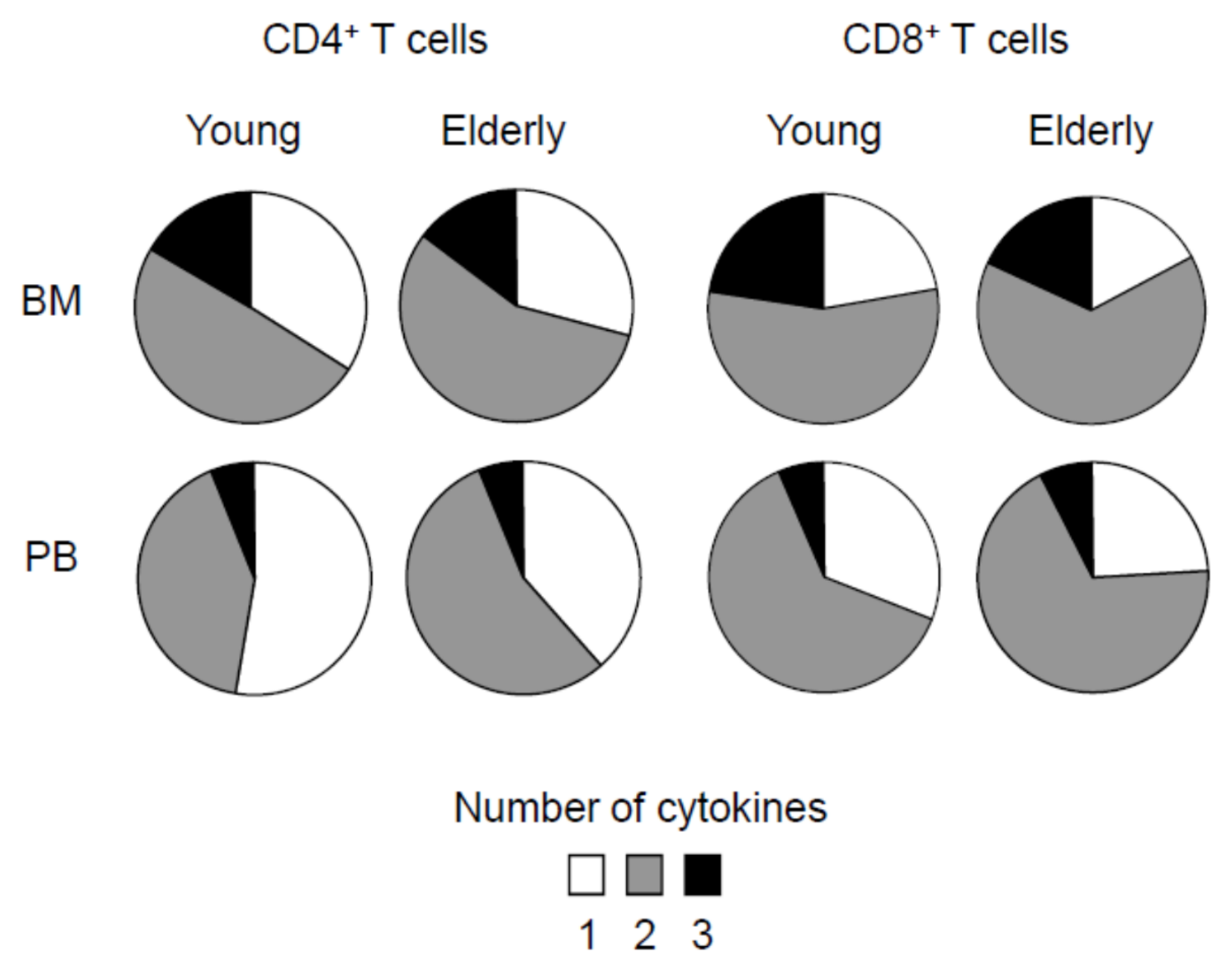




\section{Additional manuscript II}

\section{T cell receptor-mediated activation is a potent inducer of macroautophagy in human $\mathrm{CD}^{+}{ }^{+} \mathrm{CD} 28^{+} \mathrm{T}$ cells but not in $\mathrm{CD}^{+}{ }^{+} \mathrm{CD} 28^{-} \mathrm{T}$ cells}

Christoph R Arnold ${ }^{\mathrm{a}}$; Theresa Pritz ${ }^{\mathrm{a}}$; Stefan Brunnera; Carina Knabbª ${ }^{\mathrm{a}}$, Willi

Salvenmoser ${ }^{\mathrm{b}}$; Birgit Holzwarth ${ }^{\mathrm{c}}$; Kathrin Thedieck ${ }^{\mathrm{d}, 1}$; Beatrix GrubeckLoebenstein ${ }^{\mathrm{a}, 1, *}$

a Institute for Biomedical Aging Research, Immunology Division, University of Innsbruck, 6020 Innsbruck, Austria.

b Institute for Zoology, University of Innsbruck, 6020 Innsbruck, Austria.

${ }^{c}$ Bioinformatics and Molecular Genetics, Faculty of Biology, Albert-LudwigsUniversity Freiburg, 79104 Freiburg, Germany.

${ }^{d}$ Bioinformatics and Molecular Genetics, Faculty of Biology, Albert-LudwigsUniversity Freiburg, 79104 Freiburg, Germany; Center for Liver, Digestive and Metabolic Diseases, Department of Pediatrics, University of Groningen, University Medical Center Groningen, 9713 GZ Groningen, The Netherlands; BIOSS Center for Biological Signalling Studies and Center for Systems Biology (ZBSA), Albert-Ludwigs-University Freiburg, 79104 Freburg, Germany.

1 These authors contributed equally as senior authors.

* Corresponding author

Experimental Gerontology 2014, 54:75-83. doi: 10.1016/j.exger.2014.01.018. This article is available from: http://www.sciencedirect.com/science/article/pii/S016524781400129 
$\mathrm{T}$ cell receptor-mediated activation is a potent inducer of macroautophagy in human $\mathrm{CD} 8^{+} \mathrm{CD} 28^{+} \mathrm{T}$ cells but not in $\mathrm{CD} 8^{+} \mathrm{CD} 28^{-} \mathrm{T}$ cells

Christoph R Arnold ${ }^{\mathrm{a}}$, Theresa Pritz ${ }^{\mathrm{a}}$, Stefan Brunner ${ }^{\mathrm{a}}$, Carina Knabb ${ }^{\mathrm{a}}$, Willi Salvenmoser ${ }^{\mathrm{b}}$, Birgit Holzwarth $^{\mathrm{c}}$, Kathrin Thedieck $^{\mathrm{d} 1}$, Beatrix Grubeck-Loebenstein $^{\mathrm{a}{ }^{1} *}$

${ }^{a}$ Institute for Biomedical Aging Research, Immunology Division, University of Innsbruck, 6020 Innsbruck, Austria

${ }^{\mathrm{b}}$ Institute for Zoology, University of Innsbruck, 6020 Innsbruck, Austria

${ }^{\mathrm{c}}$ Bioinformatics and Molecular Genetics, Institute for Biology 3, University of Freiburg, 79098 Freiburg, Germany

${ }^{\mathrm{d}}$ University Medical Center Groningen, Center for Liver, Digestive and Metabolic Diseases, Department of Pediatrics, University of Groningen, 9712 CP Groningen, The Netherlands

${ }^{1}$ These authors contributed equally as senior authors.

*Corresponding author:

Beatrix Grubeck-Loebenstein

Institute for Biomedical Aging Research, Immunology Division, University of Innsbruck, 6020 Innsbruck, Austria

Phone: +4351250750855

Fax: +43 51250750899

E-Mail: beatrix.grubeck@uibk.ac.at 
Abstract

A key feature of the aged human immune system is the accumulation of highly differentiated $\mathrm{CD}^{+} \mathrm{CD} 28^{-} \mathrm{T}$ cells, a phenomenon that negatively influences immune function in the elderly. However, the mechanisms that regulate survival or death of $\mathrm{CD}^{+} \mathrm{CD} 28^{-} \mathrm{T}$ cells remain incompletely understood. Macroautophagy has been shown to protect cells from unfavorable environmental conditions and extend lifespan of various cells and organisms. In this study, we investigated autophagy in $\mathrm{CD} 8^{+} \mathrm{CD} 28^{+}$and $\mathrm{CD} 8^{+} \mathrm{CD} 28^{-} \mathrm{T}$ cells following $\mathrm{T}$ cell receptor (TCR) engagement. We demonstratethat TCR-mediated activation led to a potent induction of autophagy in $\mathrm{CD} 8^{+} \mathrm{CD} 28^{+} \mathrm{T}$ cells which was accompanied by an increased activity of the mammalian target of rapamycin complex 1 (mTORC1). This was surprising, as mTORC1 is generally perceived as an inhibitor of autophagy. Inhibition of mTORC1 by rapamycin could still enhance activation-induced autophagy. In contrast, $\mathrm{CD} 8^{+} \mathrm{CD} 28^{-} \mathrm{T}$ cells induced autophagy to a significantly lower extent in response to TCR engagement compared to $\mathrm{CD} 8^{+} \mathrm{CD} 28^{+} \mathrm{T}$ cells and failed to increase autophagy upon mTORC1 inhibition.In conclusion, we describe for the first time the induction of autophagy in human $\mathrm{CD}^{+} \mathrm{T}$ cells following TCR engagement and the decreased ability of $\mathrm{CD}^{+} \mathrm{CD} 28^{-} \mathrm{T}$ cells to induce autophagy, suggesting that they cannot meet the metabolic needs of antigen receptor-mediated activation and are therefore unlikely to survive when confronted by their specific antigens.

Key Words

human; T cells;aging; autophagy; mTOR; CD28

\begin{abstract}
Abbreviations
mTOR, mammalian target of rapamycin; mTORC1/2, mTOR complex 1/2; TCR, T cell receptor; CMV, cytomegalovirus; PI3K, phosphoinositide 3-kinase; PKB, protein kinase B; PDK, phosphoinositide-dependent protein kinase 1; S6K1, S6 kinase 1; 4E-BP1, 4E-binding


protein 1; PRAS40, prolin-rich Akt1 substrate of 40kDa; PBMC, peripheral blood mononuclear cells; MACS, magnetic-activated cell sorting;APC, allophycocyanin; LC3B, microtubule-associated protein 1A/1B-light chain 3 homolog $\mathrm{B} ; \mathrm{PE}$, phosphatidylethanolamine, phycoerythrin; 7AAD, 7-aminoactinomycin D;GAPDH, glyceraldehyde 3-phosphate dehydrogenase; CMA, concanamycin A; JNK1, Jun kinase 1; Bcl-2, B-cell lymphoma 2; IL, interleukin; BM, bone marrow; 


\section{Introduction}

The aged immune system is characterized by an altered proportional representation of $\mathrm{T}$ cell subsets caused by the involution of the thymus and the recurrent contact to antigens (Aspinall and Andrew 2000; Steinmann et al., 1985). While the number of antigen-inexperienced naïve $\mathrm{T}$ cells decreases with age, memory and effector $\mathrm{T}$ cells accumulate and dominate the $\mathrm{T}$ cell repertoire. These changes are more pronounced in the $\mathrm{CD}^{+}$than in the $\mathrm{CD}^{+} \mathrm{T}$ cell pool(Arnold et al., 2011). Within antigen-experienced T cells a subset of highly differentiated $\mathrm{CD} 8^{+} \mathrm{CD} 28^{-} \mathrm{T}$ cells hasspecifically gained scientific attention over the last decade. Much effort has been spent on understanding the origin, nature, function and physiological relevance of these cells.

Not only do these cells dominate the $\mathrm{T}$ cell repertoire in elderly persons, especially in those who are also infected with Cytomegalovirus (CMV)(Brunner et al., 2011; Griffiths et al., 2013), but they have also been linked to an enhanced progression of age-related diseases such as Alzheimer's disease or atherosclerosis, as well as a decreased efficacy of vaccination(Chen et al., 2009; Dumitriu et al., 2009; Goronzy et al., 2001; Lurain et al., 2013; Panossian et al., 2003; Saurwein-Teissl et al., 2002; Sun et al., 2013). Moreover, high numbers of CD8 ${ }^{+} \mathrm{CD} 28^{-}$ $\mathrm{T}$ cells are found in many autoimmune diseases, such as Grave's disease, rheumatoid arthritis, or ankylosing spondylitis, and, in combination with a disturbed CD4/CD8 ratio and CMV seropositivity, predict a higher two year mortality (Dejaco et al., 2010; Gerli et al., 2004; Hadrup et al., 2006; Schirmer et al., 2002; Sun et al., 2008; Wikby et al., 2005; Wikby et al., 2006).Therefore, the circumstances under which these cells survive or die are a matter of interest.

We have recently shown that highly differentiated $\mathrm{CD} 8^{+} \mathrm{CD} 28^{-} \mathrm{T}$ cells display a defective DNA damage response, making them prone to undergo apoptosis (Brunner et al., 2012). Still it remains unclear why these cells accumulate with increasing age despite their susceptibility to undergo apoptosis. 
One mechanism that has been shown to protect lymphocytes from unfavorable environmental autophagy)(McLeod et al., 2012). Autophagy is a highly conserved cellular recycle and maintenance mechanism that maintains cellular homeostasis by constant turnover of proteins and organelles. Autophagic capacity has been shown to decline with chronological age and defective regulation of autophagy has been linked to several age-related diseases(Gelino and Hansen, 2012).In contrast, the induction of autophagy has been shown to increase lifespan in various organisms (Eisenberg et al., 2009).CD8 ${ }^{+} \mathrm{T}$ cells of late differentiation stages have been shown to display lower levels of autophagy in a resting state as well as following nutrient starvation (Phadwal et al., 2012). However, autophagy seems to be particularly important during $\mathrm{T}$ cell activation. The transition of resting naïve or memory $\mathrm{T}$ cells to activated effector $\mathrm{T}$ cells requires increased production of energy to sustain cell growth, proliferation, differentiation and synthesis of effector molecules (Fox et al., 2005; Frauwirth and Thompson, 2004). To meet these energetic demands, T cells up-regulate the expression of glucose transporter 1 and increase glucose metabolism as well as $\beta$-oxidation (Buzzai et al., 2005; Frauwirth et al., 2002; Greiner et al., 1994).Successful T cell receptor(TCR)-mediated activation of murine $\mathrm{CD}^{+} \mathrm{Th}$ cells has been shown to rely on autophagy in order to accommodate the bioenergetic requirements of activated $\mathrm{T}$ cells(Hubbard et al., 2010), but there is still no information available on the T cell activation-mediated induction of autophagy in human $\mathrm{T}$ cells. There is also no information on the mammalian target of rapamycin (mTOR), a well-known repressor of autophagy (Kamada et al., 2000; Kim et al., 2011;Stephan et al., 2009), in the context of autophagy in human T lymphocytes.

mTOR is a central regulator of cellular growth and is conserved in all eukaryotes examined (Laplante and Sabatini, 2012). mTOR exists in two structurally and functionally different multiprotein complexes, mTOR complex 1 (mTORC1) and mTORC2. Whereas mTORC1 primarily controls protein synthesis and represses autophagy(Polak and Hall, 2009), mTORC2 
has been linked to lipolysis and glycolysis (Hagiwara et al., 2012; Lamming et al., 2012). The acutely - is rapamycin insensitive. mTORC1 is activated by class I-phosphoinositide 3kinases (PI3Ks), which have been shown to respond to antigen receptor stimulation in $\mathrm{T}$ cells(Gamper and Powell, 2012). PI3K targets the AGC kinase Akt (also called protein kinase $\mathrm{B}[\mathrm{PKB}])$ to the plasma membrane where Akt is activated by phosphoinositide-dependent protein kinase $1(\mathrm{PDK})$ to stimulate mTORC1 activity. The best characterized mTORC1 substrates are the AGC kinase ribosomal protein S6 kinase 1 (S6K1), the 4E-binding protein 1 (4E-BP1), andprolin-rich Akt1 substrate of 40kDa(PRAS40). Upon activation by mTORC1, S6K1 phosphorylates mTOR at S2448. Translational control by mTORC1 occurs at several levels, short term by regulation of several translation initiation factors including 4E-BP1, and long term by controlling translation and processing of ribosomal components(Thedieck and Hall, 2009).

In the present study we aimed to test if autophagy is induced in human $\mathrm{T}$ cellsfollowing $\mathrm{T}$ cell activation, as previously observed in mice. This is of particular importance, as mice are comparably short lived and several longevity effects observed in lower organisms and mice do not translate to humans (Mattison et al., 2012). Specifically, we analyzed the induction of autophagy and the role of mTORC1 in this process in $\mathrm{CD}^{+} \mathrm{CD} 28^{+}$and in $\mathrm{CD}^{+} \mathrm{CD} 28^{-} \mathrm{T}$ cells.We decided to study $\mathrm{CD} 8^{+}$, but not $\mathrm{CD}^{+} \mathrm{T}$ cells, as changes in the differentiation pattern, particularly in the context of aging, are more pronounced in this cell type. 


\section{Materials and Methods}

\subsection{Blood donors and isolation of peripheral blood mononuclear cells (PBMCs)}

In total, blood samples were obtained from 30 healthy elderly (>65 years, 15 male, 15 female)CMV seropositive volunteers who did not receive medication known to influence the immune system. These donors have characteristically large quantities of $\mathrm{CD}^{+} \mathrm{CD} 28^{-} \mathrm{T}$ cells. Young individuals typically have only small numbers of $\mathrm{CD} 8^{+} \mathrm{CD} 28^{-} \mathrm{T}$ cells and these cells are therefore difficult to purify. We have shown in a previous study that $\mathrm{CD}^{+} \mathrm{CD} 28^{-} \mathrm{T}$ cells of young and elderly persons are highly similar regarding their gene expression profile(Lazuardi et al., 2009). Therefore, we only used blood from elderly donors. The number of donors used for each individual experiment is indicated in the figure legends. All donors had given their written informed consent to participate in this study that was approved by the Ethics Committee of Innsbruck Medical University. Peripheral blood was collected in sodium heparin tubes and PBMCs were freshly isolated using Ficoll-Hypaque (Amersham Biosciences, Amersham, UK) density centrifugation.

\subsection{Purification of $C D 8^{+} T$ cell subsets}

$\mathrm{CD}^{+} \mathrm{CD} 28^{+}$and $\mathrm{CD} 8^{+} \mathrm{CD} 28^{-} \mathrm{T}$ cells were isolated using a three-step magnetic-activated cell sorting (MACS; MiltenyiBiotec, BergischGladbach, Germany) procedure. In a first step, $\mathrm{CD}^{+} \mathrm{T}$ cells were positively selected with the CD8 MultiSort Kit (MiltenyiBiotec). Thereafter, $\mathrm{CD}^{+} \mathrm{T}$ cells were incubated with anti-CD28 APC-conjugated antibodies (BD Pharmingen, Franklin Lakes, NJ, USA) and anti-APC microbeads (MiltenyiBiotec). $\mathrm{CD}^{+} \mathrm{CD} 28^{-} \mathrm{T}$ cells were depleted of contaminating NK cells using anti-CD16 microbeads (MiltenyiBiotec). Finally, the purity of obtained $\mathrm{CD}^{+} \mathrm{CD} 28^{+}$and $\mathrm{CD} 8^{+} \mathrm{CD} 28^{-} \mathrm{T}$ cells was assessed with a FACSCanto II flow cytometer (BD Biosciences, Franklin Lakes, NJ, USA) and T cell subpopulations with purities of $\geq 95 \%$ were used for further experiments. 


\subsection{Cell culture}

PBMCs and isolated T cell subsets were cultured at a cell density of $1-2 \times 10^{6}$ cells $/ \mathrm{ml}$ at $37^{\circ} \mathrm{C}$ in complete RPMI 1640 medium (Lonza, Basel, Switzerland) supplemented with 10\% FCS (Sigma-Aldrich, St. Louis, MO, USA) and 1\% Kanamycin (Invitrogen, Carlsbad, CA, USA). PBMCs were cultured as well as treatedin 48 or 96 well cell culture plates (Midsci, St. Louis, MO, USA). Isolated $\mathrm{T}$ cell subsets were cultured and treated in high protein binding capacity 96-well plates (Greiner Bio-One, Frickenhausen, Germany) coated with either anti-mouseIgG antibodies $(1 \mu \mathrm{g} / \mathrm{ml}$; BD Pharmingen) or IL-15 $(1 \mu \mathrm{g} / \mathrm{ml}$; Millipore Corporation, Billerica, MA, USA). For stimulation, antibodies against CD3, CD28, or CD137 (all BD Pharmingen) were used. Rapamycin (Millipore Corporation) was used at concentrations of 100nM. To stabilize the LC3B signal the V-ATPase inhibitor concanamycin A (Sigma-Aldrich) was used at a concentration of $2 \mathrm{nM}$.

\subsection{FACS analysis}

For analysis of $\mathrm{T}$ cell proliferation, PBMCs were labeled with CFSE (Invitrogen) according to the manufacturer's protocol. Cells were then activated using anti-CD3 antibodies (3ng/ml; BD Pharmingen). After 2 and 4 days, cells were harvested, stained with fluorescent antibodies against CD3 (APC-Cy7; eBiosciences, San Diego, CA, USA), CD8 (PE-Cy7; BD Pharmingen) and CD28 (APC; MiltenyiBiotec), and CFSE content was measured using a FACS Canto II (BD Biosciences).For determination of apoptotic cells PBMCs were activated using anti-CD3 antibodies (3ng/ml; BD Pharmingen) for $48 \mathrm{~h}$, stained with AnnexinV/7AAD, and analyzedwith a FACS Canto II flow cytometer (BD Biosciences).AnnexinV singlepositive as well as double-positive cells were considered apoptotic.

\subsection{Western Blotting}


$1-2 \times 10^{6}$ cells were lysed in TNE buffer (50mMTrisHCl pH $8.0,150 \mathrm{mMNaCl}$, and $1 \%$ TritonX100) supplemented with phosphatase (1:100; Sigma-Aldrich) and proteinase (1:25; Roche, Basel, Switzerland) inhibitors. Proteins were separated by gel electrophoresis on 420\% Tris-Glycine precast gradient gels (Lonza) and detected with antibodies against phosphor-Ser2448-mTOR (Cell Signaling Technologies, Danvers, MA, USA), microtubuleassociated protein 1A/1B-light chain 3 homolog B (LC3B; Nanotools, Teningen, Germany), and glyceraldehyde 3-phosphate dehydrogenase (GAPDH;Abcam, Cambridge, UK). Proteins were visualized using horseradish-peroxidase-conjugated secondary antibodies, ECL Western Blotting Substrate or SuperSignal West Femto Substrate (both Thermo Scientific, Waltham, MA, USA), and an Alpha/InnotechFluorChem HD2 chemiluminescence detection camera with AlphaEase software (Bioyzm, HessischOldendorf, Germany). Obtained greyscale values were densitrometically evaluated and normalized to GAPDH for statistical analyses.

\subsection{Analysis of autophagy and mTORC1 activity}

To analyze autophagy we measured the presence of LC3B by immunoblotting, as suggested in the guidelines for the use and interpretation of assays for monitoring autophagy in higher eukaryotes (Klionsky et al., 2012). LC3B is present in two distinct forms within the cell: LC3B-I, which is cytosolic and diffusely distributed, and LC3B-II, which is conjugated to phosphatidylethanolamine (PE) and is present in isolation membranes and autophagosomes, and much less in autolysosomes(Kabeya et al., 2000; Kabeya et al., 2004). The comparison of LC3B-II between samples has been shown to be the most accurate method for analyzing autophagy (Mizushima and Yoshimori, 2007). To inhibit the degradation of LC3B-II, we performed the experiments in the presence of the V-ATPase inhibitor concanamycin A (CMA; Sigma-Aldrich) at a concentration of $2 \mathrm{nM}$. Due to the fact that the isolation procedure of human $\mathrm{CD}^{+} \mathrm{CD} 28^{+}$and $\mathrm{CD} 8^{+} \mathrm{CD} 28^{-} \mathrm{T}$ cells takes a whole day, cells were stimulated in the evening and autophagy was immediately measured after an overnight incubation. Earlier time 
points were only analyzed in pilot experiments (Suppl. Fig. 1A). Later time points were not tested for autophagy, because of relatively high levels of apoptosis in isolated $\mathrm{T}$ cells when cultured for longer than 16 hours (Suppl. Fig. 1B). For assessment of mTORC1 activity we measured phosphorylation of mTOR at S2248 by immunoblotting(Foster and Fingar, 2010).

\subsection{Transmission electron microscopy}

Isolated $\mathrm{CD}^{+} \mathrm{CD} 28^{+} \mathrm{T}$ cells were harvested, centrifuged with $500 \mathrm{~g}$ for 10 minutes, resuspended in sterile PBS and centrifuged again with $500 \mathrm{~g}$ for 10 minutes. Pellets were fixed with $2.5 \%$ glutaraldehyde in $0.1 \mathrm{M}$ PBS for 1-2 hours on ice, washed again with PBS, spinned and postfixed with $1 \%$ osmium tetroxide in $0.1 \mathrm{M}$ sodium cacodylate buffer (pH 7.2) for 1 hour at $+4^{\circ} \mathrm{C}$. After washing with sodium cacodylate buffer, pellets were dehydrated in an ethanol series and embedded in PolyBed 812 (Polysciences, Warrington, PA, USA). Ultrathin sections were cut with a Leica ultracut UCT (Leica, Vienna, Austria) and a diamond knife (Diatome, Biel, Switzerland) and examined with a Zeiss Libra 120 energy filter transmission electron microscope (Zeiss,Göttingen, Germany). Images were made by using a TRS 2x2K camera (Troendle, Germany) and a SiS software (Olympus, Tokyo Japan) using zero loss electrons.

\subsection{Statistical analysis}

All statistical analyses were calculated with the Student's $t$-test. A p-value of $<0.05$ was considered significant. 


\section{Results}

\subsection{TCR-mediated activation induces autophagy and mTORC1 activity in human CD $8^{+}$CD28 $8^{+}$T cells.}

We first determined macroautophagy and mTORC1 activity in isolated human $\mathrm{CD}^{+} \mathrm{CD} 28^{+} \mathrm{T}$ cells by immunoblotting before and after TCR-mediated activation (Fig. 1).Our results show that $\mathrm{T}$ cell activation led to a significant increase in LC3B-II levels (Figs. 1A and B) as well as mTOR-S2448 phosphorylation (Figs. 1A and C), indicating simultaneous induction of mTORC1 activity and autophagy, despite the extensive characterization of mTORC1 as an inhibitor of autophagy. To confirm our finding, we performed transmission electron microscopy images of isolated human $\mathrm{CD} 8^{+} \mathrm{CD} 28^{+} \mathrm{T}$ cells in a resting state as well as following TCR-mediated activation (Suppl. Fig. 2). Compared to the resting state (upper panel), autophagic vacuoles found in activated $\mathrm{T}$ cells (lower panel) are more abundant in numbers, smaller, and contain less organellar material, such as mitochondria. We additionally found very small vacuolar structures in activated $\mathrm{CD} 8^{+} \mathrm{CD} 28^{+} \mathrm{T}$ cells that contain almost exclusively cytosolic material consistent with autophagic vacuoles. We conclude that autophagy and mTORC1 activity are induced upon antigen receptor-mediated activation of human $\mathrm{CD} 8^{+} \mathrm{CD} 28^{+} \mathrm{T}$ cells.

\subsection{Co-stimulation during TCR-mediated activation further increases autophagy in human} $C D 8^{+}$CD28 $8^{+}$T cells.

Co-stimulationis important for TCR activation. We therefore assessed the effect of costimulation on the induction of autophagy and mTORC1 activity in TCR-activated human $\mathrm{CD} 8^{+} \mathrm{CD} 28^{+} \mathrm{T}$ cells (Fig. 1). Isolated $\mathrm{CD} 8^{+} \mathrm{CD} 28^{+} \mathrm{T}$ cells were activated with anti-CD3 antibodies in the presence or absence of antibodies against CD28 and CD137, two costimulatory molecules on $\mathrm{CD}^{+} \mathrm{T}$ cells (Duttagupta et al., 2009; Kober et al., 2008; Zhang et 
al., 2007). Co-stimulation via CD28 as well as CD137 significantly increased autophagy compared to anti-CD3 activation alone, as evidenced by higher LC3B-II levels (Figs. 1A and B).In contrast, mTORC1 activity was not modulated by co-stimulation (Figs.1A and C). We conclude that co-stimulation is an important element for the optimal induction of autophagy via TCR stimulation, whereas mTORC1induction is refractory to co-stimulation.

\subsection{Rapamycin inhibits $m$ TORC1 and increases autophagy in activated human $C D 8^{+} C D 28^{+}$ T cells.}

mTORC1 is known to be a potent negative regulator of autophagy. Yet, following TCR stimulation mTORC1 upregulation co-occurs with the induction of autophagy (Fig.1).To investigate whether a reduction of mTORC1 still played a role in the control of autophagy in human $\mathrm{T}$ cells, we activated isolated human $\mathrm{CD} 8^{+} \mathrm{CD} 28^{+} \mathrm{T}$ cells with anti-CD3 antibodies, inhibited mTORC1 by applying rapamycin and detected mTOR-S2448 phosphorylation and LC3B-II levels (Figs. 2A and B). mTORC1 activity was significantly decreased in TCRactivated $\mathrm{CD} 8^{+} \mathrm{CD} 28^{+} \mathrm{T}$ cells following rapamycin treatment compared to $\mathrm{T}$ cells activated in the absence of rapamycin. LC3B-II levels were significantly higher in rapamycin treated activated $\mathrm{CD} 8^{+} \mathrm{CD} 28^{+} \mathrm{T}$ cells compared to cells stimulated in the absence of rapamycin. These data indicate that, despite the fact that autophagy can be up-regulated in $\mathrm{CD} 8^{+} \mathrm{CD} 28^{+} \mathrm{T}$ cells simultaneously with mTORC1 following activation, downregulation of mTORC1 by rapamycin still has a stimulatory influence on autophagy in activated $\mathrm{CD} 8^{+} \mathrm{CD} 28^{+} \mathrm{T}$ cells.

\section{4. $C D 8^{+} C D 28^{-}$T cells display defects in autophagy and mTORC1 induction following TCR- mediated activation.}

Our next goal was to answer the question whether the regulation of autophagy was altered in human $\mathrm{CD}^{+} \mathrm{CD} 28^{-} \mathrm{T}$ cells. We thereforecompared LC3B-II levels and mTORC1 activity in $\mathrm{CD} 8^{+} \mathrm{CD} 28^{+}$and $\mathrm{CD} 8^{+} \mathrm{CD} 28^{-} \mathrm{T}$ cells before and after TCR-mediated activation. Our results 
demonstrate that $\mathrm{CD} 8^{+} \mathrm{CD} 28^{-} \mathrm{T}$ cells do activate mTORC1 and induce autophagy in response to TCR engagement, but not at the same extent as $\mathrm{CD} 8^{+} \mathrm{CD} 28^{+} \mathrm{T}$ cells (Fig. 3A). In order to exclude that $\mathrm{CD}^{+} \mathrm{CD} 28^{-} \mathrm{T}$ cells had an intrinsic defect in mTORC1 activation or LC3B lipidation, we analyzed mTOR-S2448 phosphorylation and LC3B-II levels in $\mathrm{CD}^{+} \mathrm{CD} 28^{+}$ and $\mathrm{CD}^{+} \mathrm{CD} 28^{-} \mathrm{T}$ cells following stimulation with the homeostatic cytokine Interleukin (IL)15 , which is known to be a good stimulator of $\mathrm{CD}^{+} \mathrm{CD} 28^{-} \mathrm{T}$ cells. Fig. 3B shows that mTORC1 activity can be readily up-regulated in $\mathrm{CD}^{+} \mathrm{CD} 28^{-}$following stimulation with IL15 , ruling out anintrinsic defect in mTORC1 activation in these cells. In contrast, LC3B-II levels in $\mathrm{CD}^{+} \mathrm{CD} 28^{-}$were not regulated by $\mathrm{IL}-15$.

To analyze whether low mTORC1 and LC3B-II induction was paralleled by a typical mTORC1-mediated function, PBMCs were activated with anti-CD3 antibodies, stained with antibodies against CD3, CD8, and CD28, and proliferation after two and four days was monitored.CD8 ${ }^{+} \mathrm{CD} 28^{-} \mathrm{T}$ cells showed a significantly lower proliferation at both days (Figs. $3 \mathrm{C}$ and D).

\subsection{Lack of increased autophagy upon rapamycin treatment of activatedCD8 ${ }^{+} C D 28^{-} T$ cells.}

As autophagy could be increased in activated $\mathrm{CD}^{+} \mathrm{CD} 28^{+} \mathrm{T}$ cells by downregulating the function of mTORC1 duringrapamycin treatment (Fig. 2), the same experiment was performed in $\mathrm{CD}^{+} \mathrm{CD} 28^{-} \mathrm{T}$ cells (Fig. 4). Similarly to $\mathrm{CD} 8^{+} \mathrm{CD} 28^{+}$, rapamycin markedly reduced mTOR-S2448 phosphorylation in $\mathrm{CD}^{+} \mathrm{CD} 28^{-} \mathrm{T}$ cells (Figs. 4A and B). While this change was accompanied by an increase of LC3B-II levels in $\mathrm{CD}^{+} \mathrm{CD} 28^{+} \mathrm{T}$ cells, no alteration in LC3B-II was observed in $\mathrm{CD}^{+} \mathrm{CD} 28^{-} \mathrm{T}$ cells (Figs. 4A and C). This demonstrates that $\mathrm{CD} 8^{+} \mathrm{CD} 28^{-} \mathrm{T}$ cells fail to increase autophagy upon mTORC1 inhibition. 


\section{Discussion}

Our results for the first time demonstrate that TCR activation leads to autophagy in primary $\mathrm{CD}^{+}$human $\mathrm{T}$ cells, demonstrating that previous results on in vitro activated $\mathrm{CD} 4^{+} \mathrm{Th}$ cells from mice(Hubbard et al., 2010)can be translated to the human ex vivo situation. At the same time, we observed strongly induced mTORC1 activity in $\mathrm{CD}^{+} \mathrm{CD} 28^{+} \mathrm{T}$ cells following TCRmediated activation. This was surprising, as mTORC1 is extensively characterized as an inhibitor of autophagy by inhibiting the Ulk complexes (Kamada et al., 2000; Kim et al., 2011; Stephan et al., 2009).Simultaneous upregulation of mTORC1 and autophagy might allow the cells to generate energy necessary for protein synthesis, cell growth and proliferation, which are all needed for $\mathrm{T}$ cell activation (Powell and Delgoffe, 2010). By which signals the induction of mTORC1 and autophagy are interconnected cannot be explained by the present study. Further work is needed to throw light on this interesting question.An mTORC1-independent pathway for the induction of autophagy, which can be activated with certain drugs such as trehalose, coibamide A, or glucosamine, has been described (Hau et al., 2013; Sarkar et al., 2007; Shintani et al., 2010). Autophagy induction in activated $\mathrm{T}$ cells despite high levels of mTORC1 activity may also involve Jun kinase 1 (JNK1) which phosphorylates B-cell lymphoma 2 (Bcl-2) leading to its dissociation from Beclin1, an important protein in the autophagy induction cascade (Lorin et al., 2010; Puissant et al., 2010; Wei et al., 2008a; Wei et al., 2008b).

To test whether mTORC1 is still involved in the control of autophagy in activated T cells, we used rapamycin, which has been shown in several models to increase lifespan by inhibiting mTOR and inducing autophagy (Melendez et al., 2003; Rubinsztein et al., 2011). Despite the simultaneous upregulation of autophagy and mTORC1 following $\mathrm{T}$ cell activation, autophagy was further induced by downregulation of mTORC1 by rapamycin, indicating that mTORC1 is still participating in the control of autophagy in activated $\mathrm{CD} 8^{+} \mathrm{CD} 28^{+} \mathrm{T}$ cells. The fact that autophagy was increased by rapamycin in the presence of antigenic stimuli may also explain 
why rapamycin was beneficial in inducing a high-quality memory response in mice (Araki et al., 2009; Rao et al., 2010). Based on the results in mice, it has recently been suggested that inhibition of mTORC1 by rapamycin or related compounds might be a good way to optimize the results of vaccinations. In a similar way, immunological memory generation might also benefit from substances which induce autophagy independently of the mTOR pathway, such as spermidine(Eisenberg et al., 2009), resveratrol (Morselli et al., 2011), or related molecules. In the context of clinical application, it is also of relevance that our results demonstrate that co-stimulation increases autophagy in T cells. We show that co-stimulation via CD137 and CD28 is effective, but other co-stimulatory molecules might function in a similar way. This fact should be considered for immunotherapeutic regimes which either aim to increase or decrease $\mathrm{T}$ cell stimulation by interfering with co-stimulatory molecules (Chen et al., 2006; Kremer et al., 2003; Suntharalingam et al., 2006; Taylor et al., 2005). It is certainly interesting to see that co-stimulation does not affect mTORC1 activity. The reason for this might be that anti-CD3 stimulation leads to full mTORC1 activation that cannot be further enhanced by costimulatory signals.

A major problem of current autophagy research in primary human T cells is the lack of highly specific autophagy inhibitors which makes it difficult to perform functional tests to prove the importance of autophagy for $\mathrm{T}$ cell function.Work presently under way in our laboratory aiming to knock out autophagy-related genes in $\mathrm{T}$ cell lines will help to address this important issue.

Induction of autophagy in $\mathrm{T}$ cells might be of particular importance for the aging immune system, in which the number of $\mathrm{CD} 8^{+} \mathrm{CD} 28^{+}$naïve and memory $\mathrm{T}$ cells decreases, while $\mathrm{CD} 8^{+} \mathrm{CD} 28^{-} \mathrm{T}$ cells accumulate.In particular, the number of $\mathrm{CD} 8^{+} \mathrm{CD} 28^{+} \mathrm{T}$ cells may be very low in elderly persons who also have latent CMV infections(Brunner et al., 2011). Certain T cell specificities may even have totally disappeared under this condition(Pfister et al., 2006). It seems tempting to speculate that the loss of rare specificities upon antigenic stimulation in 
old age could be prevented by autophagy-inducing compounds. An improved clonal propagation leading to improved memory generation or maintenance could thus be achieved in old age. In this context it is of interest that $\mathrm{CD} 8^{+} \mathrm{CD} 28^{-} \mathrm{T}$ cells had a significantly decreased capacity to induce autophagy. Upon stimulation of $\mathrm{CD}^{+} \mathrm{CD} 28^{-} \mathrm{T}$ cells via the TCR we found a significant induction of autophagy and mTORC1 activity in these cells, but both were significantly lower as compared to their $\mathrm{CD} 8^{+} \mathrm{CD} 28^{+}$counterparts. Rapamycin, which was able to further increase autophagy in $\mathrm{CD} 8^{+} \mathrm{CD} 28^{+} \mathrm{T}$ cells, did not induce autophagy in $\mathrm{CD} 8^{+} \mathrm{CD} 28^{-} \mathrm{T}$ cells at all, even though it inhibited mTOR significantly in both subsets. These results suggest that rapamycin may specifically favor survival and expansion of $\mathrm{CD}^{+} \mathrm{CD} 28^{+}$ T cells via autophagy, whereas $\mathrm{CD} 8^{+} \mathrm{CD} 28^{-} \mathrm{T}$ cells do not profit from rapamycin treatment.As the accumulation of this specific cell type is presently believed to be of disadvantage for the function of the aged immune system(Weng et al., 2009), this might be of special benefit, as $\mathrm{CD} 8^{+} \mathrm{CD} 28^{-} \mathrm{T}$ cells would be likely to perish following antigenic stimulation under rapamycin treatment.

Our group has recently demonstrated that $\mathrm{CD}^{+} \mathrm{CD} 28^{-} \mathrm{T}$ cells are enriched in the human bone marrow (BM)(Herndler-Brandstetter et al., 2011). We hypothesize that they might occupy immunological space at this site formerly reserved for plasma cells and $\mathrm{CD}^{+} \mathrm{Th}$ cells(Tokoyoda et al., 2009). The maintenance of $\mathrm{CD}^{+} \mathrm{CD} 28^{-} \mathrm{T}$ cells in the $\mathrm{BM}$ seems to be supported by the increased production of survival factors such asIL-15, which is produced in the BM at particularly high concentrations in old age (Herndler-Brandstetter et al., 2011; Herndler-Brandstetter et al., 2012). Our study demonstrates that IL-15 also induces mTORC1 activity in $\mathrm{CD}^{+} \mathrm{CD} 28^{-} \mathrm{T}$ cells, but does not affect autophagy. Work is presently under way in our laboratory to clarify whether $\mathrm{CD}^{+} \mathrm{CD} 28^{-} \mathrm{T}$ cells would, due to their inability to induce autophagy, be likely to undergo activation-induced cell death in the presence of IL-15. Answering this question will be important to make a decision about the potential advantage of including regulators of autophagy in immunization regimes. 
In conclusion, our results suggest that the induction of autophagy may be important for the activation of naïve and memory $\mathrm{T}$ cells in humans. The special composition of the $\mathrm{T}$ cell pool in old age - low numbers of naïve and memory $\mathrm{T}$ cells and high numbers of effector $\mathrm{T}$ cells renders this observation even more interesting. Thus, the regulation of autophagy may lead to maintenance or increase of memory $\mathrm{T}$ cell populations and eliminate effector $\mathrm{T}$ cells which may no longer be of use for the aged system at the same time. 


\section{Acknowledgements}

The research leading to these results has received funding from the European Union's Sixth Framework Programme, Network of Excellence LifeSpan (LSHG-CT-2007-036894) as well as European Union's Seventh Framework Programme [FP7/2007-2013] under Grant Agreement No: 280873 ADITEC. KT is supported by the Schlieben-Lange-Programm and BMBF Gerontosys II - NephAge (031 5896A). We thank Birgit Weinberger for critically reading the manuscript, Andreas Meryk for helping with the revised version, Werner Zwerschke for stimulating discussions, and Michael Keller for excellent technical assistance.

Declaration of interest

The authors declare that none of them has any conflict of interest related to this manuscript. 
Figure legends

Fig. 1 Induction of autophagy in human $\mathrm{CD8}^{+} \mathrm{CD}^{+} 8^{+} \mathrm{T}$ cells.

A: Western Blot analysis of LC3B levels and mTOR-S2448 phosphorylation (mTOR$\mathrm{pS} 2448$ ) in isolated human $\mathrm{CD} 8^{+} \mathrm{CD} 28^{+} \mathrm{T}$ cells in a resting state (unstim) or following activation with plate-bound anti-CD3 antibodies $(\alpha-\mathrm{CD} 3 ; 3 \mathrm{ng} / \mathrm{ml} ; 16 \mathrm{~h})$ in the absence or presence of anti-CD28 and anti-CD137 antibodies ( $\alpha-\mathrm{CD} 28, \alpha-\mathrm{CD} 137$; each $30 \mathrm{ng} / \mathrm{ml})$. One representative exampleof 3 independent experiments is shown. B/C: Statistical analysis of western blot data of LC3B-II levels (B) and mTOR-S2448 phosphorylation (C) in human $\mathrm{CD} 8^{+} \mathrm{CD} 28^{+} \mathrm{T}$ cells in a resting state (unstim) as well as following activation with platebound anti-CD3 antibodies antibodies $(\alpha-\mathrm{CD} 3 ; 3 \mathrm{ng} / \mathrm{ml} ; 16 \mathrm{~h})$ in the absence or presence of the indicated co-stimulatory antibodies (each $30 \mathrm{ng} / \mathrm{ml}$ ). Values represent mean $\pm \mathrm{SEM} ; \mathrm{n}=4$; $* \mathrm{p}<0.05 ; * * * \mathrm{p}<0.001 ;$ n.s. not significant.

\section{Fig. 2 Induction of autophagy following treatment with rapamycin.}

A: Western Blot analysis of mTOR-pS2448 and LC3B-II regulation in $\mathrm{CD}^{+} \mathrm{CD} 28^{+} \mathrm{T}$ cells following activation with plate-bound anti-CD3 antibodies $(\alpha-\mathrm{CD} 3 ; 3 \mathrm{ng} / \mathrm{ml} ; 16 \mathrm{~h})$ and treatment with rapamycin $(\alpha-\mathrm{CD} 3+$ rapa; $100 \mathrm{nM})$. One representative example of 3 independent experiments is shown. B: Statistical analysis of western blot data of mTORS2448 phosphorylation and LC3B-II regulation in human $\mathrm{CD}^{+} \mathrm{CD} 28^{+} \mathrm{T}$ cells following activation with plate-bound anti-CD3 antibodies $(\alpha-\mathrm{CD} 3 ; 3 \mathrm{ng} / \mathrm{ml} ; 16 \mathrm{~h})$ in the absence or presence of rapamycin $(\alpha-\mathrm{CD} 3+$ rapa; $100 \mathrm{nM})$. Values represent mean $\pm \mathrm{SEM} ; \mathrm{n}=6$; $* * \mathrm{p}<0.01 ; * * * \mathrm{p}<0.001$

Fig. 3 Proliferation, autophagy and mTORC1 activity in highly differentiated $\mathrm{CD8}^{+} \mathrm{CD}^{-} \mathbf{T}^{-} \mathrm{T}$ cells. 
A: Western blot and statistical analysis of LC3B-II levels and mTOR-pS2448 in isolated $\mathrm{CD}^{+} \mathrm{CD} 28^{+}$and $\mathrm{CD}^{+} \mathrm{CD} 28^{-} \mathrm{T}$ cells following anti-CD3 ( $\alpha-\mathrm{CD} 3 ; 3 \mathrm{ng} / \mathrm{ml} ; 16 \mathrm{~h}$ ) stimulation. One representative example of 3 independent experiments is shown. Values represent mean \pm SEM; $\mathrm{n}=8 ; * * \mathrm{p}<0.01 ; * * * \mathrm{p}<0.001 ; \mathrm{n} . \mathrm{s}$. not significant. B: Western blot analysis of LC3B-II levels and mTOR-pS2448 in $\mathrm{CD}^{+} \mathrm{CD} 28^{+}$and $\mathrm{CD}^{+} \mathrm{CD} 28^{-} \mathrm{T}$ cells following incubation on IL-15-coated plates (IL15; $1 \mu \mathrm{g} / \mathrm{ml} ; 16 \mathrm{~h}$ ). One representative example of 3 independent experiments is shown. Values represent mean \pm SEM; $n=4$; ${ }^{*} \mathrm{p}<0.05$; ${ }^{*} \mathrm{p}<0.01$; n.s. not significant. C: CFSE proliferation assay of $\mathrm{CD}^{+} \mathrm{CD} 28^{+}$(white, upper panel) and $\mathrm{CD} 8^{+} \mathrm{CD} 28^{-}$ (black, lower panel) T cells 2 (left panel) and 4 (right panel) days following anti-CD3 (3 $\mathrm{ng} / \mathrm{ml}$ ) stimulation. One representative example is shown. D: Statistical analysis of $\mathrm{CD}^{+} \mathrm{CD} 28^{+}$and $\mathrm{CD}^{+} \mathrm{CD} 28^{-} \mathrm{T}$ cell proliferation at day 2 and 4 after anti-CD3 $(3 \mathrm{ng} / \mathrm{ml})$ stimulation. Values represent mean $\pm \mathrm{SEM} ; \mathrm{n}=8 ; * * \mathrm{p}<0.01 ; * * * \mathrm{p}<0.001$.

\section{Fig. 4 Induction of autophagy following rapamycin treatment in TCR-activated isolated $\mathrm{CD8}^{+} \mathrm{CD}^{+}{ }^{+}$and $\mathrm{CD8}^{+} \mathrm{CD}^{-} \mathrm{T}$ cells.}

A: Western blot analysis of LC3B-II levels and mTOR-pS2448 in isolated CD8 ${ }^{+} \mathrm{CD} 28^{+}$and $\mathrm{CD}^{+}{ }^{+} \mathrm{CD} 28^{-} \mathrm{T}$ cells following activation with anti-CD3 antibodies $(\alpha-\mathrm{CD} 3 ; 3 \mathrm{ng} / \mathrm{ml} ; 16 \mathrm{~h})$ in the absence or presence of rapamycin $(\alpha-C D 3+$ rapa; $100 \mathrm{nM})$. One representative example of 3 independent experiments is shown. B/C: Statistical analysis of western blot data of LC3B-II levels and mTOR-pS2448 in isolated $\mathrm{CD}^{+} \mathrm{CD} 28^{+}$and $\mathrm{CD} 8^{+} \mathrm{CD} 28^{-} \mathrm{T}$ cells following activation with anti-CD3 antibodies $(\alpha-\mathrm{CD} 3 ; 3 \mathrm{ng} / \mathrm{ml} ; 16 \mathrm{~h})$ in the absence or presence of rapamycin $(\alpha-\mathrm{CD} 3+$ rapa; $100 \mathrm{nM})$. Values represent mean \pm SEM; $\mathrm{n}=6 ;{ }^{*} \mathrm{p}<0.05$; $* * \mathrm{p}<0.01 ; * * * \mathrm{p}<0.001 ;$ n.s. not significant.

\section{Suppl Fig. 1 Monitoring of autophagy and apoptosis.}


A:Statistical analysis of LC3B-II western blots at different time points in $\mathrm{CD}^{+} \mathrm{CD} 28^{+}$and $\mathrm{CD}^{+} \mathrm{CD} 28^{-} \mathrm{T}$ cells. Values represent mean $\pm \mathrm{SEM} ; \mathrm{n}=3 ; * \mathrm{p}<0.05 ; * * \mathrm{p}<0.01 . \mathbf{B}$ : Apoptotic $\mathrm{CD}^{+} \mathrm{CD} 28^{+}$and $\mathrm{CD} 8^{+} \mathrm{CD} 28^{-} \mathrm{T}$ cells as determined with AnnexinV/7-AAD staining and FACS analysis at day 2 after anti-CD3 $(\alpha-\mathrm{CD} 3 ; 3 \mathrm{ng} / \mathrm{ml})$ stimulation. Values represent mean $\pm \mathrm{SEM} ; \mathrm{n}=8 ; * \mathrm{p}<0.05$.

\section{Suppl. Fig. 2TCR-mediated induction of autophagy.}

Transmission electron microscopy of isolated human $\mathrm{CD} 8^{+} \mathrm{CD} 28^{+} \mathrm{T}$ cells in a resting state (upper panel) as well as following activation with plate-bound anti-CD3 antibodies $(\alpha-C D 3 ; 3$ $\mathrm{ng} / \mathrm{ml} ; 16 \mathrm{~h}$; lower panel). Autophagosomes (black/whitearrows) and vacuolar structures that are compatible with autophagosomes (black asterisks) are indicated. 


\section{References}

Araki, K.; Turner, A.P.; Shaffer, V.O.; Gangappa, S.; Keller, S.A.; Bachmann, M.F.; Larsen, C.P.; Ahmed, R. mTOR regulates memory CD8 T-cell differentiation. Nature. 460:108-112; 2009

Arnold, C.R.; Wolf, J.; Brunner, S.; Herndler-Brandstetter, D.; Grubeck-Loebenstein, B. Gain and loss of T cell subsets in old age--age-related reshaping of the T cell repertoire. J Clin Immunol. 31:137-146; 2011

Aspinall, R.; Andrew, D. Thymic involution in aging. J Clin Immunol. 20:250-256; 2000

Brunner, S.; Herndler-Brandstetter, D.; Arnold, C.R.; Wiegers, G.J.; Villunger, A.; Hackl, M.; Grillari, J.; Moreno-Villanueva, M.; Burkle, A.; Grubeck-Loebenstein, B. Upregulation of miR-24 is associated with a decreased DNA damage response upon etoposide treatment in highly differentiated CD8(+) T cells sensitizing them to apoptotic cell death. Aging Cell. 11:579-587; 2012

Brunner, S.; Herndler-Brandstetter, D.; Weinberger, B.; Grubeck-Loebenstein, B. Persistent viral infections and immune aging. Ageing Res Rev. 10:362-369; 2011

Buzzai, M.; Bauer, D.E.; Jones, R.G.; Deberardinis, R.J.; Hatzivassiliou, G.; Elstrom, R.L.; Thompson, C.B. The glucose dependence of Akt-transformed cells can be reversed by pharmacologic activation of fatty acid beta-oxidation. Oncogene. 24:4165-4173; 2005

Chen, C.R.; Aliesky, H.A.; Guo, J.; Rapoport, B.; McLachlan, S.M. Blockade of costimulation between T cells and antigen-presenting cells: an approach to suppress murine Graves' disease induced using thyrotropin receptor-expressing adenovirus. Thyroid. 16:427-434; 2006

Chen, W.H.; Kozlovsky, B.F.; Effros, R.B.; Grubeck-Loebenstein, B.; Edelman, R.; Sztein, M.B. Vaccination in the elderly: an immunological perspective. Trends Immunol. 30:351-359; 2009

Dejaco, C.; Duftner, C.; Klauser, A.; Schirmer, M. Altered T-cell subtypes in spondyloarthritis, rheumatoid arthritis and polymyalgia rheumatica. Rheumatol Int. 30:297-303; 2010

Dumitriu, I.E.; Araguas, E.T.; Baboonian, C.; Kaski, J.C. CD4+ CD28 null T cells in coronary artery disease: when helpers become killers. Cardiovasc Res. 81:11-19; 2009

Duttagupta, P.A.; Boesteanu, A.C.; Katsikis, P.D. Costimulation signals for memory CD8+ T cells during viral infections. Crit Rev Immunol. 29:469-486; 2009

Eisenberg, T.; Knauer, H.; Schauer, A.; Buttner, S.; Ruckenstuhl, C.; Carmona-Gutierrez, D.; Ring, J.; Schroeder, S.; Magnes, C.; Antonacci, L.; Fussi, H.; Deszcz, L.; Hartl, R.; Schraml, E.; Criollo, A.; Megalou, E.; Weiskopf, D.; Laun, P.; Heeren, G.; Breitenbach, M.; Grubeck-Loebenstein, B.; Herker, E.; Fahrenkrog, B.; Frohlich, K.U.; Sinner, F.; Tavernarakis, N.; Minois, N.; Kroemer, G.; Madeo, F. Induction of autophagy by spermidine promotes longevity. Nat Cell Biol. 11:1305-1314; 2009 
Foster, K.G.; Fingar, D.C. Mammalian target of rapamycin (mTOR): conducting the cellular signaling symphony. J Biol Chem. 285:14071-14077; 2010

Fox, C.J.; Hammerman, P.S.; Thompson, C.B. Fuel feeds function: energy metabolism and the T-cell response. Nat Rev Immunol. 5:844-852; 2005

Frauwirth, K.A.; Riley, J.L.; Harris, M.H.; Parry, R.V.; Rathmell, J.C.; Plas, D.R.; Elstrom, R.L.; June, C.H.; Thompson, C.B. The CD28 signaling pathway regulates glucose metabolism. Immunity. 16:769-777; 2002

Frauwirth, K.A.; Thompson, C.B. Regulation of T lymphocyte metabolism. J Immunol. 172:4661-4665; 2004

Gamper, C.J.; Powell, J.D. All PI3Kinase signaling is not mTOR: dissecting mTOR-dependent and independent signaling pathways in T cells. Front Immunol. 3:312; 2012

Gelino, S.; Hansen, M. Autophagy - An Emerging Anti-Aging Mechanism. J Clin Exp Pathol. Suppl 4; 2012

Gerli, R.; Schillaci, G.; Giordano, A.; Bocci, E.B.; Bistoni, O.; Vaudo, G.; Marchesi, S.; Pirro, M.; Ragni, F.; Shoenfeld, Y.; Mannarino, E. CD4+CD28- T lymphocytes contribute to early atherosclerotic damage in rheumatoid arthritis patients. Circulation. 109:2744-2748; 2004

Goronzy, J.J.; Fulbright, J.W.; Crowson, C.S.; Poland, G.A.; O'Fallon, W.M.; Weyand, C.M. Value of immunological markers in predicting responsiveness to influenza vaccination in elderly individuals. J Virol. 75:12182-12187; 2001

Greiner, E.F.; Guppy, M.; Brand, K. Glucose is essential for proliferation and the glycolytic enzyme induction that provokes a transition to glycolytic energy production. J Biol Chem. 269:31484-31490; 1994

Griffiths, S.J.; Riddell, N.E.; Masters, J.; Libri, V.; Henson, S.M.; Wertheimer, A.; Wallace, D.; Sims, S.; Rivino, L.; Larbi, A.; Kemeny, D.M.; Nikolich-Zugich, J.; Kern, F.; Klenerman, P.; Emery, V.C.; Akbar, A.N. Age-associated increase of low-avidity cytomegalovirus-specific CD8+ T cells that re-express CD45RA. J Immunol. 190:5363-5372; 2013

Hadrup, S.R.; Strindhall, J.; Kollgaard, T.; Seremet, T.; Johansson, B.; Pawelec, G.; thor Straten, P.; Wikby, A. Longitudinal studies of clonally expanded CD8 T cells reveal a repertoire shrinkage predicting mortality and an increased number of dysfunctional cytomegalovirus-specific $T$ cells in the very elderly. J Immunol. 176:2645-2653; 2006 
Hagiwara, A.; Cornu, M.; Cybulski, N.; Polak, P.; Betz, C.; Trapani, F.; Terracciano, L.; Heim, M.H.; Ruegg, M.A.; Hall, M.N. Hepatic mTORC2 activates glycolysis and lipogenesis through Akt, glucokinase, and SREBP1c. Cell Metab. 15:725-738; 2012

Hau, A.M.; Greenwood, J.A.; Lohr, C.V.; Serrill, J.D.; Proteau, P.J.; Ganley, I.G.; McPhail, K.L.; Ishmael, J.E. Coibamide A Induces mTOR-Independent Autophagy and Cell Death in Human Glioblastoma Cells. PLoS One. 8:e65250; 2013

Herndler-Brandstetter, D.; Landgraf, K.; Jenewein, B.; Tzankov, A.; Brunauer, R.; Brunner, S.; Parson, W.; Kloss, F.; Gassner, R.; Lepperdinger, G.; Grubeck-Loebenstein, B. Human bone marrow hosts polyfunctional memory CD4+ and CD8+ T cells with close contact to IL-15-producing cells. J Immunol. 186:6965-6971; 2011

Herndler-Brandstetter, D.; Landgraf, K.; Tzankov, A.; Jenewein, B.; Brunauer, R.; Laschober, G.T.; Parson, W.; Kloss, F.; Gassner, R.; Lepperdinger, G.; Grubeck-Loebenstein, B. The impact of aging on memory $T$ cell phenotype and function in the human bone marrow. J Leukoc Biol. 91:197-205; 2012

Hubbard, V.M.; Valdor, R.; Patel, B.; Singh, R.; Cuervo, A.M.; Macian, F. Macroautophagy regulates energy metabolism during effector T cell activation. J Immunol. 185:7349-7357; 2010

Kabeya, Y.; Mizushima, N.; Ueno, T.; Yamamoto, A.; Kirisako, T.; Noda, T.; Kominami, E.; Ohsumi, Y.; Yoshimori, T. LC3, a mammalian homologue of yeast Apg8p, is localized in autophagosome membranes after processing. EMBO J. 19:5720-5728; 2000

Kabeya, Y.; Mizushima, N.; Yamamoto, A.; Oshitani-Okamoto, S.; Ohsumi, Y.; Yoshimori, T. LC3, GABARAP and GATE16 localize to autophagosomal membrane depending on form-II formation. J Cell Sci. 117:2805-2812; 2004

Kamada, Y.; Funakoshi, T.; Shintani, T.; Nagano, K.; Ohsumi, M.; Ohsumi, Y. Tor-mediated induction of autophagy via an Apg1 protein kinase complex. J Cell Biol. 150:1507-1513; 2000

Kim, J.; Kundu, M.; Viollet, B.; Guan, K.L. AMPK and mTOR regulate autophagy through direct phosphorylation of Ulk1. Nat Cell Biol. 13:132-141; 2011

Klionsky, D.J.; Abdalla, F.C.; Abeliovich, H.; Abraham, R.T.; Acevedo-Arozena, A.; Adeli, K.; Agholme, L.; Agnello, M.; Agostinis, P.; Aguirre-Ghiso, J.A.; Ahn, H.J.; Ait-Mohamed, O.; Ait-Si-Ali, S.; Akematsu, T.; Akira, S.; Al-Younes, H.M.; Al-Zeer, M.A.; Albert, M.L.; Albin, R.L.; Alegre-Abarrategui, J.; Aleo, M.F.; Alirezaei, M.; Almasan, A.; Almonte-Becerril, M.; Amano, A.; Amaravadi, R.; Amarnath, S.; Amer, A.O.; Andrieu-Abadie, N.; Anantharam, V.; Ann, D.K.; Anoopkumar-Dukie, S.; Aoki, H.; Apostolova, N.; Arancia, G.; Aris, J.P.; Asanuma, K.; Asare, N.Y.; Ashida, H.; Askanas, V.; Askew, D.S.; Auberger, P.; Baba, M.; Backues, S.K.; Baehrecke, E.H.; Bahr, B.A.; Bai, X.Y.; Bailly, Y.; Baiocchi, R.; Baldini, G.; Balduini, W.; Ballabio, A.; Bamber, B.A.; Bampton, E.T.; Banhegyi, G.; Bartholomew, C.R.; Bassham, D.C.; Bast, R.C., Jr.; Batoko, H.; Bay, B.H.; Beau, I.; Bechet, D.M.; Begley, T.J.; Behl, C.; Behrends, C.; Bekri, S.; Bellaire, B.; Bendall, L.J.; Benetti, L.; Berliocchi, L.; Bernardi, H.; Bernassola, F.; Besteiro, S.; Bhatia-Kissova, I.; Bi, X.; Biard-Piechaczyk, M.; Blum, J.S.; Boise, L.H.; Bonaldo, P.; Boone, D.L.; Bornhauser, B.C.; Bortoluci, K.R.; Bossis, I.; Bost, F.; Bourquin, J.P.; Boya, P.; Boyer-Guittaut, M.; 24 
Bozhkov, P.V.; Brady, N.R.; Brancolini, C.; Brech, A.; Brenman, J.E.; Brennand, A.; Bresnick, E.H.; Brest, P.; Bridges, D.; Bristol, M.L.; Brookes, P.S.; Brown, E.J.; Brumell, J.H.; Brunetti-Pierri, N.; Brunk, U.T.; Bulman, D.E.; Bultman, S.J.; Bultynck, G.; Burbulla, L.F.; Bursch, W.; Butchar, J.P.; Buzgariu, W.; Bydlowski, S.P.; Cadwell, K.; Cahova, M.; Cai, D.; Cai, J.; Cai, Q.; Calabretta, B.; Calvo-Garrido, J.; Camougrand, N.; Campanella, M.; Campos-Salinas, J.; Candi, E.; Cao, L.; Caplan, A.B.; Carding, S.R.; Cardoso, S.M.; Carew, J.S.; Carlin, C.R.; Carmignac, V.; Carneiro, L.A.; Carra, S.; Caruso, R.A.; Casari, G.; Casas, C.; Castino, R.; Cebollero, E.; Cecconi, F.; Celli, J.; Chaachouay, H.; Chae, H.J.; Chai, C.Y.; Chan, D.C.; Chan, E.Y.; Chang, R.C.; Che, C.M.; Chen, C.C.; Chen, G.C.; Chen, G.Q.; Chen, M.; Chen, Q.; Chen, S.S.; Chen, W.; Chen, X.; Chen, X.; Chen, X.; Chen, Y.G.; Chen, Y.; Chen, Y.; Chen, Y.J.; Chen, Z.; Cheng, A.; Cheng, C.H.; Cheng, Y.; Cheong, H.; Cheong, J.H.; Cherry, S.; Chess-Williams, R.; Cheung, Z.H.; Chevet, E.; Chiang, H.L.; Chiarelli, R.; Chiba, T.; Chin, L.S.; Chiou, S.H.; Chisari, F.V.; Cho, C.H.; Cho, D.H.; Choi, A.M.; Choi, D.; Choi, K.S.; Choi, M.E.; Chouaib, S.; Choubey, D.; Choubey, V.; Chu, C.T.; Chuang, T.H.; Chueh, S.H.; Chun, T.; Chwae, Y.J.; Chye, M.L.; Ciarcia, R.; Ciriolo, M.R.; Clague, M.J.; Clark, R.S.; Clarke, P.G.; Clarke, R.; Codogno, P.; Coller, H.A.; Colombo, M.I.; Comincini, S.; Condello, M.; Condorelli, F.; Cookson, M.R.; Coombs, G.H.; Coppens, I.; Corbalan, R.; Cossart, P.; Costelli, P.; Costes, S.; Coto-Montes, A.; Couve, E.; Coxon, F.P.; Cregg, J.M.; Crespo, J.L.; Cronje, M.J.; Cuervo, A.M.; Cullen, J.J.; Czaja, M.J.; D'Amelio, M.; Darfeuille-Michaud, A.; Davids, L.M.; Davies, F.E.; De Felici, M.; de Groot, J.F.; de Haan, C.A.; De Martino, L.; De Milito, A.; De Tata, V.; Debnath, J.; Degterev, A.; Dehay, B.; Delbridge, L.M.; Demarchi, F.; Deng, Y.Z.; Dengjel, J.; Dent, P.; Denton, D.; Deretic, V.; Desai, S.D.; Devenish, R.J.; Di Gioacchino, M.; Di Paolo, G.; Di Pietro, C.; Diaz-Araya, G.; Diaz-Laviada, I.; Diaz-Meco, M.T.; Diaz-Nido, J.; Dikic, I.; Dinesh-Kumar, S.P.; Ding, W.X.; Distelhorst, C.W.; Diwan, A.; Djavaheri-Mergny, M.; Dokudovskaya, S.; Dong, Z.; Dorsey, F.C.; Dosenko, V.; Dowling, J.J.; Doxsey, S.; Dreux, M.; Drew, M.E.; Duan, Q.; Duchosal, M.A.; Duff, K.; Dugail, I.; Durbeej, M.; Duszenko, M.; Edelstein, C.L.; Edinger, A.L.; Egea, G.; Eichinger, L.; Eissa, N.T.; Ekmekcioglu, S.; ElDeiry, W.S.; Elazar, Z.; Elgendy, M.; Ellerby, L.M.; Eng, K.E.; Engelbrecht, A.M.; Engelender, S.; Erenpreisa, J.; Escalante, R.; Esclatine, A.; Eskelinen, E.L.; Espert, L.; Espina, V.; Fan, H.; Fan, J.; Fan, Q.W.; Fan, Z.; Fang, S.; Fang, Y.; Fanto, M.; Fanzani, A.; Farkas, T.; Farre, J.C.; Faure, M.; Fechheimer, M.; Feng, C.G.; Feng, J.; Feng, Q.; Feng, Y.; Fesus, L.; Feuer, R.; Figueiredo-Pereira, M.E.; Fimia, G.M.; Fingar, D.C.; Finkbeiner, S.; Finkel, T.; Finley, K.D.; Fiorito, F.; Fisher, E.A.; Fisher, P.B.; Flajolet, M.; Florez-McClure, M.L.; Florio, S.; Fon, E.A.; Fornai, F.; Fortunato, F.; Fotedar, R.; Fowler, D.H.; Fox, H.S.; Franco, R.; Frankel, L.B.; Fransen, M.; Fuentes, J.M.; Fueyo, J.; Fujii, J.; Fujisaki, K.; Fujita, E.; Fukuda, M.; Furukawa, R.H.; Gaestel, M.; Gailly, P.; Gajewska, M.; Galliot, B.; Galy, V.; Ganesh, S.; Ganetzky, B.; Ganley, I.G.; Gao, F.B.; Gao, G.F.; Gao, J.; Garcia, L.; Garcia-Manero, G.; Garcia-Marcos, M.; Garmyn, M.; Gartel, A.L.; Gatti, E.; Gautel, M.; Gawriluk, T.R.; Gegg, M.E.; Geng, J.; Germain, M.; Gestwicki, J.E.; Gewirtz, D.A.; Ghavami, S.; Ghosh, P.; Giammarioli, A.M.; Giatromanolaki, A.N.; Gibson, S.B.; Gilkerson, R.W.; Ginger, M.L.; Ginsberg, H.N.; Golab, J.; Goligorsky, M.S.; Golstein, P.; Gomez-Manzano, C.; Goncu, E.; Gongora, C.; Gonzalez, C.D.; Gonzalez, R.; Gonzalez-Estevez, C.; Gonzalez-Polo, R.A.; Gonzalez-Rey, E.; Gorbunov, N.V.; Gorski, S.; Goruppi, S.; Gottlieb, R.A.; Gozuacik, D.; Granato, G.E.; Grant, G.D.; Green, K.N.; Gregorc, A.; Gros, F.; Grose, C.; Grunt, T.W.; Gual, P.; Guan, J.L.; Guan, K.L.; Guichard, S.M.; Gukovskaya, A.S.; Gukovsky, I.; Gunst, J.; Gustafsson, A.B.; Halayko, A.J.; Hale, A.N.; Halonen, S.K.; Hamasaki, M.; Han, F.; Han, T.; Hancock, M.K.; Hansen, M.; Harada, H.; Harada, M.; Hardt, S.E.; Harper, J.W.; Harris, A.L.; Harris, J.; Harris, S.D.; Hashimoto, M.; Haspel, J.A.; Hayashi, S.; Hazelhurst, L.A.; He, C.; He, Y.W.; Hebert, M.J.; Heidenreich, K.A.; Helfrich, M.H.; Helgason, G.V.; Henske, E.P.; Herman, B.; Herman, P.K.; Hetz, C.; Hilfiker, S.; Hill, J.A.; Hocking, L.J.; Hofman, P.; Hofmann, T.G.; Hohfeld, J.; Holyoake, T.L.; Hong, M.H.; Hood, D.A.; Hotamisligil, G.S.; Houwerzijl, E.J.; Hoyer-Hansen, M.; Hu, B.; Hu, C.A.; Hu, H.M.; Hua, Y.; Huang, C.; Huang, J.; Huang, S.; Huang, W.P.; Huber, T.B.; Huh, W.K.; Hung, T.H.; Hupp, T.R.; Hur, G.M.; Hurley, J.B.; Hussain, S.N.; Hussey, P.J.; Hwang, J.J.; Hwang, S.; Ichihara, A.; Ilkhanizadeh, S.; Inoki, K.; Into, T.; lovane, V.; Iovanna, J.L.; Ip, N.Y.; Isaka, Y.; Ishida, H.; Isidoro, C.; Isobe, K.; Iwasaki, A.; Izquierdo, M.; Izumi, Y.; Jaakkola, P.M.; Jaattela, M.; Jackson, G.R.; Jackson, W.T.; Janji, B.; Jendrach, M.; Jeon, J.H.; Jeung, E.B.; Jiang, H.; Jiang, H.; Jiang, J.X.; Jiang, M.; Jiang, Q.; Jiang, X.; Jiang, X.; Jimenez, A.; Jin, M.; Jin, S.; Joe, C.O.; Johansen, T.; Johnson, D.E.; Johnson, G.V.; Jones, N.L.; Joseph, B.; Joseph, S.K.; 
Joubert, A.M.; Juhasz, G.; Juillerat-Jeanneret, L.; Jung, C.H.; Jung, Y.K.; Kaarniranta, K.; Kaasik, A.; Kabuta, T.; Kadowaki, M.; Kagedal, K.; Kamada, Y.; Kaminskyy, V.O.; Kampinga, H.H.; Kanamori, H.; Kang, C.; Kang, K.B.; Kang, K.I.; Kang, R.; Kang, Y.A.; Kanki, T.; Kanneganti, T.D.; Kanno, H.; Kanthasamy, A.G.; Kanthasamy, A.; Karantza, V.; Kaushal, G.P.; Kaushik, S.; Kawazoe, Y.; Ke, P.Y.; Kehrl, J.H.; Kelekar, A.; Kerkhoff, C.; Kessel, D.H.; Khalil, H.; Kiel, J.A.; Kiger, A.A.; Kihara, A.; Kim, D.R.; Kim, D.H.; Kim, D.H.; Kim, E.K.; Kim, H.R.; Kim, J.S.; Kim, J.H.; Kim, J.C.; Kim, J.K.; Kim, P.K.; Kim, S.W.; Kim, Y.S.; Kim, Y.; Kimchi, A.; Kimmelman, A.C.; King, J.S.; Kinsella, T.J.; Kirkin, V.; Kirshenbaum, L.A.; Kitamoto, K.; Kitazato, K.; Klein, L.; Klimecki, W.T.; Klucken, J.; Knecht, E.; Ko, B.C.; Koch, J.C.; Koga, H.; Koh, J.Y.; Koh, Y.H.; Koike, M.; Komatsu, M.; Kominami, E.; Kong, H.J.; Kong, W.J.; Korolchuk, V.I.; Kotake, Y.; Koukourakis, M.I.; Kouri Flores, J.B.; Kovacs, A.L.; Kraft, C.; Krainc, D.; Kramer, H.; KretzRemy, C.; Krichevsky, A.M.; Kroemer, G.; Kruger, R.; Krut, O.; Ktistakis, N.T.; Kuan, C.Y.; Kucharczyk, R.; Kumar, A.; Kumar, R.; Kumar, S.; Kundu, M.; Kung, H.J.; Kurz, T.; Kwon, H.J.; La Spada, A.R.; Lafont, F.; Lamark, T.; Landry, J.; Lane, J.D.; Lapaquette, P.; Laporte, J.F.; Laszlo, L.; Lavandero, S.; Lavoie, J.N.; Layfield, R.; Lazo, P.A.; Le, W.; Le Cam, L.; Ledbetter, D.J.; Lee, A.J.; Lee, B.W.; Lee, G.M.; Lee, J.; Lee, J.H.; Lee, M.; Lee, M.S.; Lee, S.H.; Leeuwenburgh, C.; Legembre, P.; Legouis, R.; Lehmann, M.; Lei, H.Y.; Lei, Q.Y.; Leib, D.A.; Leiro, J.; Lemasters, J.J.; Lemoine, A.; Lesniak, M.S.; Lev, D.; Levenson, V.V.; Levine, B.; Levy, E.; Li, F.; Li, J.L.; Li, L.; Li, S.; Li, W.; Li, X.J.; Li, Y.B.; Li, Y.P.; Liang, C.; Liang, Q.; Liao, Y.F.; Liberski, P.P.; Lieberman, A.; Lim, H.J.; Lim, K.L.; Lim, K.; Lin, C.F.; Lin, F.C.; Lin, J.; Lin, J.D.; Lin, K.; Lin, W.W.; Lin, W.C.; Lin, Y.L.; Linden, R.; Lingor, P.; Lippincott-Schwartz, J.; Lisanti, M.P.; Liton, P.B.; Liu, B.; Liu, C.F.; Liu, K.; Liu, L.; Liu, Q.A.; Liu, W.; Liu, Y.C.; Liu, Y.; Lockshin, R.A.; Lok, C.N.; Lonial, S.; Loos, B.; Lopez-Berestein, G.; Lopez-Otin, C.; Lossi, L.; Lotze, M.T.; Low, P.; Lu, B.; Lu, B.; Lu, B.; Lu, Z.; Luciano, F.; Lukacs, N.W.; Lund, A.H.; Lynch-Day, M.A.; Ma, Y.; Macian, F.; MacKeigan, J.P.; Macleod, K.F.; Madeo, F.; Maiuri, L.; Maiuri, M.C.; Malagoli, D.; Malicdan, M.C.; Malorni, W.; Man, N.; Mandelkow, E.M.; Manon, S.; Manov, I.; Mao, K.; Mao, X.; Mao, Z.; Marambaud, P.; Marazziti, D.; Marcel, Y.L.; Marchbank, K.; Marchetti, P.; Marciniak, S.J.; Marcondes, M.; Mardi, M.; Marfe, G.; Marino, G.; Markaki, M.; Marten, M.R.; Martin, S.J.; Martinand-Mari, C.; Martinet, W.; MartinezVicente, M.; Masini, M.; Matarrese, P.; Matsuo, S.; Matteoni, R.; Mayer, A.; Mazure, N.M.; McConkey, D.J.; McConnell, M.J.; McDermott, C.; McDonald, C.; McInerney, G.M.; McKenna, S.L.; McLaughlin, B.; McLean, P.J.; McMaster, C.R.; McQuibban, G.A.; Meijer, A.J.; Meisler, M.H.; Melendez, A.; Melia, T.J.; Melino, G.; Mena, M.A.; Menendez, J.A.; Menna-Barreto, R.F.; Menon, M.B.; Menzies, F.M.; Mercer, C.A.; Merighi, A.; Merry, D.E.; Meschini, S.; Meyer, C.G.; Meyer, T.F.; Miao, C.Y.; Miao, J.Y.; Michels, P.A.; Michiels, C.; Mijaljica, D.; Milojkovic, A.; Minucci, S.; Miracco, C.; Miranti, C.K.; Mitroulis, I.; Miyazawa, K.; Mizushima, N.; Mograbi, B.; Mohseni, S.; Molero, X.; Mollereau, B.; Mollinedo, F.; Momoi, T.; Monastyrska, I.; Monick, M.M.; Monteiro, M.J.; Moore, M.N.; Mora, R.; Moreau, K.; Moreira, P.I.; Moriyasu, Y.; Moscat, J.; Mostowy, S.; Mottram, J.C.; Motyl, T.; Moussa, C.E.; Muller, S.; Muller, S.; Munger, K.; Munz, C.; Murphy, L.O.; Murphy, M.E.; Musaro, A.; Mysorekar, I.; Nagata, E.; Nagata, K.; Nahimana, A.; Nair, U.; Nakagawa, T.; Nakahira, K.; Nakano, H.; Nakatogawa, H.; Nanjundan, M.; Naqvi, N.I.; Narendra, D.P.; Narita, M.; Navarro, M.; Nawrocki, S.T.; Nazarko, T.Y.; Nemchenko, A.; Netea, M.G.; Neufeld, T.P.; Ney, P.A.; Nezis, I.P.; Nguyen, H.P.; Nie, D.; Nishino, I.; Nislow, C.; Nixon, R.A.; Noda, T.; Noegel, A.A.; Nogalska, A.; Noguchi, S.; Notterpek, L.; Novak, I.; Nozaki, T.; Nukina, N.; Nurnberger, T.; Nyfeler, B.; Obara, K.; Oberley, T.D.; Oddo, S.; Ogawa, M.; Ohashi, T.; Okamoto, K.; Oleinick, N.L.; Oliver, F.J.; Olsen, L.J.; Olsson, S.; Opota, O.; Osborne, T.F.; Ostrander, G.K.; Otsu, K.; Ou, J.H.; Ouimet, M.; Overholtzer, M.; Ozpolat, B.; Paganetti, P.; Pagnini, U.; Pallet, N.; Palmer, G.E.; Palumbo, C.; Pan, T.; Panaretakis, T.; Pandey, U.B.; Papackova, Z.; Papassideri, I.; Paris, I.; Park, J.; Park, O.K.; Parys, J.B.; Parzych, K.R.; Patschan, S.; Patterson, C.; Pattingre, S.; Pawelek, J.M.; Peng, J.; Perlmutter, D.H.; Perrotta, I.; Perry, G.; Pervaiz, S.; Peter, M.; Peters, G.J.; Petersen, M.; Petrovski, G.; Phang, J.M.; Piacentini, M.; Pierre, P.; Pierrefite-Carle, V.; Pierron, G.; Pinkas-Kramarski, R.; Piras, A.; Piri, N.; Platanias, L.C.; Poggeler, S.; Poirot, M.; Poletti, A.; Pous, C.; Pozuelo-Rubio, M.; Praetorius-lbba, M.; Prasad, A.; Prescott, M.; Priault, M.; ProduitZengaffinen, N.; Progulske-Fox, A.; Proikas-Cezanne, T.; Przedborski, S.; Przyklenk, K.; Puertollano, R.; Puyal, J.; Qian, S.B.; Qin, L.; Qin, Z.H.; Quaggin, S.E.; Raben, N.; Rabinowich, H.; Rabkin, S.W.; Rahman, I.; Rami, A.; Ramm, G.; Randall, G.; Randow, F.; Rao, V.A.; Rathmell, J.C.; Ravikumar, B.; Ray, S.K.; 
Reed, B.H.; Reed, J.C.; Reggiori, F.; Regnier-Vigouroux, A.; Reichert, A.S.; Reiners, J.J., Jr.; Reiter, R.J.; Ren, J.; Revuelta, J.L.; Rhodes, C.J.; Ritis, K.; Rizzo, E.; Robbins, J.; Roberge, M.; Roca, H.; Roccheri, M.C.; Rocchi, S.; Rodemann, H.P.; Rodriguez de Cordoba, S.; Rohrer, B.; Roninson, I.B.; Rosen, K.; Rost-Roszkowska, M.M.; Rouis, M.; Rouschop, K.M.; Rovetta, F.; Rubin, B.P.; Rubinsztein, D.C.; Ruckdeschel, K.; Rucker, E.B., 3rd; Rudich, A.; Rudolf, E.; Ruiz-Opazo, N.; Russo, R.; Rusten, T.E.; Ryan, K.M.; Ryter, S.W.; Sabatini, D.M.; Sadoshima, J.; Saha, T.; Saitoh, T.; Sakagami, H.; Sakai, Y.; Salekdeh, G.H.; Salomoni, P.; Salvaterra, P.M.; Salvesen, G.; Salvioli, R.; Sanchez, A.M.; Sanchez-Alcazar, J.A.; Sanchez-Prieto, R.; Sandri, M.; Sankar, U.; Sansanwal, P.; Santambrogio, L.; Saran, S.; Sarkar, S.; Sarwal, M.; Sasakawa, C.; Sasnauskiene, A.; Sass, M.; Sato, K.; Sato, M.; Schapira, A.H.; Scharl, M.; Schatzl, H.M.; Scheper, W.; Schiaffino, S.; Schneider, C.; Schneider, M.E.; Schneider-Stock, R.; Schoenlein, P.V.; Schorderet, D.F.; Schuller, C.; Schwartz, G.K.; Scorrano, L.; Sealy, L.; Seglen, P.O.; Segura-Aguilar, J.; Seiliez, I.; Seleverstov, O.; Sell, C.; Seo, J.B.; Separovic, D.; Setaluri, V.; Setoguchi, T.; Settembre, C.; Shacka, J.J.; Shanmugam, M.; Shapiro, I.M.; Shaulian, E.; Shaw, R.J.; Shelhamer, J.H.; Shen, H.M.; Shen, W.C.; Sheng, Z.H.; Shi, Y.; Shibuya, K.; Shidoji, Y.; Shieh, J.J.; Shih, C.M.; Shimada, Y.; Shimizu, S.; Shintani, T.; Shirihai, O.S.; Shore, G.C.; Sibirny, A.A.; Sidhu, S.B.; Sikorska, B.; Silva-Zacarin, E.C.; Simmons, A.; Simon, A.K.; Simon, H.U.; Simone, C.; Simonsen, A.; Sinclair, D.A.; Singh, R.; Sinha, D.; Sinicrope, F.A.; Sirko, A.; Siu, P.M.; Sivridis, E.; Skop, V.; Skulachev, V.P.; Slack, R.S.; Smaili, S.S.; Smith, D.R.; Soengas, M.S.; Soldati, T.; Song, X.; Sood, A.K.; Soong, T.W.; Sotgia, F.; Spector, S.A.; Spies, C.D.; Springer, W.; Srinivasula, S.M.; Stefanis, L.; Steffan, J.S.; Stendel, R.; Stenmark, H.; Stephanou, A.; Stern, S.T.; Sternberg, C.; Stork, B.; Stralfors, P.; Subauste, C.S.; Sui, X.; Sulzer, D.; Sun, J.; Sun, S.Y.; Sun, Z.J.; Sung, J.J.; Suzuki, K.; Suzuki, T.; Swanson, M.S.; Swanton, C.; Sweeney, S.T.; Sy, L.K.; Szabadkai, G.; Tabas, I.; Taegtmeyer, H.; Tafani, M.; Takacs-Vellai, K.; Takano, Y.; Takegawa, K.; Takemura, G.; Takeshita, F.; Talbot, N.J.; Tan, K.S.; Tanaka, K.; Tanaka, K.; Tang, D.; Tang, D.; Tanida, I.; Tannous, B.A.; Tavernarakis, N.; Taylor, G.S.; Taylor, G.A.; Taylor, J.P.; Terada, L.S.; Terman, A.; Tettamanti, G.; Thevissen, K.; Thompson, C.B.; Thorburn, A.; Thumm, M.; Tian, F.; Tian, Y.; TocchiniValentini, G.; Tolkovsky, A.M.; Tomino, Y.; Tonges, L.; Tooze, S.A.; Tournier, C.; Tower, J.; Towns, R.; Trajkovic, V.; Travassos, L.H.; Tsai, T.F.; Tschan, M.P.; Tsubata, T.; Tsung, A.; Turk, B.; Turner, L.S.; Tyagi, S.C.; Uchiyama, Y.; Ueno, T.; Umekawa, M.; Umemiya-Shirafuji, R.; Unni, V.K.; Vaccaro, M.I.; Valente, E.M.; Van den Berghe, G.; van der Klei, I.J.; van Doorn, W.; van Dyk, L.F.; van Egmond, M.; van Grunsven, L.A.; Vandenabeele, P.; Vandenberghe, W.P.; Vanhorebeek, I.; Vaquero, E.C.; Velasco, G.; Vellai, T.; Vicencio, J.M.; Vierstra, R.D.; Vila, M.; Vindis, C.; Viola, G.; Viscomi, M.T.; Voitsekhovskaja, O.V.; von Haefen, C.; Votruba, M.; Wada, K.; Wade-Martins, R.; Walker, C.L.; Walsh, C.M.; Walter, J.; Wan, X.B.; Wang, A.; Wang, C.; Wang, D.; Wang, F.; Wang, F.; Wang, G.; Wang, H.; Wang, H.G.; Wang, H.D.; Wang, J.; Wang, K.; Wang, M.; Wang, R.C.; Wang, X.; Wang, X.; Wang, Y.J.; Wang, Y.; Wang, Z.; Wang, Z.C.; Wang, Z.; Wansink, D.G.; Ward, D.M.; Watada, H.; Waters, S.L.; Webster, P.; Wei, L.; Weihl, C.C.; Weiss, W.A.; Welford, S.M.; Wen, L.P.; Whitehouse, C.A.; Whitton, J.L.; Whitworth, A.J.; Wileman, T.; Wiley, J.W.; Wilkinson, S.; Willbold, D.; Williams, R.L.; Williamson, P.R.; Wouters, B.G.; Wu, C.; Wu, D.C.; Wu, W.K.; Wyttenbach, A.; Xavier, R.J.; Xi, Z.; Xia, P.; Xiao, G.; Xie, Z.; Xie, Z.; Xu, D.Z.; Xu, J.; Xu, L.; Xu, X.; Yamamoto, A.; Yamamoto, A.; Yamashina, S.; Yamashita, M.; Yan, X.; Yanagida, M.; Yang, D.S.; Yang, E.; Yang, J.M.; Yang, S.Y.; Yang, W.; Yang, W.Y.; Yang, Z.; Yao, M.C.; Yao, T.P.; Yeganeh, B.; Yen, W.L.; Yin, J.J.; Yin, X.M.; Yoo, O.J.; Yoon, G.; Yoon, S.Y.; Yorimitsu, T.; Yoshikawa, Y.; Yoshimori, T.; Yoshimoto, K.; You, H.J.; Youle, R.J.; Younes, A.; Yu, L.; Yu, L.; Yu, S.W.; Yu, W.H.; Yuan, Z.M.; Yue, Z.; Yun, C.H.; Yuzaki, M.; Zabirnyk, O.; Silva-Zacarin, E.; Zacks, D.; Zacksenhaus, E.; Zaffaroni, N.; Zakeri, Z.; Zeh, H.J., 3rd; Zeitlin, S.O.; Zhang, H.; Zhang, H.L.; Zhang, J.; Zhang, J.P.; Zhang, L.; Zhang, L.; Zhang, M.Y.; Zhang, X.D.; Zhao, M.; Zhao, Y.F.; Zhao, Y.; Zhao, Z.J.; Zheng, X.; Zhivotovsky, B.; Zhong, Q.; Zhou, C.Z.; Zhu, C.; Zhu, W.G.; Zhu, X.F.; Zhu, X.; Zhu, Y.; Zoladek, T.; Zong, W.X.; Zorzano, A.; Zschocke, J.; Zuckerbraun, B. Guidelines for the use and interpretation of assays for monitoring autophagy. Autophagy. 8:445-544; 2012

Kober, J.; Leitner, J.; Klauser, C.; Woitek, R.; Majdic, O.; Stockl, J.; Herndler-Brandstetter, D.; GrubeckLoebenstein, B.; Reipert, B.M.; Pickl, W.F.; Pfistershammer, K.; Steinberger, P. The capacity of the TNF 
family members 4-1BBL, OX40L, CD70, GITRL, CD30L and LIGHT to costimulate human T cells. Eur J Immunol. 38:2678-2688; 2008

Kremer, J.M.; Westhovens, R.; Leon, M.; Di Giorgio, E.; Alten, R.; Steinfeld, S.; Russell, A.; Dougados, M.; Emery, P.; Nuamah, I.F.; Williams, G.R.; Becker, J.C.; Hagerty, D.T.; Moreland, L.W. Treatment of rheumatoid arthritis by selective inhibition of T-cell activation with fusion protein CTLA4Ig. N Engl J Med. 349:1907-1915; 2003

Lamming, D.W.; Ye, L.; Katajisto, P.; Goncalves, M.D.; Saitoh, M.; Stevens, D.M.; Davis, J.G.; Salmon, A.B.; Richardson, A.; Ahima, R.S.; Guertin, D.A.; Sabatini, D.M.; Baur, J.A. Rapamycin-induced insulin resistance is mediated by mTORC2 loss and uncoupled from longevity. Science. 335:1638-1643; 2012

Laplante, M.; Sabatini, D.M. mTOR signaling in growth control and disease. Cell. 149:274-293; 2012

Lazuardi, L.; Herndler-Brandstetter, D.; Brunner, S.; Laschober, G.T.; Lepperdinger, G.; GrubeckLoebenstein, B. Microarray analysis reveals similarity between CD8+CD28- T cells from young and elderly persons, but not of CD8+CD28+ T cells. Biogerontology. 10:191-202; 2009

Lorin, S.; Pierron, G.; Ryan, K.M.; Codogno, P.; Djavaheri-Mergny, M. Evidence for the interplay between JNK and p53-DRAM signalling pathways in the regulation of autophagy. Autophagy. 6:153$154 ; 2010$

Lurain, N.S.; Hanson, B.A.; Martinson, J.; Leurgans, S.E.; Landay, A.L.; Bennett, D.A.; Schneider, J.A. Virological and Immunological Characteristics of Human Cytomegalovirus Infection Associated With Alzheimer Disease. J Infect Dis; 2013

Mattison, J.A.; Roth, G.S.; Beasley, T.M.; Tilmont, E.M.; Handy, A.M.; Herbert, R.L.; Longo, D.L.; Allison, D.B.; Young, J.E.; Bryant, M.; Barnard, D.; Ward, W.F.; Qi, W.; Ingram, D.K.; de Cabo, R. Impact of caloric restriction on health and survival in rhesus monkeys from the NIA study. Nature. 489:318$321 ; 2012$

McLeod, I.X.; Jia, W.; He, Y.W. The contribution of autophagy to lymphocyte survival and homeostasis. Immunol Rev. 249:195-204; 2012

Melendez, A.; Talloczy, Z.; Seaman, M.; Eskelinen, E.L.; Hall, D.H.; Levine, B. Autophagy genes are essential for dauer development and life-span extension in C. elegans. Science. 301:1387-1391; 2003

Mizushima, N.; Yoshimori, T. How to interpret LC3 immunoblotting. Autophagy. 3:542-545; 2007

Morselli, E.; Marino, G.; Bennetzen, M.V.; Eisenberg, T.; Megalou, E.; Schroeder, S.; Cabrera, S.; Benit, P.; Rustin, P.; Criollo, A.; Kepp, O.; Galluzzi, L.; Shen, S.; Malik, S.A.; Maiuri, M.C.; Horio, Y.; LopezOtin, C.; Andersen, J.S.; Tavernarakis, N.; Madeo, F.; Kroemer, G. Spermidine and resveratrol induce autophagy by distinct pathways converging on the acetylproteome. J Cell Biol. 192:615-629; 2011 
Panossian, L.A.; Porter, V.R.; Valenzuela, H.F.; Zhu, X.; Reback, E.; Masterman, D.; Cummings, J.L.; Effros, R.B. Telomere shortening in T cells correlates with Alzheimer's disease status. Neurobiol Aging. 24:77-84; 2003

Pfister, G.; Weiskopf, D.; Lazuardi, L.; Kovaiou, R.D.; Cioca, D.P.; Keller, M.; Lorbeg, B.; Parson, W.; Grubeck-Loebenstein, B. Naive T cells in the elderly: are they still there? Ann N Y Acad Sci. 1067:152$157 ; 2006$

Phadwal, K.; Alegre-Abarrategui, J.; Watson, A.S.; Pike, L.; Anbalagan, S.; Hammond, E.M.; WadeMartins, R.; McMichael, A.; Klenerman, P.; Simon, A.K. A novel method for autophagy detection in primary cells: impaired levels of macroautophagy in immunosenescent T cells. Autophagy. 8:677-689; 2012

Polak, P.; Hall, M.N. mTOR and the control of whole body metabolism. Curr Opin Cell Biol. 21:209218; 2009

Powell, J.D.; Delgoffe, G.M. The mammalian target of rapamycin: linking T cell differentiation, function, and metabolism. Immunity. 33:301-311; 2010

Puissant, A.; Robert, G.; Fenouille, N.; Luciano, F.; Cassuto, J.P.; Raynaud, S.; Auberger, P. Resveratrol promotes autophagic cell death in chronic myelogenous leukemia cells via JNK-mediated p62/SQSTM1 expression and AMPK activation. Cancer Res. 70:1042-1052; 2010

Rao, R.R.; Li, Q.; Odunsi, K.; Shrikant, P.A. The mTOR kinase determines effector versus memory CD8+ $\mathrm{T}$ cell fate by regulating the expression of transcription factors T-bet and Eomesodermin. Immunity. $32: 67-78 ; 2010$

Rubinsztein, D.C.; Marino, G.; Kroemer, G. Autophagy and aging. Cell. 146:682-695; 2011

Sarkar, S.; Davies, J.E.; Huang, Z.; Tunnacliffe, A.; Rubinsztein, D.C. Trehalose, a novel mTORindependent autophagy enhancer, accelerates the clearance of mutant huntingtin and alphasynuclein. J Biol Chem. 282:5641-5652; 2007

Saurwein-Teissl, M.; Lung, T.L.; Marx, F.; Gschosser, C.; Asch, E.; Blasko, I.; Parson, W.; Bock, G.; Schonitzer, D.; Trannoy, E.; Grubeck-Loebenstein, B. Lack of antibody production following immunization in old age: association with CD8(+)CD28(-) T cell clonal expansions and an imbalance in the production of Th1 and Th2 cytokines. J Immunol. 168:5893-5899; 2002

Schirmer, M.; Goldberger, C.; Wurzner, R.; Duftner, C.; Pfeiffer, K.P.; Clausen, J.; Neumayr, G.; Falkenbach, A. Circulating cytotoxic CD8(+) CD28(-) T cells in ankylosing spondylitis. Arthritis Res. 4:71-76; 2002 
Shintani, T.; Yamazaki, F.; Katoh, T.; Umekawa, M.; Matahira, Y.; Hori, S.; Kakizuka, A.; Totani, K.; Yamamoto, K.; Ashida, H. Glucosamine induces autophagy via an mTOR-independent pathway. Biochem Biophys Res Commun. 391:1775-1779; 2010

Steinmann, G.G.; Klaus, B.; Muller-Hermelink, H.K. The involution of the ageing human thymic epithelium is independent of puberty. A morphometric study. Scand J Immunol. 22:563-575; 1985

Stephan, J.S.; Yeh, Y.Y.; Ramachandran, V.; Deminoff, S.J.; Herman, P.K. The Tor and PKA signaling pathways independently target the Atg1/Atg13 protein kinase complex to control autophagy. Proc Natl Acad Sci U S A. 106:17049-17054; 2009

Sun, Z.; Ye, H.; Tang, B.; Shen, X.; Wu, X.; Zhong, H.; Song, W. Prevalence of circulating CD4+CD28null $T$ cells is associated with early atherosclerotic damage in patients with end-stage renal disease undergoing hemodialysis. Hum Immunol. 74:6-13; 2013

Sun, Z.; Zhong, W.; Lu, X.; Shi, B.; Zhu, Y.; Chen, L.; Zhang, G.; Zhang, X. Association of Graves' disease and prevalence of circulating IFN-gamma-producing CD28(-) T cells. J Clin Immunol. 28:464-472; 2008

Suntharalingam, G.; Perry, M.R.; Ward, S.; Brett, S.J.; Castello-Cortes, A.; Brunner, M.D.; Panoskaltsis, $\mathrm{N}$. Cytokine storm in a phase 1 trial of the anti-CD28 monoclonal antibody TGN1412. N Engl J Med. 355:1018-1028; 2006

Taylor, P.A.; Panoskaltsis-Mortari, A.; Freeman, G.J.; Sharpe, A.H.; Noelle, R.J.; Rudensky, A.Y.; Mak, T.W.; Serody, J.S.; Blazar, B.R. Targeting of inducible costimulator (ICOS) expressed on alloreactive T cells down-regulates graft-versus-host disease (GVHD) and facilitates engraftment of allogeneic bone marrow (BM). Blood. 105:3372-3380; 2005

Thedieck, K.; Hall, M.N. Translational control by amino acids and energy. in: Bradshaw R.A., Dennis E.A., eds. The Handbook of Cell Signaling. Amsterdam: Elsevier, Academic Press; 2009

Tokoyoda, K.; Zehentmeier, S.; Hegazy, A.N.; Albrecht, I.; Grun, J.R.; Lohning, M.; Radbruch, A. Professional memory $\mathrm{CD} 4+\mathrm{T}$ lymphocytes preferentially reside and rest in the bone marrow. Immunity. 30:721-730; 2009

Wei, Y.; Pattingre, S.; Sinha, S.; Bassik, M.; Levine, B. JNK1-mediated phosphorylation of Bcl-2 regulates starvation-induced autophagy. Mol Cell. 30:678-688; 2008a

Wei, Y.; Sinha, S.; Levine, B. Dual role of JNK1-mediated phosphorylation of Bcl-2 in autophagy and apoptosis regulation. Autophagy. 4:949-951; 2008b

Weng, N.P.; Akbar, A.N.; Goronzy, J. CD28(-) T cells: their role in the age-associated decline of immune function. Trends Immunol. 30:306-312; 2009 
Wikby, A.; Ferguson, F.; Forsey, R.; Thompson, J.; Strindhall, J.; Lofgren, S.; Nilsson, B.O.; Ernerudh, J.; Pawelec, G.; Johansson, B. An immune risk phenotype, cognitive impairment, and survival in very late life: impact of allostatic load in Swedish octogenarian and nonagenarian humans. J Gerontol A Biol Sci Med Sci. 60:556-565; 2005

Wikby, A.; Nilsson, B.O.; Forsey, R.; Thompson, J.; Strindhall, J.; Lofgren, S.; Ernerudh, J.; Pawelec, G.; Ferguson, F.; Johansson, B. The immune risk phenotype is associated with IL-6 in the terminal decline stage: findings from the Swedish NONA immune longitudinal study of very late life functioning. Mech Ageing Dev. 127:695-704; 2006

Zhang, H.; Snyder, K.M.; Suhoski, M.M.; Maus, M.V.; Kapoor, V.; June, C.H.; Mackall, C.L. 4-1BB is superior to $\mathrm{CD} 28$ costimulation for generating CD8+ cytotoxic lymphocytes for adoptive immunotherapy. J Immunol. 179:4910-4918; 2007 


\section{CURRICULUM VITAE}

THERESA PRITZ

Personal data: Date of Birth: $12^{\text {th }}$ December 1984

Place of Birth: Krems/Donau

Nationality: Austria

Phone number: 0043-660-6515269

E-Mail: theresa.pritz@uibk.ac.at

\section{Education}

Since June 2011

PhD studies at the Institute for Biomedical Aging Research, University of Innsbruck, Austria.

Enrolled in the $\mathrm{PhD}$ program "The aging of biological communication systems" at the Innsbruck Medical University, Austria.

October 2005 - April 2011 Diploma studies in Molecular Biology at the University of Vienna, Austria.

Graduation: A-Level Examination

October 2003 - October 2005 Medical School, Medical University of Vienna, Austria.

September 1995 - June 2003

Private High School "Englische Fräulein", Krems, Austria. 
Since June 2011

April 2010 - December 2010

March 2010

January 2010 - February 2010

July 2009 - August 2009

November 2008 - July 2009
PhD studies at the Institute for Biomedical Aging Research, University of Innsbruck, Austria

Division: Immunology

Project: "Cytokine production of T cells in old age"

Supervision: Univ.-Prof. Dr. Beatrix

Grubeck-Loebenstein

Diploma student at Intercell AG, Vienna, Austria

Division: IC31® Department

Project: "IC31®-mediated induction of CD8 $+\mathrm{T}$ cell responses"

Supervision: Benjamin Wizel, PhD

Internship at the Vienna Competence

Center, Vienna, Austria

Division: Herbert Strobl Group

Internship at Boehringer Ingelheim,

Vienna, Austria

Division: Frank Hilberg Group

September 2009 - December 2009 Internship at the IMP, Vienna, Austria Division: Christine Hartmann Group Internship at the Institute of Cancer Research, Vienna, Austria Division: Jozefa Gadek-Wesierski Group Technical Assistance at the Medical University of Vienna, Austria Division: Pharmacology and Toxicology 
January 2008 - November 2008

August 2007 - September 2007

September 2005 - December 2007
Technical Assistance at the IMBA, Vienna, Austria

Division: Fly House

Internship at the Danube University

Krems, Austria

Division: Department for Biomedical

Technology

Minor employment at Esprit $\mathrm{GmbH}$,

Vienna, Austria

Division: Sales

\section{Publications}

2014 Pritz T. et al., The impact of aging on plasma cells and memory B cells in the human bone marrow. Eur $\mathrm{J}$ Immunol, in revision

2014 Pritz T. et al., The aging bone marrow and its impact on immune responses in old age. Immmunol Lett, in press

2014 Arnold CR., Pritz T. et al., T cell receptor-mediated activation is a potent inducer of macroautophagy in human $\mathrm{CD}^{+} \mathrm{CD} 28^{+} \mathrm{T}$ cells but not in CD8+CD28- T cells. Exp Gerontol 2014

2013 Pritz T. et al., Bone marrow T cells from the femur are similar to iliac crest derived cells in old age and represent a useful tool for studying the aged immune system, Immun Ageing 2013

\section{Awards}

2014 Fellowship for the Summer School "Next generation leaders in Biology of Ageing", Rimini, Italy

2013 Forschungsförderbeitrag Aktion Swarovski KG 2013, University of Innsbruck, Austria

2012 Poster Award, 3rd CIIT Science Day 2012, Innsbruck, Austria 
$201412^{\text {th }}$ International Symposium on Neurobiology and Neuroendocrinology of Aging, Bregenz, Austria.

Poster: "The impact of aging on lymphocytes and their function in the BM"

$5^{\text {th }}$ CIIT Science Day, Innsbruck Medical University, Austria.

Poster: "The impact of aging on lymphocytes and their function in the BM"

Summer School "Next generation leaders in Biology of Ageing", Rimini, Italy.

Talk: "The impact of aging on lymphocytes and their function in the BM"

$20139^{\text {th }}$ Meeting of Doctoral Students of the Innsbruck Medical University, Innsbruck, Austria.

Poster: "BM T cells from the femur are similar to iliac crest-derived cells in old age and represent a useful tool for studying the aged immune system"

$2^{\text {nd }}$ Joint Meeting of Middle European Societies for Allergology and Immunology, Opatija, Croatia.

Poster: "BM T cells from the femur are similar to iliac crest-derived cells in old age and represent a useful tool for studying the aged immune system"

$15^{\text {th }}$ International Congress of Immunology (ICI), Milan, Italy.

Poster: "BM T cells from the femur are similar to iliac crest-derived cells in old age and represent a useful tool for studying the aged immune system"

Satellite Meeting of the $15^{\text {th }} \mathrm{ICl}$ "Aging and the Immune System", Milan, Italy.

Poster: "BM T cells from the femur are similar to iliac crest-derived cells in old age and represent a useful tool for studying the aged immune system"

$4^{\text {th }}$ CIIT Science Day 2013, Innsbruck, Austria. 
Poster: "BM T cells from the femur are similar to iliac crest-derived cells in old age and represent a useful tool for studying the aged immune system"

$2012 \quad 3^{\text {rd }}$ CIIT Science Day 2012, Innsbruck, Austria.

Poster: "Polyfunctional CD8 ${ }^{+} \mathrm{CD} 28^{-} \mathrm{T}$ cells are preserved in human BM during aging"

$20117^{\text {th }}$ Meeting of Science Doctoral Students, Innsbruck, Austria.

Poster: "mTOR activity in CD8 ${ }^{+} \mathrm{T}$ cells is dependent on differentiation stage and stimulation"

\section{Attended Scientific Meetings}

$201412^{\text {th }}$ International Symposium on Neurobiology and Neuroendocrinology of Aging, Bregenz, Austria.

$5^{\text {th }}$ CIIT Science Day, Innsbruck Medical University, Austria.

Summer School "Next generation leaders in Biology of Ageing", Rimini, Italy.

$2013 \quad 9^{\text {th }}$ Meeting of Doctoral Students, Innsbruck, Austria.

$2^{\text {nd }}$ Joint Meeting of Middle European Societies for Allergology and Immunology, Opatija, Croatia

$15^{\text {th }}$ International Congress of Immunology (ICl), Milan, Italy.

Satellite Meeting "Aging and the Immune System" of the $15^{\text {th }} \mathrm{ICI}$, Milan, Italy.

$4^{\text {th }}$ CIIT Science Day 2013, Innsbruck, Austria.

$20124^{\text {th }}$ Life Science Meeting Innsbruck, Igls, Austria.

$3^{\text {rd }}$ CIIT Science Day 2012, Innsbruck, Austria.

$2011 \quad 7^{\text {th }}$ Meeting of Doctoral Students, Innsbruck, Austria.

$4^{\text {th }}$ Vaccine and ISV Annual Global Congress, Vienna, Austria. 


\section{Acknowledgments}

Mein besonderer Dank gilt Prof. Beatrix Grubeck-Loebenstein für die Ermöglichung und ausgezeichnete Betreuung meiner Dissertation und die kontinuierliche Förderung meiner wissenschaftlichen Fähigkeiten.

Besonders möchte ich mich bei allen derzeitigen und ehemaligen „Immunos“ sowie IBA-Mitarbeitern für die ausgezeichnete Zusammenarbeit bedanken. Auch Dietmar Herndler-Brandstetter gebührt großer Dank. Ohne die ersten Daten über das adaptive Immunsystem im Knochenmark wäre mein Projekt nicht so erfolgreich geworden.

Ein spezielles Dankeschön gilt auch Birgit Weinberger. Ohne die ständige Unterstützung, Motivation und ein offenes Ohr für jegliche Probleme wäre meine Dissertation wohl nicht so gelungen. Vor allem möchte ich mich auch für die vielen unvergesslichen Stunden bei den Weinbergers in Mieming bedanken.

Ganz besonders bedanken möchte ich mich auch bei Dani Trimmel, Juliane Wolf, Kathi Welzl und Christoph Arnold für die schöne gemeinsame Zeit am IBA und außerhalb. Es waren unvergessliche Stunden, die durch eine gute Zusammenarbeit, viel Spaß und moralische Unterstützung geprägt wurden.

Nicht unerwähnt bleiben darf Anita Hohenegger, welche stets ein offenes Ohr für meine Sorgen und Probleme sowie eine unerschöpflichen Bereitschaft zum Korrekturlesen sämtlicher Texte hatte.

Ein großes Dankeschön gebührt auch unseren Kooperationspartern Julian Lair und Michael Ban. Ohne ihre Geduld und die gute Zusammenarbeit im „Kampf um Knochenproben“ wäre mein Projekt unmöglich gewesen.

Ebenfalls bedanken möchte ich mich bei den Mitgliedern meines Dissertationskomitees, Prof. Martin Thurnher und Prof. Reinhard Würzner, für die hilfreichen Diskussionen und für ihre Bereitschaft, mich während meiner gesamten PhD-Zeit zu begleiten.

Meinen Eltern und meinen Geschwistern, Christian und Marlene, danke ich von ganzem Herzen für ihre emotionale Unterstützung, die mir während meines ganzen PhD Studiums unverzichtbaren Rückhalt gegeben hat. 
Mein größter und innigster Dank gilt Thomas für seine Liebe, grenzenlose Geduld, unermüdliche Unterstützung und Motivation in jeglicher Lebenssituation. Ohne dich wäre das alles nicht möglich gewesen! 